\title{
Influence of Sex and Blood Collection Method on Innate Immune Response following Lipopolysaccharide Administration in Sheep
}

Hoda Nikpour

Follow this and additional works at: https://researchrepository.wvu.edu/etd

\section{Recommended Citation}

Nikpour, Hoda, "Influence of Sex and Blood Collection Method on Innate Immune Response following Lipopolysaccharide Administration in Sheep" (2017). Graduate Theses, Dissertations, and Problem Reports. 6320.

https://researchrepository.wvu.edu/etd/6320

This Thesis is protected by copyright and/or related rights. It has been brought to you by the The Research Repository @ WVU with permission from the rights-holder(s). You are free to use this Thesis in any way that is permitted by the copyright and related rights legislation that applies to your use. For other uses you must obtain permission from the rights-holder(s) directly, unless additional rights are indicated by a Creative Commons license in the record and/ or on the work itself. This Thesis has been accepted for inclusion in WVU Graduate Theses, Dissertations, and Problem Reports collection by an authorized administrator of The Research Repository @ WVU. For more information, please contact researchrepository@mail.wvu.edu. 


\title{
Influence of Sex and Blood Collection Method on Innate Immune Response following Lipopolysaccharide Administration in Sheep
}

\author{
Hoda Nikpour \\ Thesis submitted to the \\ Davis College of Agriculture, Natural Resources, and Design \\ at West Virginia University \\ in partial fulfillment of requirements for the degree of \\ Master of Science \\ in \\ Reproductive Physiology \\ Robert A. Dailey, Ph.D. \\ Scott A. Bowdridge, Ph.D. \\ Ida Holásková, Ph.D.
}

Division of Animal and Nutritional Sciences

Morgantown, West Virginia

2017

Keywords: Catheter, LPS, Sexual dimorphism, Stress

Copyright 2017 Hoda Nikpour 


\title{
ABSTRACT \\ Influence of Sex and Blood Collection Method on Innate Immune Response following Lipopolysaccharide Administration in Sheep
}

\author{
Hoda Nikpour
}

Wethers and ewes were used to study the effect of catheter or repeated venipuncture on circulating cortisol and leukocyte concentrations and physical behaviors following administration of lipopolysaccharide (LPS), a gram-negative bacteria cell wall component. Animals were injected with LPS or saline, as a control, to induce an innate immune system response. In addition, blood leukocytes and cortisol levels were studied to determine the effect of sex on immunological and stress responses. Thirty-eight mature Dorset and Suffolk wethers and ewes were assigned into one of four treatment groups: 1.) no-catheter + LPS treated ewes $(n=5)$ and wethers $(n=4)$ that were restrainted to draw blood from the jugular vein; 2.) no-catheter + saline treated ewes $(n=6)$ and wethers $(n=4)$ restrained to draw blood from the jugular vein; 3.) catheter + LPS consisting of LPS-treated ewes $(n=6)$ and wethers $(n=4)$ in which a jugular catheter was placed to draw blood; and 4.) catheter + saline treated ewes $(n=6)$ and wethers $(n=4)$ with a jugular catheter. Blood was collected from the jugular vein catheter, which was placed into the jugular vein the day before the experiment and anchored with a stitch to secure it or venipuncture before the challenge followed by post challenge samples every $30 \mathrm{~min}$ for $3 \mathrm{~h}$ and every hour until $12 \mathrm{~h}$, and once at $24 \mathrm{~h}$. Physical behaviors and rectal temperatures were monitored before LPS administration and every hour for $12 \mathrm{~h}$ post challenge. Total white blood cell counts and leukocyte differentials including lymphocytes, monocytes, and granulocytes were measured immediately after collection using a veterinary hematology blood analyzer (Abaxis VetScan HM5, Abaxis Inc.), and remaining samples were centrifuged, and plasma was collected and stored at $-20^{\circ} \mathrm{C}$ until concentration of cortisol was determined by ELISA. Treatment with LPS resulted in increased cortisol concentrations, rectal temperatures, lethargy, and nasal discharge, as well as decreased WBC count and appetite in ewes and wethers. Catheter insertion alone resulted in increased WBC count, but did not affect cortisol. However, a significant increased in cortisol occurred in LPS treated sheep fitted with catheters compared to those without. Rectal temperatures during LPS challenge were greater in wethers than ewes, and a greater decrease in total WBC count and leukocyte differentials was seen in ewes when compared to wethers. Moreover, there was no significant effect of sex on cortisol concentrations. In summary, there were no differences in cortisol concentrations between sexes and no significant effect of the catheter alone. However, during the LPS challenge catheter exacerbated the innate immune response and cortisol levels, and rectal temperature and WBC count were affected by sex. Therefore, catheter placement created an additional stressor that augmented the LPS-induced immune response. 


\section{Dedication}

This thesis is dedicated to the memory of my mother, Malakeh, for making me be who I am, and to my strong father, Akbar, for supporting me all the way, and to my dear husband, Amin, who means the world to me. 


\section{Acknowledgements}

Foremost, I would like to express my sincere gratitude to my advisor Dr. Robert Dailey for the continuous support of my master study and research, for his patience, motivation, enthusiasm, and immense knowledge. The door to his office was always open whenever I ran into a trouble spot or had a question about my research or writing. He consistently allowed this thesis to be my own work, but steered me in the right direction whenever he thought I needed it. His guidance helped me in all the time of research and writing of this thesis. I could not have imagined having a better advisor and mentor for my master study.

I would also like to thank my committee members Dr. Ida Holásková and Dr. Scott Bowdridge for their time, wisdom, and patience. Without their passionate participation and input, this research could not have been successfully conducted and written. I am gratefully indebted to them for their encouragement and insightful comments. In addition, I thank Dr. Inskeep who was always willing to help and give his best advice.

I would like to thank my fellow labmates, Dr. Elizabeth Bowdridge, Jessalyn Hadfield, and Melisaa Wise, who have made valuable comments and suggestions on this project which gave me an inspiration to improve my research. I would especially like to thanks my fellow graduate students, both past and present for the countless hours of help preparing and sampling. I thank all the people for their help directly and indirectly to complete my thesis.

And finally, last but by no means least, also to my family: my husband, my parents, my brother, and my sister for their wise counsel and sympathetic ear. 


\section{TABLE OF CONTENTS}

Chapter

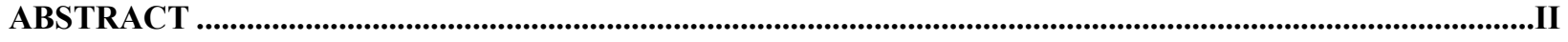

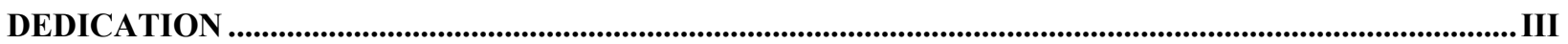

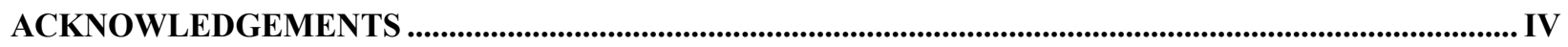

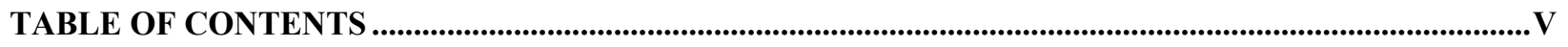

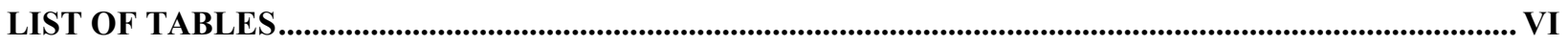

LIST OF FIGURES...........................................................................................................................................................

CHAPTER 1 INTRODUCTION AND RELATED WORKS.........................................................................

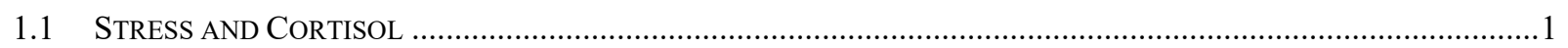

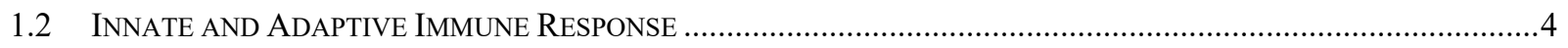

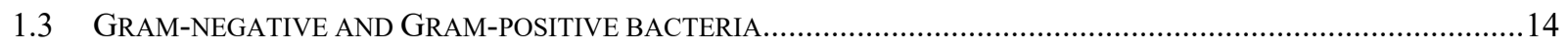

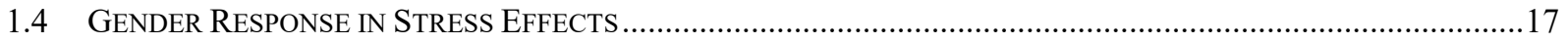

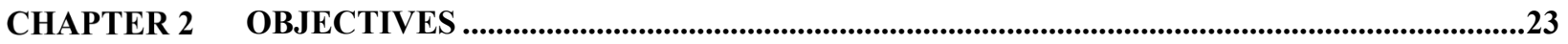

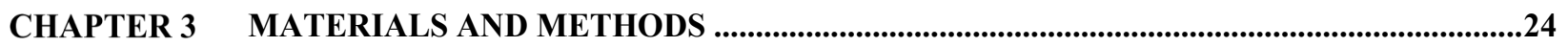

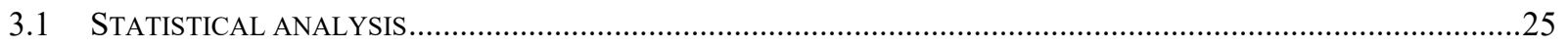

CHAPTER $4 \quad$ RESULTS ….............................................................................................................................27

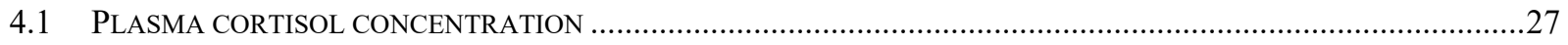

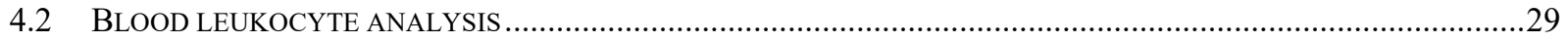

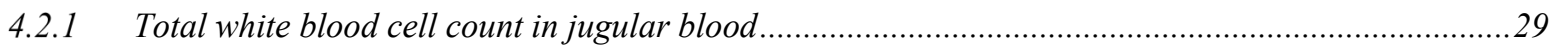

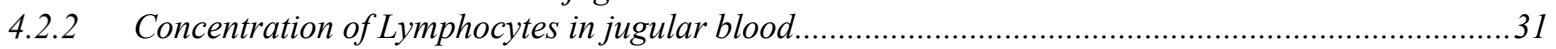

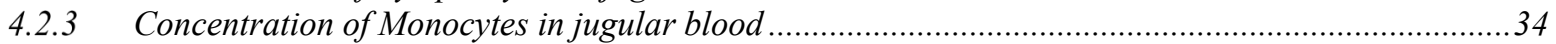

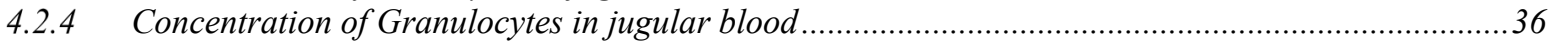

4.3 RECTAL TEMPERATURE .............................................................................................................

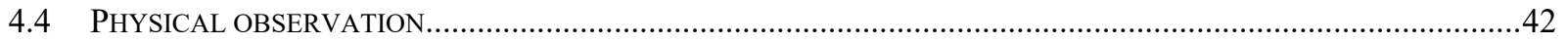

CHAPTER 5 DISCUSSION …….............................................................................................................48

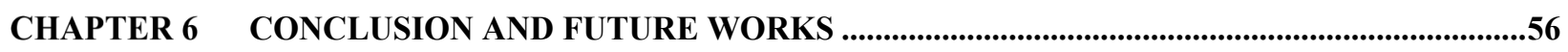

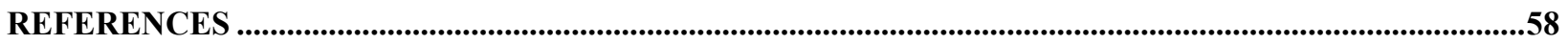




\section{LIST OF TABLES}

Table

Page

TABLE 4-1 STATISTICAL SIGNIFICANCE (P-VALUES) OF TREATMENT EFFECTS AND INTERACTIONS FOR ALL

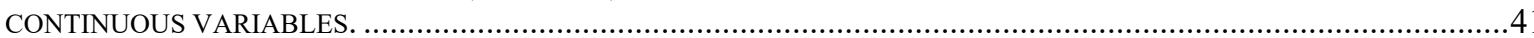




\section{LIST OF FIGURES}

Figure

Page

FIGURE 1-1 SYSTEMS ACTIVATED BY STRESS. 2

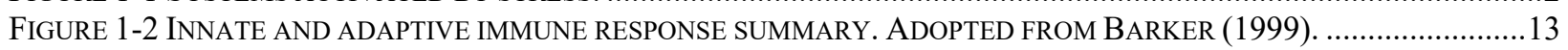

FIGURE 4-1 MEAN PLASMA CORTISOL CONCENTRATION IN JUGULAR BLOOD IN CATHETERIZED AND NON-CATHERIZED

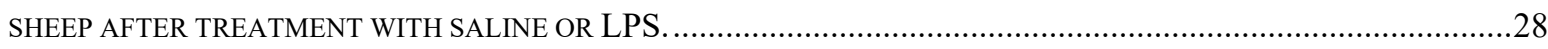

FIGURE 4-2 MEAN CORTISOL CONCENTRATIONS IN JUGULAR BLOOD IN WETHERS AND EWES WITH OR WITHOUT A CATHETER FOR 6H AFTER TREATMENT WITH EITHER SALINE OR LPS ........................................................29

FIGURE 4-3 TOTAL WHITE BLOOD CELL (WBC) CONCENTRATION IN JUGULAR BLOOD IN CATHETERIZED AND NONCATHETERIZED SHEEP (A), AND IN EWES AND WETHERS (B) AFTER TREATMENT WITH EITHER SALINE OR LPS. .30

FIGURE 4-4 TOTAL WHITE BLOOD CELL (WBC) CONCENTRATION IN JUGULAR BLOOD IN SHEEP AFTER TREATMENT WITH EITHER SALINE OR LPS. EFFECT OF LPS $(\mathrm{P}<0.0001)$, HOUR $(\mathrm{P}<0.0001)$, LPS X HOUR $(\mathrm{P}<0.0001)$, CATHETER X LPS $(\mathrm{P}=0.0002)$.

FIGURE 4-5 TOTAL WHITE BLOOD CELL (WBC) CONCENTRATION IN JUGULAR BLOOD IN CATHETERIZED AND NONCATHETERIZED EWES AND WETHERS AFTER TREATMENT WITH EITHER SALINE OR LPS.

FIGURE 4-6 CONCENTRATIONS OF LYMPHOCYTES IN JUGULAR BLOOD IN CATHETERIZED AND NON-CATHETERIZED SHEEP AFTER TREATMENT WITH EITHER SALINE OR LPS.

FIGURE 4-7 CONCENTRATIONS OF LYMPHOCYTES IN JUGULAR BLOOD IN SHEEP AFTER TREATMENT WITH EITHER

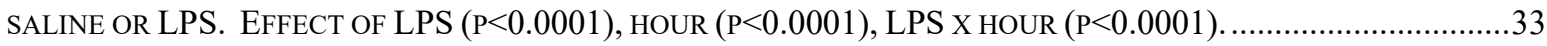

FIGURE 4-8 CONCENTRATIONS OF LYMPHOCYTES IN JUGULAR BLOOD IN CATHETERIZED AND NON-CATHETERIZED EWES AND WETHERS AFTER TREATMENT WITH EITHER SALINE OR LPS. .......................................................3

FIGURE 4-9 CONCENTRATIONS OF MONOCYTES IN JUGULAR BLOOD IN CATHETERIZED AND NON-CATHETERIZED SHEEP

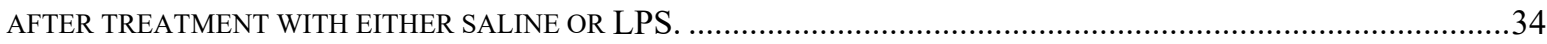

FIGURE 4-10 CONCENTRATIONS OF MONOCYTES IN JUGULAR BLOOD AFTER TREATMENT WITH EITHER SALINE OR LPS.

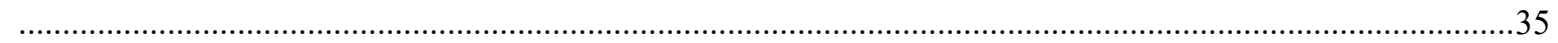

FIGURE 4-11 CONCENTRATIONS OF MONOCYTES IN JUGULAR BLOOD IN CATHETERIZED AND NON-CATHETERIZED EWES AND WETHERS AFTER TREATMENT WITH EITHER SALINE OR LPS.

FIGURE 4-12 CONCENTRATIONS OF GRANULOCYTES IN JUGULAR BLOOD IN CATHETERIZED AND NON-CATHETERIZED SHEEP AFTER TREATMENT WITH EITHER SALINE OR LPS.

FIGURE 4-13 CONCENTRATIONS OF GRANULOCYTES IN JUGULAR BLOOD AFTER TREATMENT WITH EITHER SALINE OR LPS.

FIGURE 4-14 CONCENTRATIONS OF GRANULOCYTES IN JUGULAR BLOOD IN CATHETERIZED AND NON-CATHETERIZED EWES AND WETHERS AFTER TREATMENT WITH EITHER SALINE OR LPS.

FIGURE 4-15 RECTAL TEMPERATURES AFTER TREATMENT WITH EITHER SALINE OR LPS...........................................39

FIGURE 4-16 RECTAL TEMPERATURES IN EWES AND WETHERS AFTER TREATMENT WITH EITHER SALINE OR LPS.........39

FIGURE 4-17 RECTAL TEMPERATURES AFTER TREATMENT WITH EITHER SALINE OR LPS..............................................40

FIGURE 4-18 RECTAL TEMPERATURES FOR 24 H IN EWES AND WETHERS WITH OR WITHOUT CATHETERS AND AFTER TREATMENT WITH EITHER SALINE OR LPS.

FigURE 4-19 VAGINAL DISCHARGE IN CATHETER AND NO-CATHETER EWES AFTER TREATMENT WITH EITHER SALINE OR LPS (NO-CATHETER+No-LPS N=6, NO-CATHETER+LPS N=5, CATHETER+NO-LPS N=6, CATHETER+LPS $\mathrm{N}=6$ ).

FIGURE 4-20 LETHARGY IN CATHETER AND NO-CATHETER EWES AND WETHERS AFTER TREATMENT WITH EITHER SALINE OR LPS

FIGURE 4-21 LOSS OF APPETTITE IN CATHETER AND NO-CATHETER EWES AND WETHERS AFTER TREATMENT WITH EITHER SALINE OR LPS.

FIGURE 4-22 COUGHING IN CATHETER AND NO-CATHETER EWES AND WETHERS AFTER TREATMENT WITH EITHER SALINE OR LPS.

FigURE 4-23 NASAL DISCHARGE IN CATHETER AND NO-CATHETER EWES AND WETHERS AFTER TREATMENT WITH EITHER SALINE OR LPS.

FIGURE 4-24 PHYSICAL APPEARANCE IN LPS AND NO-LPS GROUPS...................................................................

FigURE 4-25 PHYSICAL APPEARANCE IN CATHETER AND NO-CATHETER GROUPS AFTER TREATMENT WITH LPS.........47 
FIGURE 4-26 PHYSICAL APPEARANCE IN EWES AND WETHERS AFTER TREATMENT WITH LPS. .....................................47 


\section{Chapter 1 Introduction and Related Works}

\subsection{Stress and Cortisol}

Animals are continually challenged by physical and emotional stressors threatening their homeostasis (Johnson, 1992). Stress responses involve the hypothalamic-pituitary-adrenal axis (HPA) and the autonomic nervous system (ANS), both of which are required for proper response adaptation. Figure 1-1 outlines highly conserved biological systems and their main components: epinephrine, norepinephrine (NE), corticotrophin releasing hormone (CRH), and glucocorticoids (GCs). The bridge between received sensory data, such as physical or psychological challenges, and assessment procedure, is formed by limbic brain structures including the hippocampus (HIPP), amygdala (AMY) and prefrontal cortex (PFC). The HPA axis is controlled by signal transduction to the hypothalamic paraventricular nucleus (PVN) to maintain activity of corticotrophin releasing hormone (CRH) neurons (Smith, 2006). Adrenocorticotrophic hormone (ACTH) secretion from the pituitary results from release of vasopressin (VP) and CRH by the hypothalamic paraventricular nucleus. Therefore, ACTH stimulates episodic secretion of adrenal steroid glucocorticoid (GCs). Secretion of GCs is vital based on their effect on glycolysis, gluconeogenesis, and lipolysis in providing energy, and also peaks temporarily after a stressor (Lightman, 2008). Glucocortocoids affect horomone synthesis, food intake, digestion, and productivity by decreasing nonessential activities. Several mechanisms, such as inhibitory feedback by GCs, which inhibits expression of CRH and ACTH (Uchoa, Ernane, and Torres, 2014), regulate HPA axis activity. Numerous studies have investigated the role of VP in activation of the HPA axis by using various stressors, which differ in nature and intensity. Although there is no evidence to show a clear role for VP either in circadian and basal rhythmicity of plasma ACTH or after chronic stressor, VP is thought to have a stimulatory effect on ACTH secretion after an acute stressor such as LPS administration (Zelena, 2009). Studies have shown a relationship among catecholaminergic activity, HPA axis, and stress. Injection of CRH into different sites in the brain can increase $\mathrm{GC}$ and catecholamines production (epinephrine and norepinephrine, 
also known as adrenaline and noradrenaline, respectively) from the sympathetic nervous system and their metabolites. This has been shown to affect stress-related behaviors, and increase cardiovascular output and blood flow to the brain and skeletal muscles while GCs act synergistically with them. Furthermore, both GCs and catecholamines provide energy from adipose tissue and hepatic cells to precede the fight-or-flight response. Meanwhile, GCs cause decreases in nonessential behaviors such as reproduction and digestion (Sorrells, 2007).

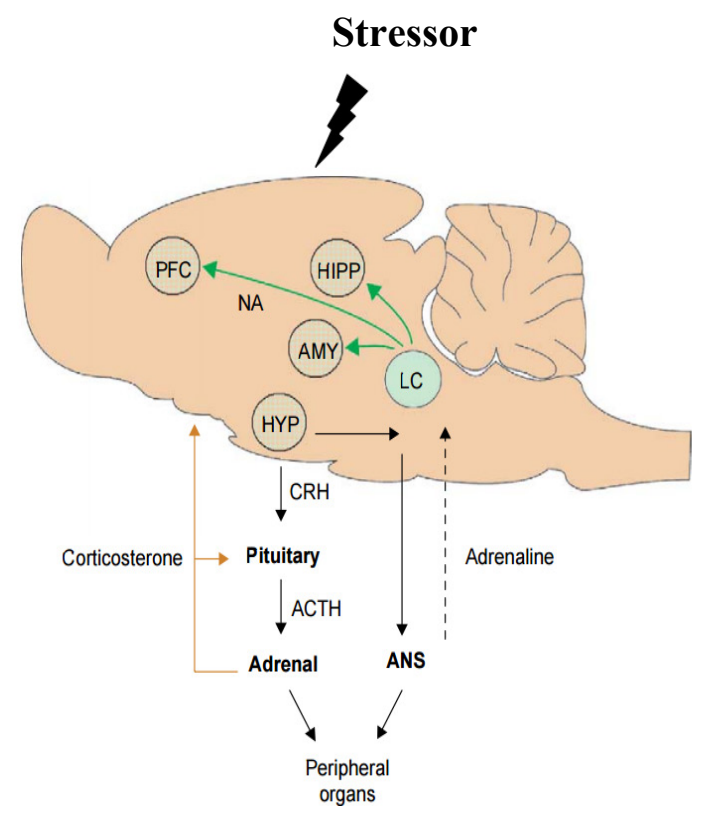

Figure 1-1 Systems activated by stress.

Note. ACTH: adrenocorticotropin hormone; AMY: amygdala nuclei; ANS: autonomic nervous system;

CORT: corticosterone; CRH: corticotropin releasing hormone; HIPP: hippocampus; HPA axis: hypothalamo-pituitary-adrenal axis; HYP: hypothalamus; LC: locus coeruleus; NA: noradrenaline; PFC: prefrontal cortex. (Adapted from www.sciencedirect.com)

Early phases of stress have stimulatory effects on the immune system with regard to the activities of catecholamines. Although GCs can suppress immune responses, small amounts of GCs are desirable to permit catecholamines to rapidly stimulate the immunity. High amounts of GCs prevent autoimmune damage due to their suppressive effects. This explains the significance of a controlled immune reaction during fight-or-flight responses to both act beforehand as well as being suppressed in the long-term (Sorrells, 2007). Animals might show alteration in catecholamine concentration based on whether they were exposed to chronic or acute and/or to novel or similar stressors. Furthermore, circulating 
GCs may function in a regulatory fashion by inducing negative feedback of norepinephrine secretion (Pacak and Karel, 1995).

Glucocorticoids are central mediators with a broad diversity of anti-inflammatory and antiproliferative effects. The primary role of GCs in stress is to suppress immunity. Glucocorticoids decrease macrophage accumulation in a wide range of diseases, such as arterial injury and are powerful anti-inflammatory mediators,. Poon et al. (1991) reported that GCs inhibition monocyte chemoattractant protein-1 (MCP-1) secretion in arterial smooth muscle cells (SMC) by altering MCP1 mRNA. Dhawan et al. (2007) described GC effect on gene expression, which is mediated by GC receptor ligation followed by triggering transcription of genes conatining a glucocorticoid-response section. They reported that GCs could reduce stability of mRNAs including transcripts encoding cyclooxygenase (COX)-2, cyclin D3, exotoxin, granulocyte-macrophage-colonystimulating factor, interferon- $\beta$, interleukin-1, interleukin-6, inducible nitric oxide synthase, leukocyte inhibitory factor, and vascular endothelial growth factor. In contrast, GCs can strengthen mRNA stability of other transcripts including COX-1 and fibronectin. Even though stressors can affect the HPA axis, its activation depends on duration, strength, and stressor etiology. Gutierrez et al. (2015) studied effects of different stressors (acute and chronic) on triggering HPA axis activity. The authors utilized two different stress models: electrical (physical) and LPS administration. Activatation of HPA axis was accomplished by chronic physical stressors and by acute or chronic LPS administration. Increased secretion of corticosterone occurred after LPS administration but not after acute physical stress. In a series of experiments by Hueston et al. (2014), an acute stressor (foot shock) caused a robust increase in IL-1 expression at $60 \mathrm{~min}$ after stress. In addition, there was a robust increase in IL-1R2, which can block IL-1 signaling, before IL-1 expression, which remained elevated for 240 minuets. There can be effects of stressors on other genes by activating them, rather than the cytokines, to limit or shut-off signals for neuroinflammation. They also studied the short-term effects of CRH and ACTH (HPA axis hormones) on the expression of cytokines and observed that there was no time relationship between HPA axis activation and robust increases in cytokine expression in the brain. However, ACTH directly links to particular inflammatory-related genes in the adrenal gland. Moreover, increased GC levels following acute stress had negative feedback on 
adrenal c-fos, COX-2 and IL-1 expression. Excessive Toll-like receptor (TLR) binding can cause hyper-activation, which can be suppressed by GCs targeting T-cells (Brewer et al., 2003). In contrast, macrophages are targeted by GCs to prevent septic shock induced by LPS (Bhattacharyya et al., 2007).

Mainly, acute stressors can stimulate brain cytokine production because a necessary amount of brain norepinephrine needs to be produced. Studies of stress in restrained rats have shown increased IL-1 $\beta$ in the hypothalamus but no changes in circulating IL-1 $\beta$, TNF$\alpha$, IL-6, or central Cox-2. Restraint stress caused higher plasma corticosterone, which has a continuous and pulsatile pattern, and high plasma epinephrine (Porterfield, 2011). Corticosterone secretion can follow different dynamic patterns based on the strain of rat, which have different responses to acute stress. Windle (1998) performed the first series of experiments studying HPA axis in catheterized rats to minimize handling and disturbance of plasma corticosterone levels. Moreover, they have shown there is a sexual dimorphism in HPA activity, which will be discussed later.

Frank (2013) proposed a novel idea about the effects of GC production on priming both central and peripheral innate immune system in reaction to the stressors in mice due to their effect on inflammatory response following infection or injury. This sensitization would make test subjecys aware of an injury or infection after GC concentration declined. After the fight-or-flight emergency is over, the immune system response to any potential inflammatory threats will be increased because it has been prepared by the neuroendocrine warning signal.

\subsection{Innate and Adaptive Immune Response}

Initial and rapid response to any pathogen, which is called innate immunity, is an antigennonspecific response in all living individuals. The host is born with this mechanism, and it is the first mechanism activated soon after being pathogen exposure (Wira et al., 2005). The four main roles of innate immunity include identifying foreign pathogens, removing them, regulating the immune response, and presenting antigen to effector immune cells. Immune activation by innate immunity is responsible for initiating both humoral and cellular components (Murphy, 2012). 
The first step in innate immunity is recognition by leukocytes of invading pathogens through pattern recognition receptors or PRRs (Takeuchi et al., 2001), which include two types: secreted molecules and cell-surface receptors. Secreted molecules are found in blood and lymph and are components of the complement system, while cell-surface molecules are found on macrophages and other phagocytic cells. The TLRs and C-type lectin receptors (CLRs) are cell-surface receptors on macrophages and dendritic cells that induce release of cytokines (Ozinsky, 2000; Pioli et al., 2004). There are at least 11 identified TLRs, which can either act together or separately (Aderem, 2004). The initial response to a pathogen is through macrophages, which are mature monocytes present in different tissues. Macrophages phagocytize pathogens through binding to TLRs on the plasma membrane (cell-extrinsic pathway) in contrast to the receptors in the cytoplasm (cytosolic PPRs/ cell-intrinsic pathway), which are known as nucleotide-binding oligomerization domain proteins (NOD) (Beutler, 2009; Takeuchi and Akira, 2010).

Despite the fact that innate immunity is antigen-nonspecific, some conserved structures named pathogen-associated molecular patterns (PAMP) can be recognized by TLRs on some immune cells. Macrophages, monocytes, dendritic cells, and neutrophils are leukocytes that can start the series of immune responses and recruit other leukocytes by recognizing PAMPs including mannose, peptidoglycan, lipopolysaccharide (LPS), bacterial DNA, glucans, viral nucleic acids, and lipoteichoic acid (LTA) (Janeway and Medzhitov, 2002). Innate immune responses and inflammation are induced by recognition of PAMPs by PRRs. Antigen presenting cells, in particular, dendritic cells, express PRRs leading to detecting microbes and triggering adaptive immune responses. Extracellular pathogens are sensed by cell-extrinsic recognition pattern through TLR-1, TLR-2, TLR-4, TLR-5 and TLR-6, and CLRs expressed on cell membranes of macrophages and DCs. Takeda (2004) has shown the reciprocal action of both TLR-2 and TLR-6 throughout the immune response to peptidoglycan and LTA PAMPs in a way that TLR-2 serves as the initial signal to induce an immune response and the second response is associated with binding of TLR-6. Because of TLR binding to the pathogen, the signal is transmitted to the

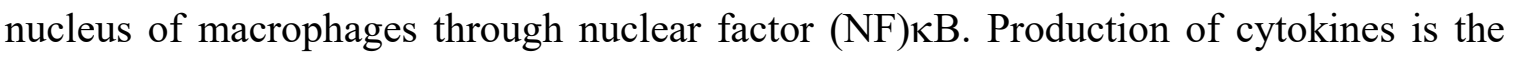
ultimate result of TLR signal transmission by stimulation of gene expressions for those cytokines (Takeda, 2005). Alternatively, cell-intrinsic recognition pathway is used to 
detect viral nucleic acids and intracellular bacteria through cytoplasmic sensors. In some cases, both cytosolic and membrane-bound PRRs can detect some PAMPs, such as viral nucleic acids and LPS (Iwasaki, 2015).

The diverse white blood cells (leukocytes) in blood and lymph are responsible for the immune response. They originate from hematopoietic stem cells (HSC) in bone marrow and are differentiated into either myeloid progenitor or lymphoid progenitor cells. Lymphocytes (B and T) and natural killer cells arise from lymphoid progenitor cells; whereas, myeloid progenitor cells give rise to mononuclear or polymorphonuclear phagocytes, mast cells, and red blood cells. Innate immunity is mostly reliant on specialized myeloid cells. Granulocytes or polymorphonuclear leukocytes include neutrophils, eosinophils, and basophils due to their cytoplasmic granules, which contain bactericidal enzymes (Murphy, 2012). Neutrophils have phagocytic properties in addition to having antibacterial enzymes and are generally the first cells to reach the infection site. Soon after infection, monocytes follow neutrophils to the site, thus accumulation of neutrophils and macrophages is a hallmark of inflammation. Mature neutrophils exit bone marrow fully maturated, however, immature neutrophils can be found in blood during the acute phase of an infection. Concentration of mature neutrophils increase in circulation during severe infection, even 5-10 fold in severe cases (Waller, 2002). Circulating neutrophils in sheep average 2,400 neutrophils/ $\mu$ of blood, while basophils and eosinophils usually average fewer than 5\% of the total leukocytes: 50 basophils/ $\mu$ l and 400 eosinophils/ $\mu 1$ in blood. Mast cells, basophils, and eosinophils have roles in allergic reactions. Eosinophils also play a part in responding to parasitic infestation.

The main components of mononuclear phagocytes are circulating monocytes and cells derived from them including macrophages (tissue monocytes) and dendritic cells. Average concentration of circulating monocytes in sheep is 200 monocytes/ $\mu 1$. Dendritic cells (DC) are professional antigen-presenting cells (APC) and take up pathogens through micropinocytosis. Then, activated DCs travel to the closest lymph node and activate Tcells, which are pathogen-specific lymphocytes and cellular elements of adaptive immunity. Moreover, activated and mature DCs can produce cytokines to affect mutually innate and adaptive immunity. Kupffer cells, microglial cells, and osteoclasts are examples of macrophages of liver, brain, and bone, respectively. Macrophages can destroy pathogens 
by phagocytosis as well as recruiting polymorphonuclear phagocytes to the infection site. Macrophages present antigen through MHC class II to T-cells (CD4+) and stimulate an adaptive immune response (Beutler, 2004). In addition, macrophages can start inflammation that causes redness, swelling, heat, and pain in the affected area. Those characteristics are based upon the increase in blood flow, increased permeability of blood vessels, and vasodilation in the affected area. Furthermore, migration of leukocytes to the site of infection is due to the effect of chemokines responsible for pain (Murphy, 2012). Inflammation is the result of TLR ligation and cytokine signaling causing secretion of additional cytokines, chemokines, and prostaglandins resulting in cell recruitment.

Regulation of immunity is accomplished by intercellular messengers named cytokines, which are released by innate immune cells including monocytes, macrophages, DCs, neutrophils, eosinophils, basophils, natural killer cells, and mast cells. For instance, tumor necrosis factor (TNF) is produced primarily by mast cells and macrophages, and RBCs are the only cells that do not have TNF receptors (Tizard, 2004). Cytokines and chemokines, which are responsible for coordinating the immune response, include interleukins (IL-1, IL-4, IL-6, IL-10, IL-12, IL-18), TNF- $\alpha$, IFN- $\gamma$, TGF- $\beta$, and CCL4/RANTES. Various stimulators cause their release; one is TLR4 binding by LPS or other pathogens through TLRs. Others are signals come from complement and immunoglobulin.

There are two types of inflammatory cytokines: pro-inflammatory cytokines and antiinflammatory cytokines. Proinflammatory cytokines, which help systemic inflammation and cause fever and tissue distruction, include TNF- $\alpha$, IL-1, IL-2, IL-8, and IFN- $\gamma$. On the other hand, anti-inflammatory cytokines mostly downregulate inflammatory responses through IL-4, IL-5, IL-6, and IL-10 (Raghupathy, 1997). Cytokine signaling ultimately causes inflammatory or allergic reactions, while proinflammatory cytokines stimulate adaptive immunity by recruiting T-cells, and anti-inflammatory cytokines to resolve the inflammatory response (McGettrick, 2007; Iwasaki, 2010). Proinflammatory cytokines, like IL-8, are released immediately after activation of innate immunity; they are responsible for the release, and production of other chemokines and cytokines. IL- 8 is essential because of its chemotactic function to attract neutrophils to the inflammation site (Papanicolau, 1998). 
One model used for immune response is the LPS model, which shows that the HPA axis is activated at different points during the acute phase response. The LPS pathway contains TLR-4, which is expressed on the surface of specific WBCs such as neutrophils, monocytes, and dendritic cells and includes CD-14 and MD-2 as co-factors. An LPS injection can affect secretion of systemic IL-1, which is the result of activation of tissue macrophages including hepatic macrophages named Kuppfer cells (Navarra et al., 2001). LPS is one of the chemical motifs that can increase secretion of pro-inflammatory cytokines including IL-1 $\beta$, as well as, causing septic shock and death due to stimulating the systemic release of IL-6, IL-1, and TNF $\alpha$. Symptoms include fever, hypotension, organ failure and acidosis (Bernheim, 1976; Lacy, 2011). Moreover, IL-1 $\beta$ has positive feedback on IL-6 secretion, which is the essential element to activate HPA axis and cause fever in acute phase response (Turnbull et al., 2003, Cartmell et al., 2000). IL-1 is also involved in growth of different cells, such as vascular smooth muscle, glial cells, and fibroblasts. Initiation of $(\mathrm{NF}) \mathrm{KB}$ is in response to TLR and NOD, which stimulate macrophages to secrete TNF $\alpha$ as the first cytokine secreted. TNF- $\alpha$ and IL-1 can work together to enhance inflammation, or TNF $\alpha$ can work separately adjacent to the site of inflammation to increase production of vasodilators. Vasodilators also loosen endothelial cell tight junctions which causes gaps to allow leakage of plasma proteins and neutrophils into the tissue. Both TNF$\alpha$ and IL-1 can cause inflammation symptoms including lethargy, fever, and low appetite (Kuwano et al., 2004, Gupta, 1995). While these two cytokines attract neutrophils to the site of inflammation and trauma, IL-6 is produced by macrophages in response to secretion of IL-1 and TNF- $\alpha$. Furthermore, IL- 6 has a negative feedback on the secretion of those cytokines and attracts macrophages to the site of inflammation; therefore, it is a major component of acute phase responses (APR), which is the first part of the systemic reaction in a case of infection. There is an increase in acute phase proteins (APP), which are reactants produced by hepatocytes, macrophages, smooth muscle and endothelial cells and released into circulation during APR. Changes in the amount of APPs occurs within two hours of inflammation and remain for about two days. Meanwhile, increases in ACTH, cortisol, and catecholamine are observed in addition to neuroendocrine changes like fever, dropped in appetite, and dizziness (Ceciliani, 2002). 
Initiation of APR depends on secretion of pro-inflammatory cytokines at the beginning of an immune response to inhibit current tissue damage due to the inflammation and reestablish homeostasis and tissue healing (Gabay, 1999). Production of pro-inflammatory cytokines affects the specific part of the brain responsible for regulation of body temperature resulting in secretion of prostaglandin related to high temperature and fever induction. Prostaglandin causes vasoconstriction and stimulation of sympathetic nervous system leading to fever occurrence, which is the defensive mechanism against pathogens via decelerating their growth while increasing host immune response and metabolism (van Deventer, 1990).

Sometimes cells are not needed for an immune response. In that case, other molecules, which are part of a humoral component of the innate immunity, would be adequate to destroy pathogens, while others just recognize them. Molecules that can kill microbes are complement, lysozyme, lactoferrin, and antimicrobial peptides. Complement includes about 30 proteins, which are proteolytic enzymes made by the liver. Thry ultimately lyse Gram-negative bacteria and disable viruses by forming a "membrane attack complex." They also make pathogens recognizable to phagocytes. Most of them are inactive proenzymes before they are initiated by a pathogen. Some of them are soluble receptors and can be directly triggered by a pathogen, while others intensify the effects of the "complement" antibodies. They are activated in three pathways: the classical pathway, the lectin pathway, and the alternative pathway. The key component of all three pathways is complement component 3 (C3), since, it is activated early in each one. Each of these pathways is triggered in a different way. The classical pathway needs antibody (IgG or IgM) binding to the surface of a pathogen, while the lectin pathway requires mannanbinding lectin, and the presence of pathogen surface is essential for the alternative pathway. Besides, activation of any of those pathways has a positive feedback on activation of the alternative pathway.

All pro-enzymes are activated by proteolytic cleavage, and C3 is activated the same way and cleaved to $\mathrm{C} 3 \mathrm{a}$ and $\mathrm{C} 3 \mathrm{~b}$. Each cleavage triggered production of serine protease to continue the series of cleavage of the next pro-enzymes. This proteolytic cascade is intensified by activation of the first elements of each chain, which depends on a cleavage with the activated enzyme. Because those enzymes can cleave and activate many 
molecules, the proteolytic cascade is being intensified. The results of this cleavage are two fragments: the larger one, which is a membrane-binding molecule, and small fragment, which is biologically active. The small fragment, for instance, the small fragment of C3, which is called C3a, sends signals to recruit lymphocytes and phagocytes to enhance the inflammatory reaction. On the other hand, the large fragment, in the case of $\mathrm{C} 3$ is $\mathrm{C} 3 \mathrm{~b}$, remains attached to the cell surface of the pathogen to amplify the phagocytic reaction. Moreover, they have a fundamental catalytic role as a protease to initiate the next step. After the activation of each of the complement pathways, $\mathrm{C} 3 \mathrm{~b}$ remains attached to both the host and pathogen cells. The mechanism to defend host cells from complement attack is based on the production of proteins to inhibit effects of complements on self-cells. Since pathogens do not have those proteins, complements recognize and destroy them. Membrane attack complexes are formed by the last component of complement, which is elicited by $\mathrm{C} 3 \mathrm{~b}$ produced in any of those ways. These complexes create a pore in a membrane of pathogens, which distorts the bilayer structure of cell membrane and makes it leaky and even lyse (Alberts, 2002). Outer surface of microorganisms such as LPS acts as an immunostimulant, which can be recognized by $\mathrm{C} 1$ and results in initiation of alternative complement cascade. Furthermore, LPS as an immune mediator can activate phagocytosis of antigens, which were opsonized with C3b (Merle et al., 2015). LPS is a potential stimulation of both the complement cascade and polymorphonuclear neutrophils via direct or indirect different inflammatory mediators. Purified Lipid A can bind to the C1 and trigger the complement classic pathway independent of antibodies, while initiation of the alternative complement pathway can happen through LPS polysaccharide independent of Lipid A and antibodies. Furthermore, Smooth-form and Rough-form, which will be explained later, stimulate the alternative complement pathway. One of the mechanisms through which LPS antibodies can affect the alternative pathway is via a bond between IgG and $\mathrm{C} 3 \mathrm{~b}$. Thus, this interaction boosts the accumulation of $\mathrm{C} 3 \mathrm{~b}$ on the surface of the bacteria induces the synthesis of new C3 and C5 convertases, which further enhance C3 stimulation and the release of new MAC. Both IgG and IgM act as opsonins independent of the complements or in conjunction with them. In a case of live bacteria it results in opsophagocytosis by the phagocytes or facilitating the LPS uptake and its clearance in other cases. The Fc receptors on Polymorphonuclear leukocytes, macrophages, and 
monocytes recognize and bind to the constant region of IgG antibodies. On the other hand, $\operatorname{IgM}$ antibodies do not have the equivalent receptors on the surface of the phagocytic cells but they still can trigger the complement cascade. IgG and IgM, as LPS antibodies, can accumulate the complement on the surface of Gram-negative bacteria by the classic or alternative pathways, which results in results in adherence of opsonized targets to the phagocytes cell membrane and inducing ingestion and intracellular killing of the antigen (Morrison, 1992).

In contrast to innate immunity, which acts immediately, the adaptive immune system is acquired over time and is mainly dependent on the innate immune system. Any defect in the innate immune system, such as antigen presenting cells, which are vital for adaptive immune function, and cytokine production (type I interferons, IL-12, TNF- $\alpha$, CD40L, IL1), may cause inefficiency in adaptive immunity. Unlike innate immunity which acts quickly, adaptive immunity needs time to perform because it takes 4 to 5 days for lymphocytes to mature and differentiate into effector cells. Similar to innate immunity, it contains humoral and cellular components, which are lymphocytes. There are two main types of lymphocytes: B- lymphocyte and T-lymphocyte. The B-lymphocytes have been developed in bone marrow, and they have receptors in their membrane, which can bind to antigens. Naïve B-cells differentiate into active plasma cells when they are exposed to the antigen. Plasma cells then produce antibodies or secreted-B-cell receptor (BCR), which are the humoral components of the adaptive immune system. Antibodies or immunoglobulins (Igs) opsonize pathogens for elimination by myeloid cells. The T-lymphocyte has three types: helper T-cell, regulatory T-cell, and cytotoxic T-cell. DCs have the main role in priming T-cells, especially Th1, by presenting bacterial and fungal antigens to them via their receptors, which is unique to them and is called T-cell receptor or TCR. The major differences between BCR and TCR are first, BCR can be secreted, but TCR is just membrane bound; second, TCR only has one antigen recognition site, but BCR has two. Furthermore, TCR can only recognize and bind to the specific type of proteins known as major histocompatibility complex or MHC (Janeway and Medzhitow, 2002). MHC1 is present on all host cells and can be recognized by T-cells to discriminate non-self from self-cells. All other cells that lack MHC1 will be recognized as foreign cells and phagocytized by natural killer cells (NKC). MHC1 presents antigen to the cytotoxic T-cells 
$(\mathrm{CD} 8+)$. The other type of MHC molecule called MHCll is found in specific immune cells including DCs, macrophages, and B-cells. It binds to pathogenic proteins and interacts with T-helper cells $(\mathrm{CD} 4+)$ to initiate proper immune response including recruitment of phagocytes or humoral immune response by activation of B-cells (Hinz, 2014). Th-1 and CD8+ T-cells are responsible for creating immunity against both protozoa and intracellular bacteria through the involvement of PAMPs and TLRs and making IL-12. Cytotoxic lymphocytes also respond to those infections via induction of IL-12 production by CD103+ DCs (Mashayekhi, 2011; Edelson, 2011). Eventually, immunological memory can be established during the late phase of infection. It means after elimination of pathogen, some lymphocytes remain, which are called memory cells. Memory cells are the fundamental part of the immunological memory, which guarantees that the next exposure to the same antigen will be more effective and more rapid. It is the major significance of the adaptive immunity, which forms the basis of vaccination and ensures the long-term protective immunity (Janeway, 2001). Summary of the immune system response is shown inFigure $1-2$. 


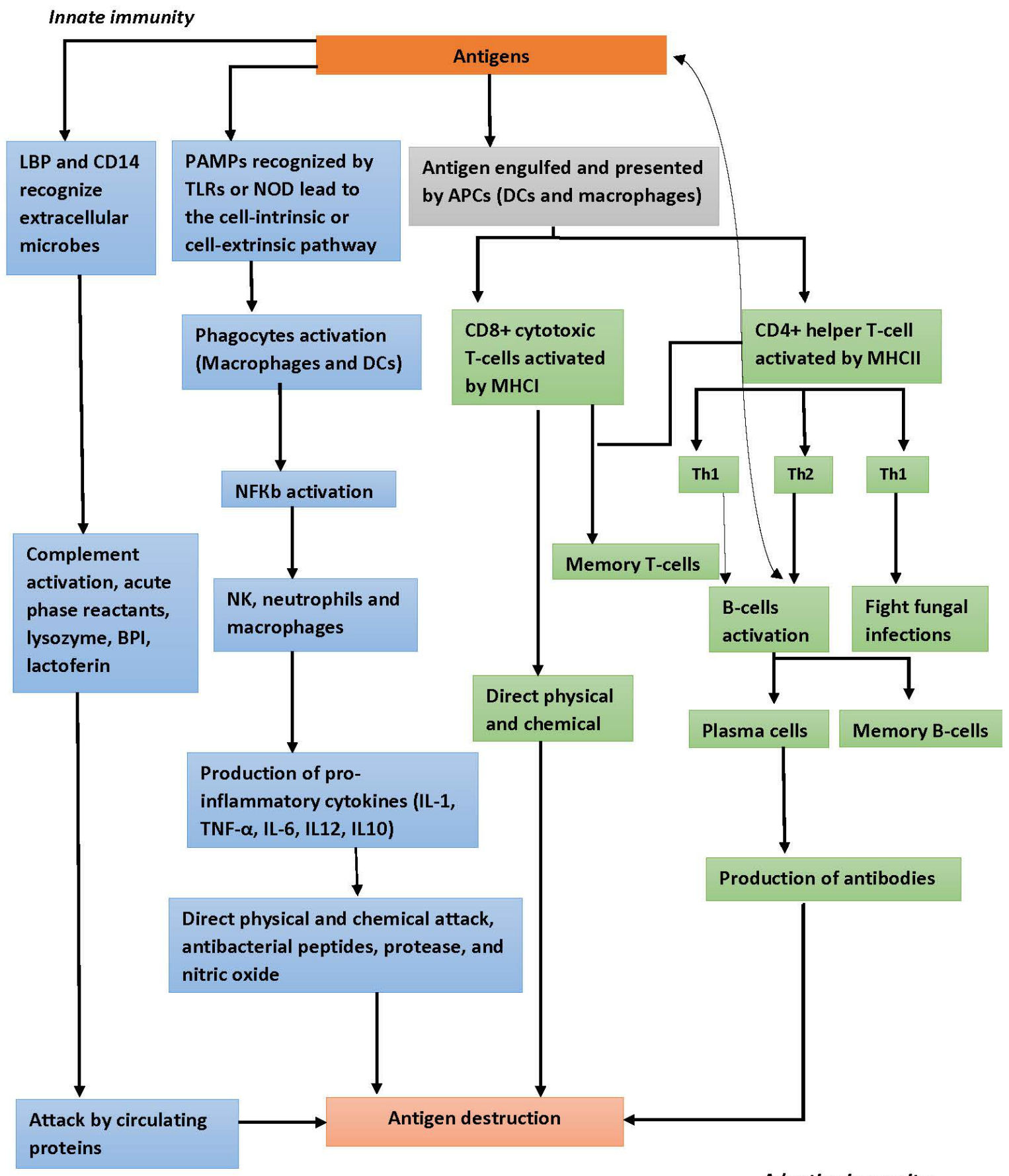

Adaptive immunity

Figure 1-2 Innate and adaptive immune response summary. Adapted from Barker (1999). 


\subsection{Gram-negative and Gram-positive bacteria}

Bacteria are single-celled and divide by binary fission and most of them at rapid rates. Despite their simplicity, they are highly adaptable and sophisticated. The significance of bacteria is related to their ability to adapt to the situation by inducing instant mutation. Pathologically, they are the main causes of infectious disease.

Bacteria are prokaryotic cells and have less complexity than eukaryotes. The major difference between eukaryotic and prokaryotic cells is the compartmentalized structure, which means the presence of membrane-bound organelles, such as mitochondria, Golgi complex, and endoplasmic reticulum, in eukaryotes but not in prokaryotes. The cytoplasm of bacteria is enclosed by a lipid cytoplasmic membrane, which is a site for oxidative phosphorylation. Bacteria are divided into gram-negative, gram-positive, mycoplasmas, and cyanobacteria. All, except mycoplasmas, have a carbohydrate cell wall (cell envelope in gram-negative bacteria) outside their cell membrane, which is thick and protective against osmotic lysis. The wall is composed of different amounts of peptidoglycan (mucopeptide or murein) such that gram-positive bacteria contain 60 to 90 percent peptidoglycan with a 20-80 nm wide wall. Gram-positive bacteria such as staphylococci, streptococci, lactobacilli, and Bacillus spp. have teichoic acid in their cell walls. In grampositive bacteria, cell wall components such as teichoic acids, which are polysaccharides with strong antigenicity, peptidoglycolipids, and polysaccharides are covalently bound to the peptidoglycan. Peptidoglycan can induce an immune response, inflammation, fever, and lethargy.

Gram staining technique has been used to distinguish bacteria. The basis of this technique is the trapping of crystal violet-iodine by gram-positive bacteria due to their cell wall components, which gives them a purple color under the microscope. In contrast, gramnegative bacteria have a low amount of peptidoglycan (5-10 nm wide) in their cell envelope, which is just a monolayer thick. Throughout Gram-staining, less crystal violetiodine is trapped in their cell envelope, which stains them pink-red, since their cell envelope is thin. Furthermore, gram-negative bacteria have an outer cell membrane of lipopolysaccharide (LPS), which is also named endotoxin (Royet, 2007; Kopecny, 2013). 
The LPS consists of two parts: toxic Lipid A (hydrophobic) that is connected to the polysaccharide chain (hydrophilic carbohydrate), which itself has a core (inner and outer core) and an O-Specific chain. The difference in LPS among different strains of bacteria is associated with the inconsistency of the O-Specific chain, which is made up of the various numbers of oligosaccharide repeating units giving each strain of bacteria a heterogeneous mixture of LPS with short, intermediate, and long O-specific chains (Baumgartner, 1993). Smooth variants of Gram-negative bacteria with short O-specific chain are resistant to complement, while rough variants with long O-specific chain are more susceptible. Lipid A and its unique conformational property presumably play a specific role in eliciting the inflammatory cascade by interacting with the host's cellular and humoral immune factors. Some general features of endotoxins include being heat-stable, biologically active, adjuvant, and membrane-bound. Moreover, circulating endotoxins can prompt a devastating inflammatory response, known as "systemic inflammatory response" or "sepsis cascade" by activation of the complement system and macrophages and by triggering interferon production. Septic shock is the result of progressive sepsis, which induces secretion of IL-6, IL-1, and TNF- $\alpha$ and causes devastating symptoms including multiple organ failures, fever, metabolic acidosis, inadequate tissue perfusion and hypotension (Silverman, 1999).

Four central proteins have been associated with cell activation by LPS in mammalian cells including lipopolysaccharide binding protein (LBP), TLR-4, MD-2, and CD14. The LBP is a glycoprotein synthetized by hepatocytes. The LBP along with CD14 are initially recognized as receptors for LPS, which are crucial for its sensing in a way that LBP simplifies LPS binding to the CD14 molecule. The LBP-LPS complex, which is formed by binding LPS to LBP, is the main mediator of sepsis in the case of detectable infection and systemic inflammatory response syndrome (SIRS) in the case of undetectable infection. In vitro studies have shown decreasing sensitivity of mononuclear cells to LPS-LBP complex. The CD14 molecule can be found on monocyte/macrophage lineage, and its interaction with LPS-LBP prompts monocytes and macrophages to secrete cytokines (IL-1, IL-6, IL8, IL-10) and TNF $\alpha$, respectfully. Among LPS natural ligands, bactericidal/permeabilityincreasing protein (BPI), which is produced and stored in primary granules in neutrophils, is associated with LBP by having similar structures and $45 \%$ identical amino acids 
(Elsbach, 1998). It has a high affinity for LPS and has an essential role in clearance and neutralizing LPS (Weiss, 2003). Besides, by studying C3H/HeJ mice for years, it has been illustrated that the crucial element of LPS receptor is TLR-4 with an extremely precise role (Beutler, 2003). Studies have shown that activation of TLR-4 is dependent on MD-2 and it is closely related to TLR-2. Activation of TLR-2 is associated with infection with Gram-

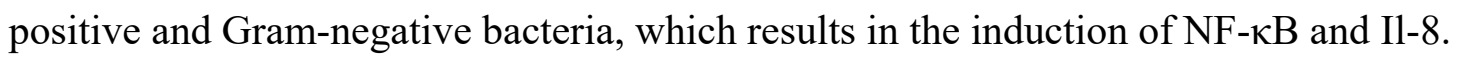

Furthermore, LPS has a major part in activation of various protein kinases (Dziarski, 2000). Another difference is associated with their functionality in a way that BPI is lethal, but LBP does not have a cytotoxic effect at the same dose. Finally, Gram-negative bacteria coated with LBP are taken up by monocytes or macrophages through mCD14, while those coated by BPI are primarily taken up by polymorphonuclear cells independently of CD14 (Dziarski, 2000; Iizasa, 2016). The LBP has an essential role in forming an LPS-CD14 complex by catalyzing LPS and transferring a single molecule to CD14. The LPS-CD14 complex is the main mediator of activation of the TLR4-dependent cell by transferring LPS to MD-2/TLR-4 complex. On the other hand, BPI prevents inflammation by blocking LBP and inhibiting transfer of LPS to CD14. Moreover, LBP can elicit secretion of proinflammatory cytokine by activating monocyte and macrophage by transporting LPS, which is absorbed via intestinal barrier, to lipoproteins and chylomicrons (Krasity, 2011). Local and limited secretion of TNF- $\alpha$, IL-1, IL-6 and IL-8 are positive factors for host body by stimulating the immune system to kill a pathogen, while their systemic release is the core cause of sepsis and SIRS in cases of endotoxemia. Most signs of sepsis and SIRS, such as organ damage, endothelial dysfunction, refractory hypotension, shock, and death, are results of overstimulation of those cytokines. Host cells with the receptor for TNF- $\alpha$, IL-1, and IL-6 over respond to LPS and induce leukocytes like monocytes and macrophages to release key mediators of tissue damage, which cause a systemic inflammatory response. These biologically activated elements including leukotrienes, proinflammatory proteases, platelet activating factor, oxygen radicals, and prostaglandins. Vasodilation resulting from the production of nitric oxide by macrophages and endothelial cells leads to vascular leakage and hypotension. Moreover, disseminated intravascular coagulation (DIC), which ultimately turns into shock, is another consequence of endotoxemia triggered by pathological activation of the coagulation system. DIC is the 
result of activation of both extrinsic and intrinsic coagulation pathways through stimulation of Factor XII of the coagulation system, which was activated by LPS. It can stimulate activation of Factor XI and trigger production of tissue factor by macrophages and endothelial cells. Factor XII is another cause of hypotension by activating bradykinin, a hypotensive mediator (Raetz, 2002).

\subsection{Gender Response in Stress Effects}

There are two types of stressors, which can influence an animal's reaction: psychological and physical stressors. Psychological stresses include restraint, handling, and novelty while physical ones are hunger, thirst, fatigue, injury and thermal extremes. In most cases, fear is a result of psychological stressors such as contact with people, restraint, and transportation. Studies revealed that electrical stimulation of the amygdala elicits fear, behavioral changes, fear-like autonomic responses, and increases in plasma corticosterone, which suggests that the amygdala is a center for fear. Various factors can cause animals' different responses to the certain stressors such as previous experiences, genetics, animal's social rank, and gender. Sometimes, the interaction between animal's genetic and previous experiences can affect an animal's reaction to the stressor as well. For example, animals with an excitable temperament are more sensitive to rough handling compared to animals having a mild temperament. Even though novelty is one of the strongest stressors, animals can get accustomed to it, some adapt to non-painful stimuli such as weighing, milking, entering a restraint device, and drawing blood through indwelling catheters. Both low and high short-term stressors like handling or slaughter procedures can cause an elevation in cortisol levels; however, heifers, cows, and steers showed higher cortisol levels than mature bulls (Grandin, 1997).

Male and female reactions to the stressor involved a cascade of physiological and behavioral responses, which start with the secretion of hormones such as vasopressin, oxytocin, CRH, and other PVN hormones. In turn, CRH stimulates the release of ACTH, which triggers secretion of GCs (cortisol or corticosterone) from the adrenal cortex. Activation of the sympathetic nervous system, in response to the stressor, and its innervation with the adrenal medulla triggers the release of catecholamines. Sympathetic arousal results in the fight-or-flight response, which is an evolved response to overcome 
the predator or flee from the threatening situation. Taylor et al. (2000) posited a theory of "tend-and-befriend" in females as an alternative behavioral response for fight-or-flight in males because the female response is affected by sex hormones, oxytocin, and endogenous opioid in humans and other specie. In the male, fight-or-flight aggressive response is mainly linked to the androgens (testosterone). In contrast, oxytocin in females, which is the basis for the biobehavioral attachment and caregiving system, downregulates the HPA and sympathetic response, based on the broad studies in rats, prairie voles, monkeys, and sheep. The tend-and-befriend pattern in females guarantees the survival of offspring in conjunction with social groupings to ensure accessing the resources and the survival of the species. However, some studies found no differences in responses between sexes nor higher cortisol level in females encountering social rejection task compares to the achievement tasks. Sex-specific stress response is a complex and tentative context, which can be affected by the nature and intensity of stress, test-subject state, and experimental techniques (Stroud et al., 2002, Dickerson and Kemeny, 2004)

Neuroimaging data in human beings showed that mild stress causes different neural activation that activates the right prefrontal cortex (RPFC) and deactivates the left orbitofrontal cortex (LOrF) in males, while causing limbic hyperactivity in females. Consistent with the tend-and-befriend stress model, the limbic system, especially the ventral striatum, which contains numerous receptors for oxytocin, vasopressin, dopamine, and endorphin, is activated in females in response to the stressor. On the other hand, suppression of the LOrF, a center for hedonic goals and positive emotion, and activation of RPFC, which is the part of the vigilance system and negative emotion, are linked to the fight-or-flight response in males (Wang, 2007). McEwen et al. (2007) also demonstrated that chronic stress could differently affect male and female's hippocampus and amygdala. It was shown that chronic restraint stress (CRS) induces proliferation in female rats' dentate gyrus (part of the hippocampus) while reducing proliferation in male rats'. Additionally, CRS decreased neural sensitization in the CA3 region of the hippocampus (part of the limbic system) in males and ovariectomized females but not in intact females. Moreover, CRS enhanced neural sensitization of amygdala in both males and estradiol-treated females. 
Dissimilar concentrations of gonadal steroids in males and females have different effects on the HPA axis, which cause sexually dimorphic activity of the HPA axis in human beings and animals. Acute alcohol treatment stimulated activation of the HPA axis in both sexes of rats (Jenkins, 1968; Ogilvie, 1996). However, alcohol administration in both sexes generates higher elevation of ACTH and corticosterone concentrations in females than males due to the inhibitory effect of androgens in comparison to the stimulatory effect of estrogens ( $\left.\mathrm{E}_{2}\right)$. Furthermore, higher levels of ACTH and corticosterone in castrated males implanted with $\mathrm{E}_{2}$ in response to the injection of alcohol indicated the activational effect of $\mathrm{E}_{2}$ on ACTH response. Besides, both females and castrated males have a higher concentration of corticosterone binding globulin (CBG), which explains the discordance between $\mathrm{ACTH}$ and corticosterone concentrations. Furthermore, $\mathrm{E}_{2}$ not only increases adrenal sensitivity to ACTH but also enhances the clearance of corticosterone (Ogilvie, 1997). Males show higher CRH and AVP mRNA levels in the PVN than females and castrated males with $\mathrm{E}_{2}$ implantation, which suggests a regulatory effect of steroid on $\mathrm{CRH}$ and AVP mRNA concentrations in the PVN. Castrated males experiencing a novel stressor had higher CRH and expression of c-fos in the PVN in comparison with intact males. Nevertheless, sex steroids do not influence basal levels of CRH and AVP mRNA in the PVN (Ogilvie, 1997).

Various types of stressor activate the sympathoadrenal medullary system as well as the HPA axis, while the sexes and gonadal steroids affect both. Gonadectomized sheep subjeced to isolation and restraint stress showed elevation in plasma epinephrine. Even though epinephrine concentrations did not differ between gonadectomized ewes and gonadectomized rams, plasma epinephrine elevation remained for a longer time in gonadectomized rams than in gonadectomized ewes. Besides, norepinephrine did not seem to be influenced by stress in either sex (Stackpole, 2003). Sex differences are apparent in human beings, although they are inconsistent because of the stages of the menstrual cycles among the test subjects and lack of standardized sex steroids. For instance, men and women have comparable responsiveness to a physical stressor, whereas, a psychological stressor increases heart rates and diastolic pressures more in women than men (Tersman, 1991). The cortisol response in ewes and rams depends on the stressors in such a way that ewes tend to have higher cortisol level in response to the psychological stressors like isolation 
and restraint. However, rams subject to the metabolic stressors such as insulin-induced hypoglycemia showed higher cortisol levels (Turner, 2012). Furthermore, some stressors, like endotoxin and exercise, do not seem to have a different effect on cortisol levels of gonadectomized rams and gonadectomized ewes (Turner, 2010). The mechanism for the different cortisol responses in various sexes to some stressors, such as tail docking and $\mathrm{ACTH}$, emerges early in life, for example, time of further maturation of HPA axis in lambs is between age 1 and 8 weeks (Turner, 2006). Distinct stress responses between sexes derives from gonadal factors as well as factors at each level of the HPA axis including neuropeptide distribution in the PVN, adrenal size, and adrenal responsiveness to ACTH. The bidirectional interaction between the HPA axis and reproductive axis means that sex steroids can elicit activation of the stress system, and the stress system can influence reproductive function. Additionally, an in vitro experiment demonstrated that estradiol-17 $\beta$ triggered catecholamine production from adrenal medullary cells, which showed effects of steroids on the sympathoadrenal medullary system. Furthermore, steroids can affect catecholaminergic neurons in different brain loci; for example, estradiol benzoate treatment in rats causes high levels of norepinephrine in the pre-optic region of the hypothalamus (Yanagihara, 2006). Moreover, in ewes it was shown that estradiol-17 $\beta$ has a direct effect on the adrenal glands by enhancing its response to $\mathrm{ACTH}$ and regulating cortisol secretion. Female human beings and rodents generally have higher basal GCs than males. Furthermore, in rodents, female have higher ACTH and GCs in response to stressors. One explanation for the stimulatory effect of $\mathrm{E}_{2}$ on HPA axis is its direct effect on the estrogenresponsive elements of the $\mathrm{CRH}$ gene and an influence on the PVN neurons via $\mathrm{E}_{2}$-receptor $\alpha$ (ERalpha). On the other hand, direct action of testosterone on the PVN neurons through $\mathrm{E}_{2}$-receptor $\beta$ (ERbeta) thus modifying oxytocinergic neurons is responsible for the inhibitory effect of androgens (Handa, 2011). In sheep, presence or absence of gonads in either sex did not influence adrenocortical response to ACTH. However, gonadectomized sheep showed higher CRH and VP levels in the median eminence despite rising VP levels in males than females, which provides a neuroanatomical description for sex differences in HPA axis regulation (Canny, 1999). Different stages of reproductive cycle affect HPA axis in a different way. For example, women in the follicular phase have lower GCs in response to the psychological stress than women in the luteal phase, which suggests the suppressive 
role of the estrogenic environment on the HPA axis in women, contradictory with its effect on rodents. Additionally, the attenuating effect of progesterone on the GCs responses was shown in both men and rodents, which suggests its down-regulating role in the stress response, the same as the influence of testosterone on the stress system. Lactation is another factor that has an attenuating effect on the GCs production and stress responsiveness based on the inhibitory effects of prolactin and oxytocin (Turner, 2012).

Jones et al. (2016) reported no differences between men and women skeletal muscle sympathetic nervous activity (MSNA) and cardiovascular activity to different standardized laboratory stressors (cold pressor and mental arithmetic). They suggested that acute stress affects the sympathetic nervous system and cardiovascular reactivity in both sexes in the same way; therefore, there is no sex-related difference in their MSNA respond to the acute stress. However, Some findings show higher sympathetic activity in males while others show no differences. Those discrepant outcomes could be, first, the result of a lack in standardized and equivalent stressors in men and women. Second, it could be related to a higher sympathoexcitatory stimulus rather than a constitutional variation. Third, sometimes cardiovascular and humoral responses may not properly reflect the sympathetic reactivity. For instance, plasma level of catecholamine (norepinephrine) is varied by different rate of clearance, release, and neural reuptake, so, it might not be consistent with the sympathetic neural release.

From an immunological point of view, men and women display striking differences in the pro-inflammatory response to an antigenic challenge: men are more susceptible to septic shock. Following administration of LPS, women show a more profound pro-inflammatory response by having higher IL-6, TNF- $\alpha$, and LBP. However, both sexes show nearly the same concentrations of IL-10, which is the anti-inflammatory cytokine. The relationship between sex hormone and innate immunity can be explained by its effect on the increased production of pro-inflammatory cytokines and LBP mRNA in women treated with $\mathrm{E}_{2}$. Due to the insignificant role of the circulating leukocytes on the systemic cytokine production, no sex differences in leukocyte differential were observed other than significantly lower monocyte counts in women. Higher levels of LBP were associated with secretion of the pro-inflammatory cytokine in women, which facilitated TL-4 signaling (van Eijk, 2007). Thus, $\mathrm{E}_{2}$ acts in a pro-inflammatory manner while testosterone is more anti-inflammatory, 
i.e., testosterone reduces eosinophil degranulation, Fc-receptor expression, antibody production, and inducible nitric oxide synthase mRNA expression. Conversely, E2 increases these immune reactions.

The complexity of the sex-specific variation in response to infection is obvious. Lastly, sex-susceptibility to different infections depends on the type of the microbe. In most cases, $\mathrm{E}_{2}$ acts to stimulate the immune system, and testosterone acts to suppress the immune system. The interaction between sex and immune responses to specific microbes may cause clearance of the infection due to enhanced immune response or amplify infection because of the decreased immune response. Bacterial cell wall components, such as LPS and LTA, can cause strong immune responses with sex differences. For example, administration of LPS from Salmonella abortus equi and LTA from Staphylococcus aureus induced higher levels of pro-inflammatory cytokines (TNF- $\alpha$, IL-1 $\beta$, IL-6, and IL-8) and IFN- $\gamma$ in male mice while females receiving LPS showed delayed apoptosis of granulocytes and higher overall survival; survival rate in female mice was $84 \%$ and $41 \%$ in male mice 24 hours after intraperitoneal LPS administration. Furthermore, males showed a rapid drop in the numbers of peritoneal macrophages with a concomitant surge in neutrophils by 18 hours after LPS administration, while females had the same drop in macrophages without the concurrent granulocyte inflow. Vulnificus LPS (Vibrio) was more lethal in intact female than male rats, but ovariectomized female rats had a mortality rate similar to males, and estrogen administration to gonadectomized rats of either sex resulted in higher rates of mortality (McClelland, 2011). 


\section{Chapter 2 Objectives}

Drawing blood from the jugular vein while the animal's head is restrained can cause a fight-or-flight response, which can elicit an immune response and elevation in white blood cell count. The aim of the current study was first to determine whether the type of blood draw from the jugular vein elicits stress, which can affect the immune response. The second aim was to determine the effect of sex on the stress and immune response. Therefore, the primary null hypothesis for this experiment was that different blood draw types do not elicit a difference in total white blood cell count, cortisol level, rectal temperature, and physical appearance. The secondary null hypothesis was that sex does not affect total white blood cell count and cortisol level, which means administration of LPS does not elicit a difference in total white blood cell count, cortisol level, mucosal response, rectal temperature, and lethargy in ewes compared to wethers. Hence, the main objectives of this study were to test the effects of different blood draw types and sexes on the immune system and the HPA axis response to LPS administration. 


\section{Chapter 3 Materials and Methods}

Thirty-eight mature Dorset and Suffolk wethers and ewes, $\sim 46 \mathrm{~kg} \mathrm{BW,} \mathrm{(WVU} \mathrm{IACUC}$ \#13-0404.1) were fed free choice native grass hay and had ad libitum access to fresh water. They were assigned randomly to a $2 \times 2 \times 2$ experimental design and assorted into four groups by blood draw type (restraint versus catheter), sex, and treatment (LPS versus saline). The first group consisted of ewes $(n=5)$ and wethers $(n=4)$ that received LPS and were restrained to draw blood by repeated puncture of a jugular vein, and the second group consisted of ewes $(n=6)$ and wethers $(n=4)$ that did not receive LPS and were restrained to draw blood from the jugular vein. The third group consisted of ewes $(n=6)$ and wethers $(n=4)$ that received LPS while having a jugular catheter to draw blood, and the fourth group consisted of ewes $(n=6)$ and wethers $(n=4)$ that did not receive LPS and had a jugular catheter to draw blood. Each sheep's neck was shorn from the dorsolateral and front to expose the jugular vein. The catheter was placed into the jugular vein the day prior to the experiment, anchored with a stitch, and covered by veterinary wrap to prevent other animals tugging on it. Jugular samples were collected from all animals $12 \mathrm{~h}$ before the challenge.

On the day of the experiment, each animal was bled before receiving either $2.5 \mathrm{~mL}$ of $0.1 \%$ BSA/PBS (controls) or $2.5 \mathrm{~mL}$ of $2.5 \mu \mathrm{g} / \mathrm{kg}$ of LPS (Sigma Altrich, St. Louis, MO) via the jugular vein through the catheter or direct draw. Jugular samples $(6-8 \mathrm{~mL})$ were collected in EDTA-treated tubes every 30 min post challenge for $180 \mathrm{~min}$, every hour through $12 \mathrm{~h}$, and $24 \mathrm{~h}$ after the initial challenge. Catheters were removed after the hour 12 samples were taken. In addition, changes in body temperature and behavior and/or physical appearance were documented during the first $12 \mathrm{~h}$ of blood sampling, and cortisol levels were measured for hours 0-6 post-treatment. Complete blood counts (CBCs) and white blood cell differentials were determined by veterinary hematology blood analyzer machine (Abaxis VetScan HM5, Abaxis Inc.) immediately after sampling. Remaining samples were centrifuged, and plasma was collected and stored at $-20^{\circ} \mathrm{C}$ until the concentrations of cortisol were measured in a single assay with a commercially available human cortisol ELISA (Diagnostic Products Corporation, Los Angeles, CA). 


\subsection{Statistical analysis}

Null Hypotheses:

1. The concentration of cortisol in jugular plasma and total white blood cell concentration, including lymphocyte, monocyte, and granulocyte concentrations, rectal temperature, and physical observation do not differ between the catheter and non-catheter groups after injection of LPS or BSA/PBS (control).

2. The concentration of cortisol in jugular plasma; total white blood cell concentrations, including lymphocyte, monocyte, and granulocyte concentrations; rectal temperature; and physical observation do not differ between sexes after injection of LPS or BSA/PBS (control).

Alternative Hypotheses:

1. The concentration of cortisol in jugular plasma and rectal temperature are higher in noncatheter groups and they show more symptoms after injection of LPS or BSA/PBS (control). Total white blood cell concentration, including lymphocyte, monocyte, and granulocyte concentrations are lower in non-catheter groups after injection of LPS or BSA/PBS (control).

2. The concentration of cortisol in jugular plasma and rectal temperature are higher in wethers compared to ewes and they show more symptoms after injection of LPS or BSA/PBS (control). Total white blood cell concentration, including lymphocyte, monocyte, and granulocyte concentrations are lower in wethers after injection of LPS or BSA/PBS (control).

All continuous variables were tested for normal distribution by goodness of fit ShapiroWilk W-test and in case of a right skewness, data were transformed using natural logarithm (ln). A 4-point logistic regression was used to develop cortisol standard curve. Data for white blood cells count (total, lymphocytes, granulocytes, and monocytes) and cortisol concentration were measured over time and were analyzed by repeated measures ANOVA in a $2 \times 2 \times 2$ factorial arrangement of treatments (sex, method of blood draw and LPS). Main effects of LPS, time, sex, method of blood draw, and interaction of catheter by LPS and LPS by sex were evaluated. Physical observations, including vaginal discharge for ewes, lethargy, loss of appetite, coughing, nasal discharge, and watery eyes, were 
analyzed as categorical data in a contingency table using Chi-square or Fisher's exact test. All data were analyzed using JMP and SAS software (JMP®, Version Pro 11, SAS Institute Inc., Cary, NC, Copyright $\mathrm{C}^{2013}$; SAS ${ }^{\circledR}$, Version 9.3, SAS Institute Inc., Cary, NC, Copyright (C2002-2010). Significance criterion alpha level for all tests was 0.05 . 


\section{Chapter 4 Results}

\subsection{Plasma cortisol concentration}

Sheep treated with LPS exhibited greater cortisol concentration (161.79 vs. $54.22 \mu \mathrm{g} / \mathrm{dL}$, $\mathrm{p}<0.0001$ ), even though effects of catheter, sex and their interaction were not statistically significant (Figure 4-1). Interaction of LPS $\mathrm{x}$ catheter, but not LPS $\mathrm{x}$ sex, was significant $(\mathrm{p}<0.0001)$. Mean cortisol concentration in catheterized sheep treated with LPS was 184.94 $\mu \mathrm{g} / \mathrm{dL}$ and in non-catherized animals treated with LPS was $126.29 \mu \mathrm{g} / \mathrm{dL}$. In addition, control group (No-LPS+No-Catheter, $\mathrm{n}=9$ ) showed higher mean level of cortisol (74.00 $\mu \mathrm{g} / \mathrm{dL})$ than No-LPS+Catheter $(41.79 \mu \mathrm{g} / \mathrm{dL}, \mathrm{n}=9)$. Ewes and wethers treated with LPS displayed high cortisol level $(162.75 \mu \mathrm{g} / \mathrm{dL}$ and $159.72 \mu \mathrm{g} / \mathrm{dL}$, respectively), while there was no significant difference between sexes. Hour $(p<0.0001)$, and LPS $x$ hour $(p<0.0001)$ differed but responses due to sex, catheter, and LPS x sex did not differ over time (Figure 4-2). Mean concentration of cortisol in hour one in wethers with LPS and catheter $(n=4)$ was the highest $(416.80 \mu \mathrm{g} / \mathrm{dL})$ of all treatment groups, and the concentration in wethers of the control group $(\mathrm{n}=4)$ at hour five was the lowest $(40.51 \mu \mathrm{g} / \mathrm{dL})$. 


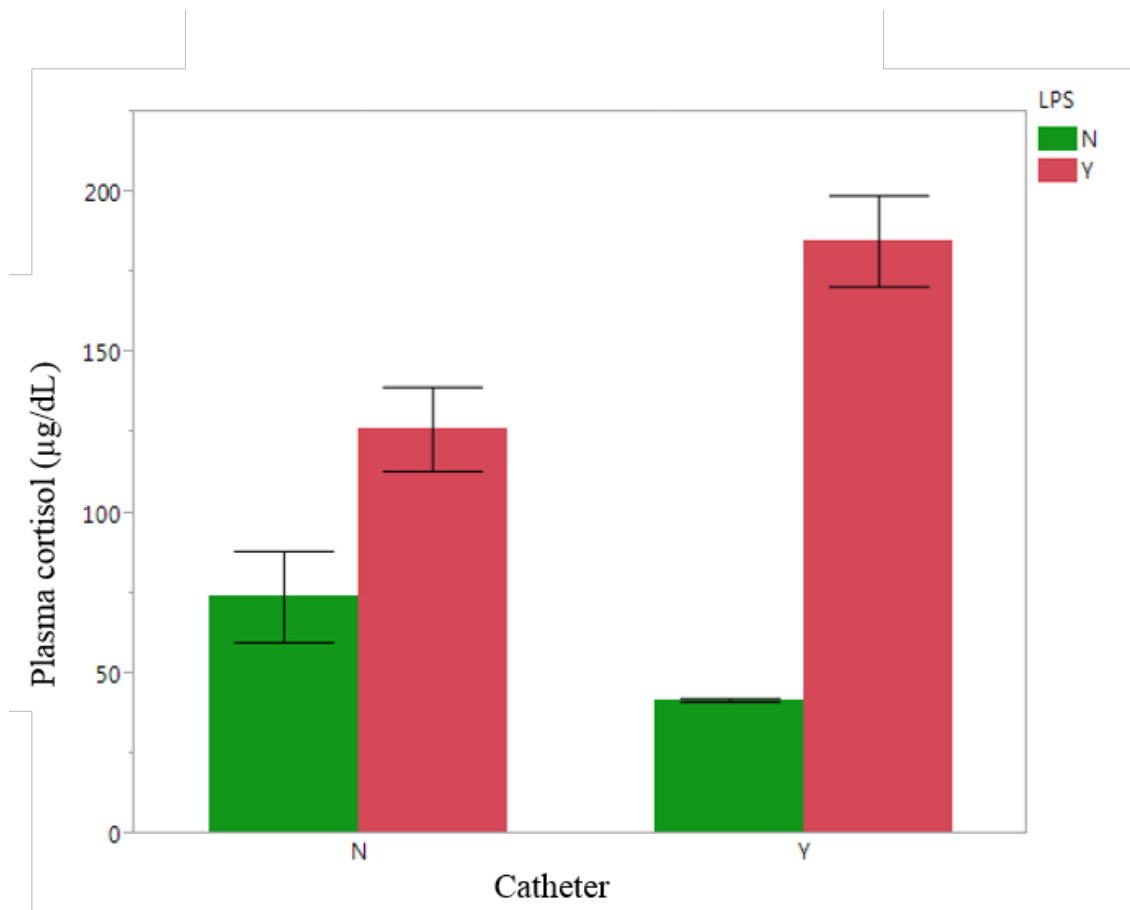

Figure 4-1 Mean plasma cortisol concentration in jugular blood in catheterized and non-catherized sheep after treatment with saline or LPS.

Effect of LPS $(p<0.0001)$, LPS x Catheter $(p<0.0001)$. 


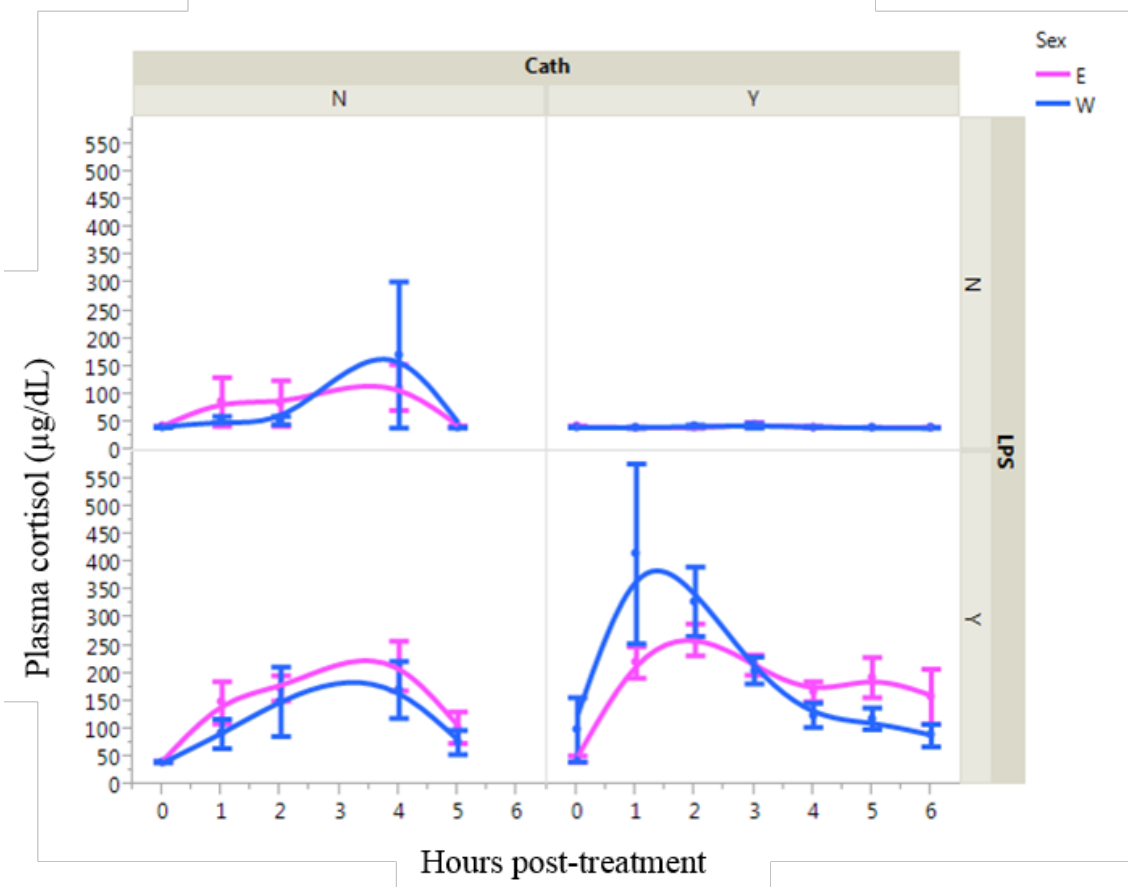

Figure 4-2 Mean cortisol concentrations in jugular blood in wethers and ewes with or without a catheter for $6 \mathrm{~h}$ after treatment with either saline or LPS .

Effect of LPS ( $p<0.0001)$, hour $(p<0.0001)$, LPS $x$ Catheter $(p=0.0007)$, LPS $x$ hour $(p<0.0001)$.

\subsection{Blood leukocyte analysis}

\subsubsection{Total white blood cell count in jugular blood}

There was no significant difference between ewes ( 7.66 million) and wethers ( 8.34 million) in their total WBCs and no significant effect of the catheter over all time points. Total white blood cell (WBC) count differed due to LPS $(\mathrm{p}<0.0001)$, catheter $(\mathrm{p}=0.0512)$, LPS $\mathrm{x}$ catheter ( $<<0.00$ Figure 4-3A), and LPS $x \operatorname{sex}(p=0.0019$, Figure 4-3 B). Mean total WBCs for no-LPS+no-catheter group $(\mathrm{n}=10)$ was 9.27 million, no-catheter + LPS $(\mathrm{n}=9)$ was 5.75 million, catheter + LPS $(n=9)$ was 3.57 million, and catheter + no-LPS $(n=11)$ was 12.65 million. Sheep treated with catheter and no LPS had the greatest increase in total WBCs, while catheter group with LPS exhibited the least increase in total WBCs. Additionally, there was a significant interaction between LPS $\mathrm{x}$ catheter $(\mathrm{p}<0.0001)$ and LPS $\mathrm{x}$ sex $(\mathrm{p}=0.0019)$. However, sheep treated with LPS maintained lower total WBCs over all the 
sampling period (Figure 4-4). The interaction between sex and LPS was not significant while the interaction between catheter and LPS was significant $(\mathrm{p}=0.0002)$. Figure 4-5 shows total WBC count repeated measures overall equally spaced time points in all four groups.

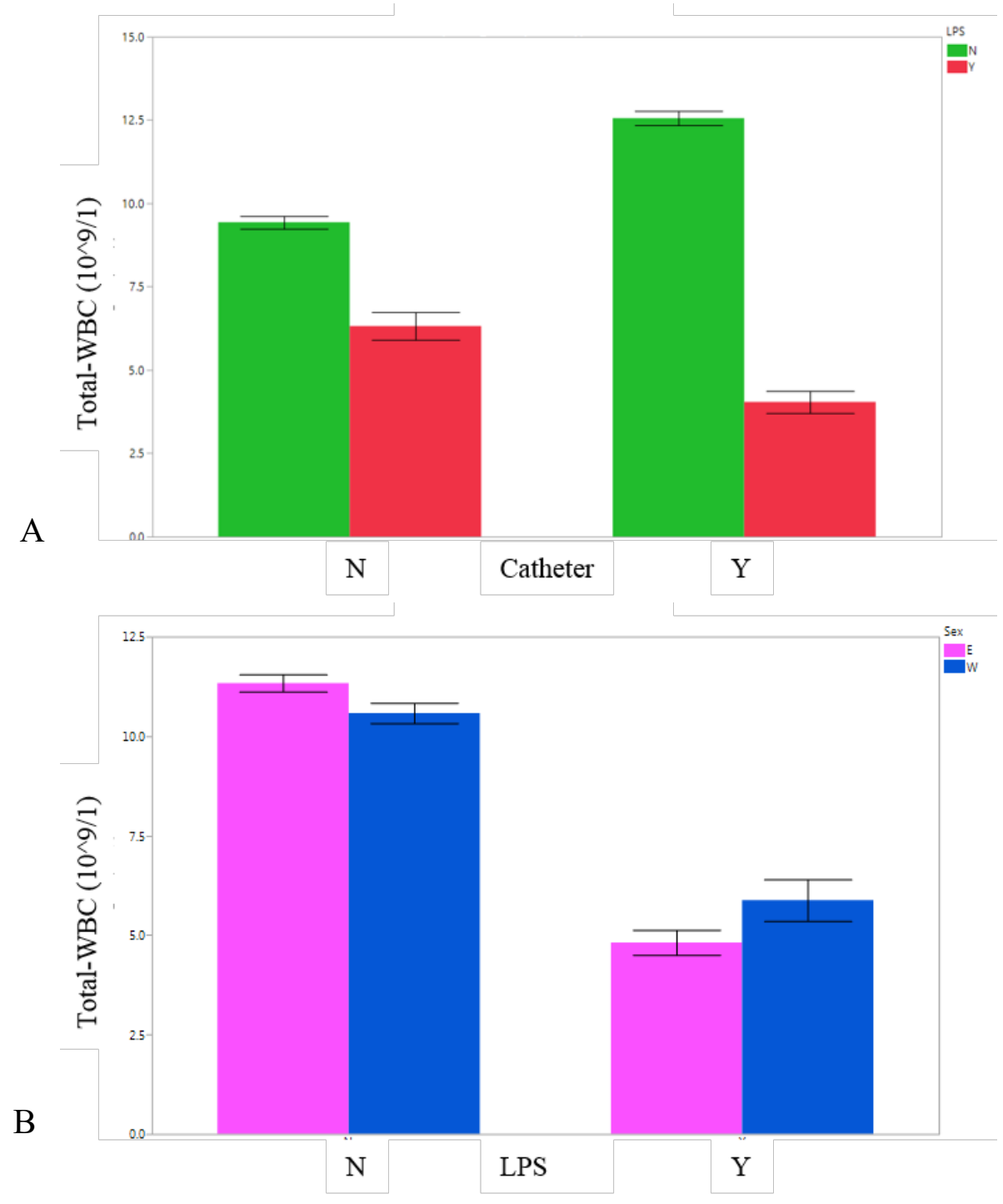

Figure 4-3 Total white blood cell (WBC) concentration in jugular blood in catheterized and noncatheterized sheep (A), and in ewes and wethers (B) after treatment with either saline or LPS.

Effect of LPS $(p<0.0001)$, catheter ( $p=0.0512)$, LPS $x$ catheter $(p<0.0001)$, LPS $x \operatorname{sex}(p=0.0019)$. 


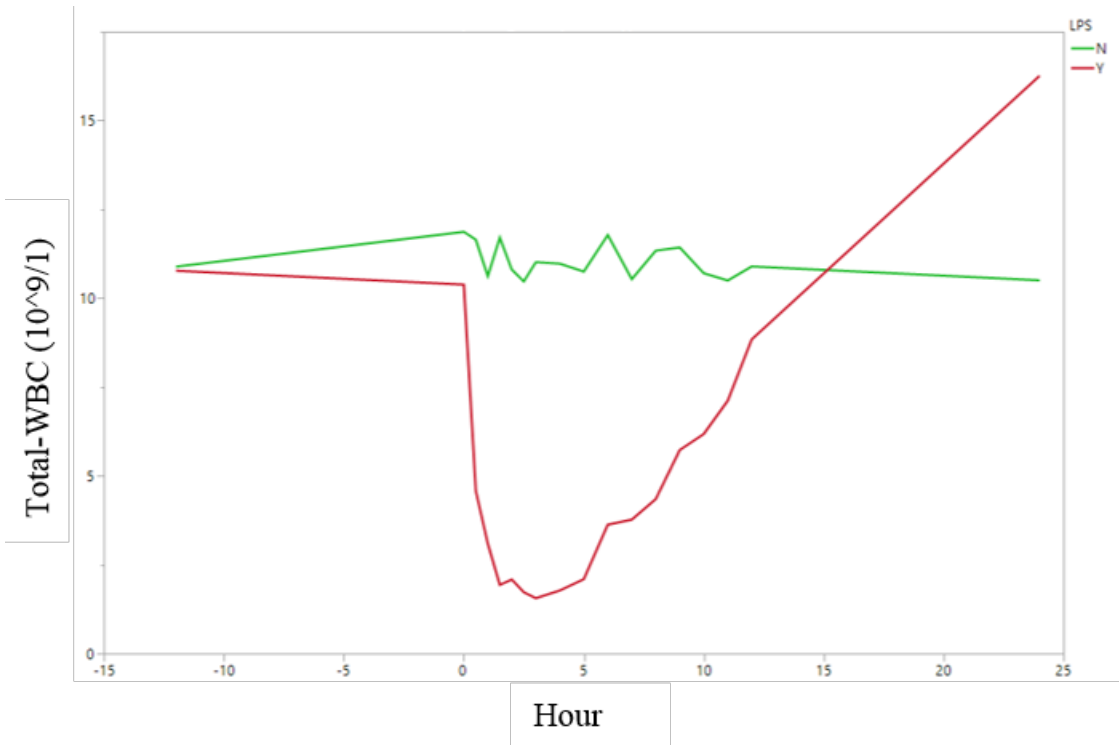

Figure 4-4 Total white blood cell (WBC) concentration in jugular blood in sheep after treatment with either saline or LPS. Effect of LPS $(p<0.0001)$, hour $(\mathrm{p}<0.0001)$, LPS $\mathrm{x}$ hour $(\mathrm{p}<0.0001)$, catheter $\mathrm{x}$ LPS $(\mathrm{p}=0.0002)$.

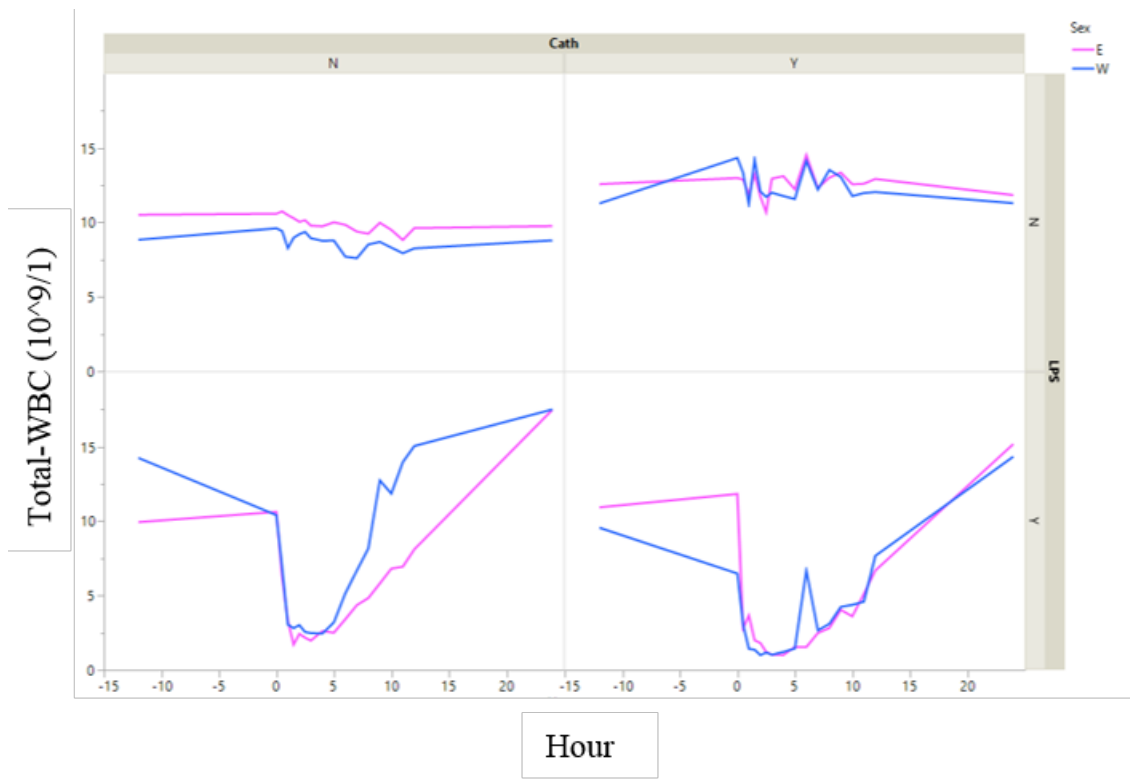

Figure 4-5 Total white blood cell (WBC) concentration in jugular blood in catheterized and noncatheterized ewes and wethers after treatment with either saline or LPS.

Effect of LPS $(p<0.0001)$, hour $(p<0.0001)$, LPS $x$ hour $(p<0.0001)$, catheter $x$ LPS $(p=0.0002)$.

\subsubsection{Concentration of Lymphocytes in jugular blood}

Lymphocyte concentrations (Figure 4-6) differed due to LPS $(\mathrm{p}<0.0001)$ and LPS $\mathrm{x}$ catheter $(p<0.0001)$ while there was no difference between sexes and catheterization or the 
interaction. Lymphocyte counts for no-LPS+no-catheter group were 7.57 million, nocatheter + LPS was 4.73 million, catheter + LPS was 3.10 million, and catheter + no-LPS was 10.50 million. Lymphocyte counts did not differ significantly between ewes (6.33 million) and wethers (6.95 million). The effects of LPS ( $p<0.0001)$, hour ( $p<0.0001)$, LPS $x$ hour $(p<0.0001$, Figure 4-7), and LPS $x$ catheter $(p<0.0001)$ were significant (Figure 4-8). Decline in numbers of lymphocytes started 1 hour post treatment in LPS groups averaging 2.54 million cells $/ \mathrm{ml}$ in ewes $(\mathrm{n}=5)$ and 3.00 million cells $/ \mathrm{ml}$ in wethers $(\mathrm{n}=4)$ in no-catheter group and 2.53 million cells $/ \mathrm{ml}$ in ewes $(\mathrm{n}=6)$ and 1.06 million cells $/ \mathrm{ml}$ in wethers $(\mathrm{n}=4)$ in catheter group.

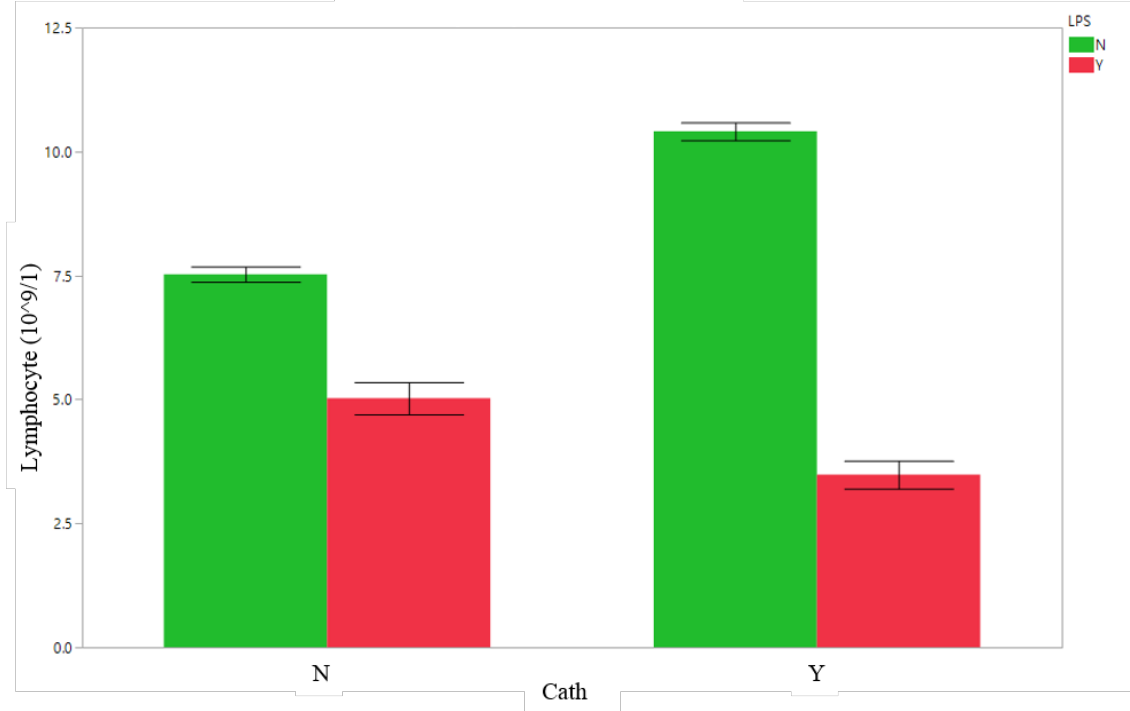

Figure 4-6 Concentrations of lymphocytes in jugular blood in catheterized and non-catheterized sheep after treatment with either saline or LPS.

Effect of LPS $(p<0.0001)$ and LPS $x$ catheter $(p<0.0001)$. 


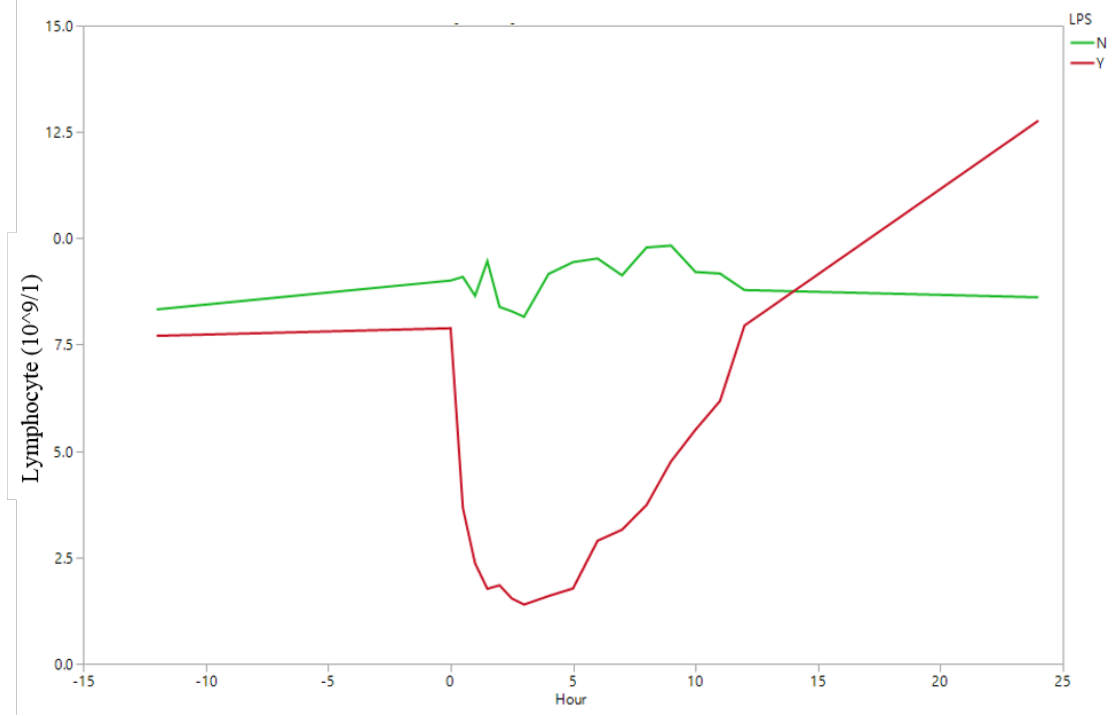

Figure 4-7 Concentrations of lymphocytes in jugular blood in sheep after treatment with either saline or LPS. Effect of LPS $(p<0.0001)$, hour $(p<0.0001)$, LPS $x$ hour $(p<0.0001)$.

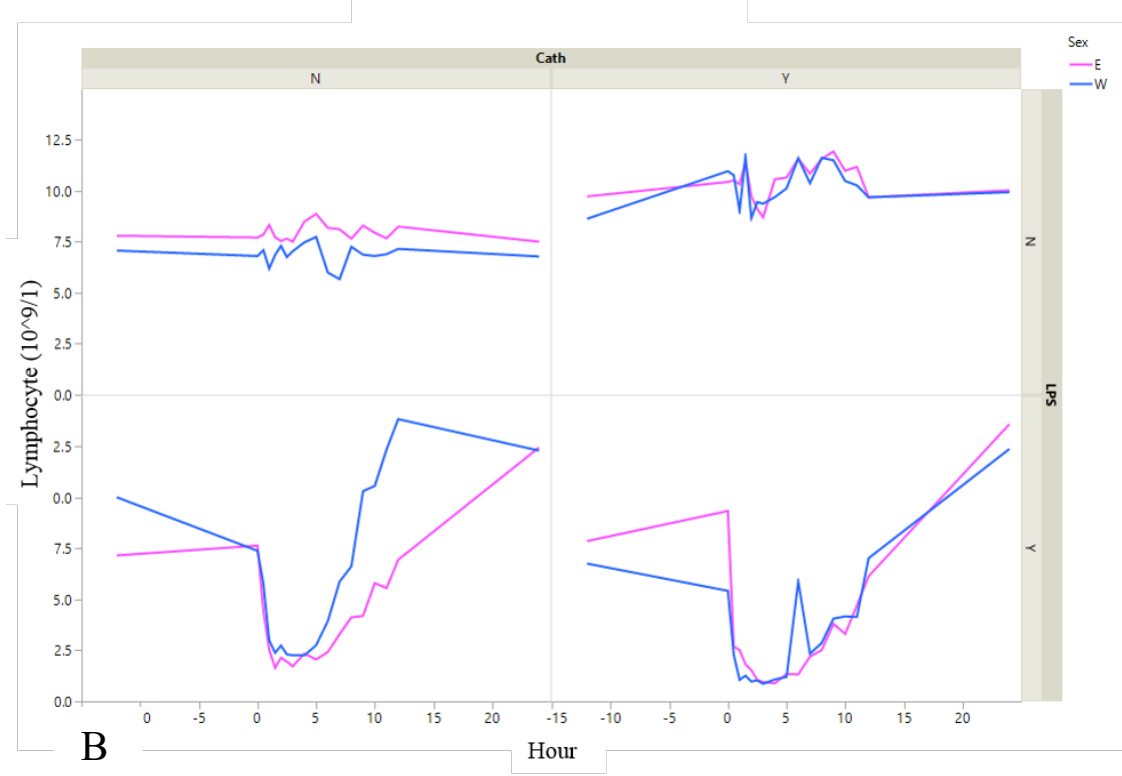

Figure 4-8 Concentrations of lymphocytes in jugular blood in catheterized and non-catheterized ewes and wethers after treatment with either saline or LPS.

Effect of LPS $(p<0.0001)$, hour ( $p<0.0001)$, LPS $x$ hour $(p<0.0001)$, catheter $x$ LPS $(p<0.0001)$. 


\subsubsection{Concentration of Monocytes in jugular blood}

Monocytes concentrations (Figure 4-9) differed due to LPS $(\mathrm{p}<0.0001)$, catheter $(\mathrm{p}=0.0428)$ and LPS $\mathrm{x}$ catheter $(\mathrm{p}<0.0001)$, while there was no difference between sexes (ewes 0.0383 million and wethers 0.0419 million) and LPS x sex. Monocyte counts for no LPS and no-catheter group were 0.0464 million, no catheter and LPS was 0.0290 million, catheter and LPS was 0.0182 million, and catheter and no LPS was 0.0630 million. Monocyte counts did not significantly differ between. Effects of hour ( $<<0.0001)$, LPS x hour ( $<<0.0001$, Figure $4-10$ ), and LPS $x$ catheter $(p<0.0001)$ were significant (Figure 4-11) even though there was no significant effect of catheter or sex over time. The decline in monocytes started 1 hour after treatment with LPS averaging 0.0160 million cells $/ \mathrm{ml}$ in ewes and 0.0133 million cells $/ \mathrm{ml}$ in wethers without catheters and 0.0060 million cells $/ \mathrm{ml}$ in ewes and 0.0027 million cells $/ \mathrm{ml}$ in wethers with catheters.

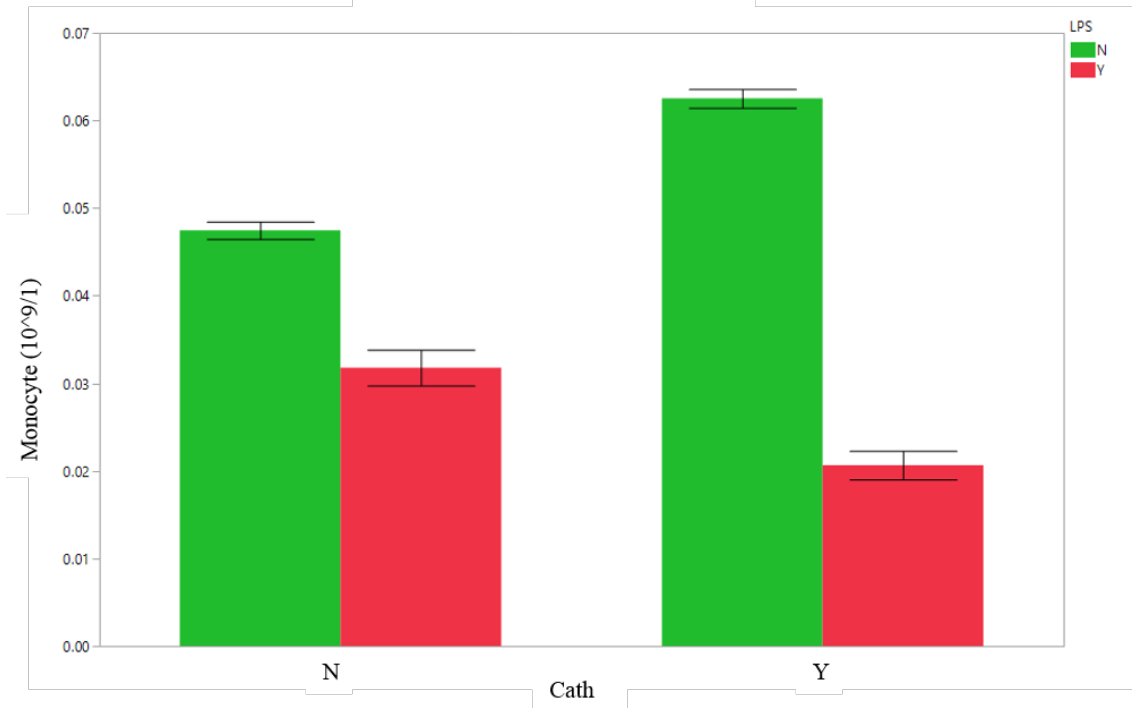

Figure 4-9 Concentrations of monocytes in jugular blood in catheterized and non-catheterized sheep after treatment with either saline or LPS.

Effect of LPS $(p<0.0001)$, catheter $(p=0.0428)$, LPS $x$ catheter $(p<0.0001)$. 


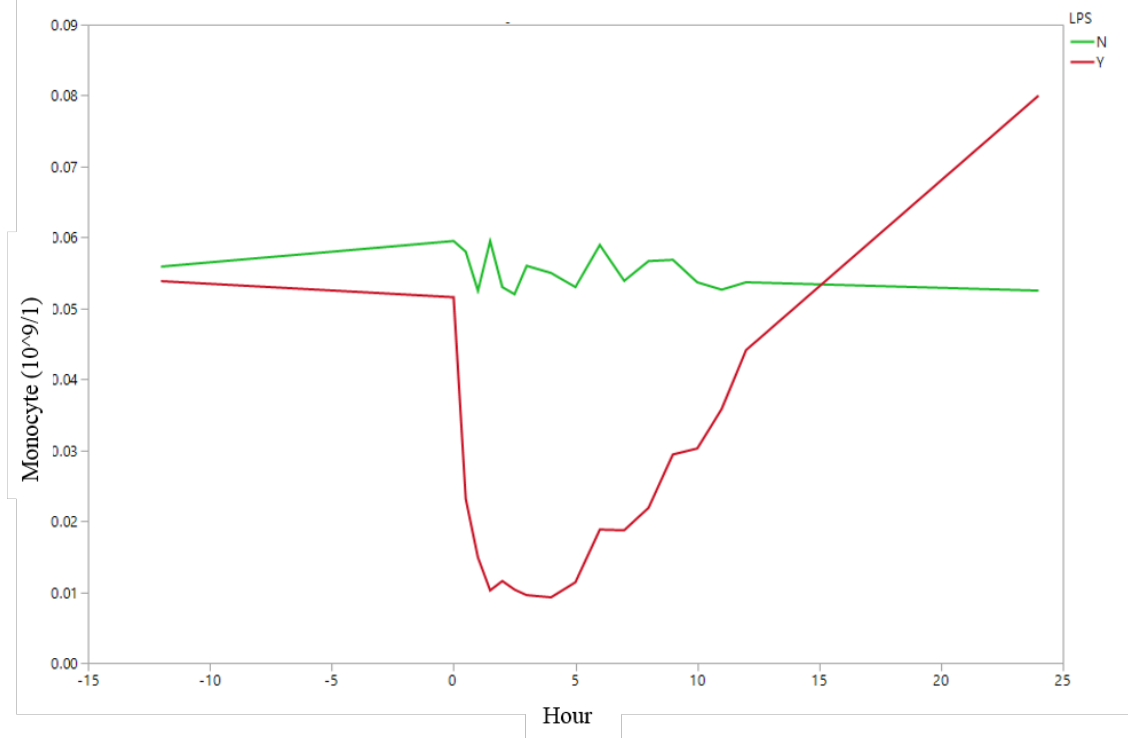

Figure 4-10 Concentrations of monocytes in jugular blood after treatment with either saline or LPS.

Effect of LPS ( $<<0.0001)$, hour $(p<0.0001)$, LPS $x$ hour $(p<0.0001)$.

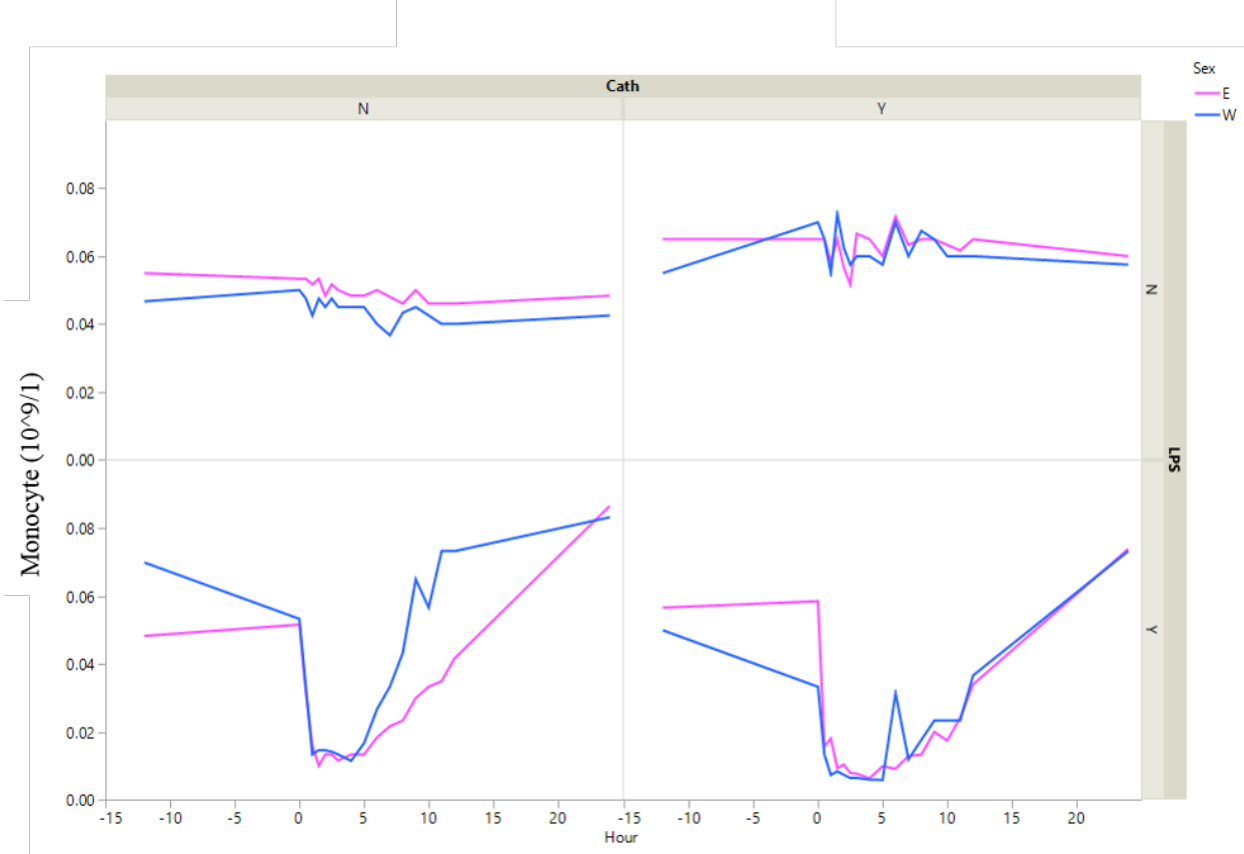

Figure 4-11 Concentrations of monocytes in jugular blood in catheterized and non-catheterized ewes and wethers after treatment with either saline or LPS.

Effect of LPS $(p<0.0001)$, hour ( $p<0.0001)$, LPS $x$ hour $(p<0.0001)$, catheter $x$ LPS $(p<0.0001)$. 


\subsubsection{Concentration of Granulocytes in jugular blood}

Granulocyte concentrations differed by LPS ( $<<0.0001)$, catheter $(\mathrm{p}<0.0001)$, and LPS $\mathrm{x}$ catheter $(p<0.0001$, Figure 4-12) but did not differ by sex (ewes 1.26 million and wethers 1.35 million) or LPS x sex. Granulocyte counts for the no LPS and no-catheter animals were 1.66 million, no catheter and LPS was 0.99 million, catheter and LPS was 2.02 million, and catheter and no-LPS was 0.45 million. There was a difference in hour $(\mathrm{p}<0.0001)$, LPS $\mathrm{x}$ hour $(\mathrm{p}<0.0001$, Figure 4-13), catheter $(\mathrm{p}=0.0037)$, catheter $\mathrm{x}$ hour $(\mathrm{p}=0.0491)$, and catheter $\mathrm{x}$ LPS $(\mathrm{p}=0.0005$, Figure $4-14)$. Decline in granulocytes started 1-hour post treatment in LPS groups averaging 0.76 million cells $/ \mathrm{ml}$ in ewes and 0.01 million cells $/ \mathrm{ml}$ in wethers in no-catheter group, and 1.12 million cells $/ \mathrm{ml}$ in ewes and 0.36 million cells $/ \mathrm{ml}$ in wethers in catheter group.

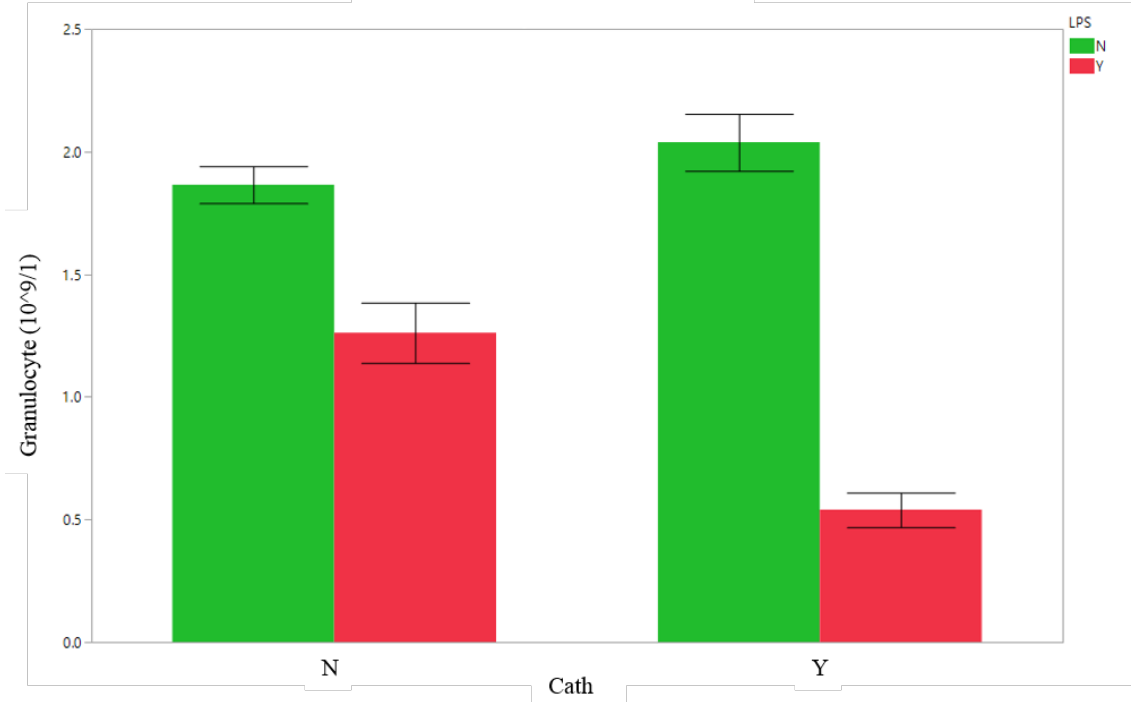

Figure 4-12 Concentrations of granulocytes in jugular blood in catheterized and non-catheterized sheep after treatment with either saline or LPS.

Effect of LPS $(p<0.0001)$, catheter $(p<0.0001)$, LPS $x$ catheter $(p<0.0001)$. 


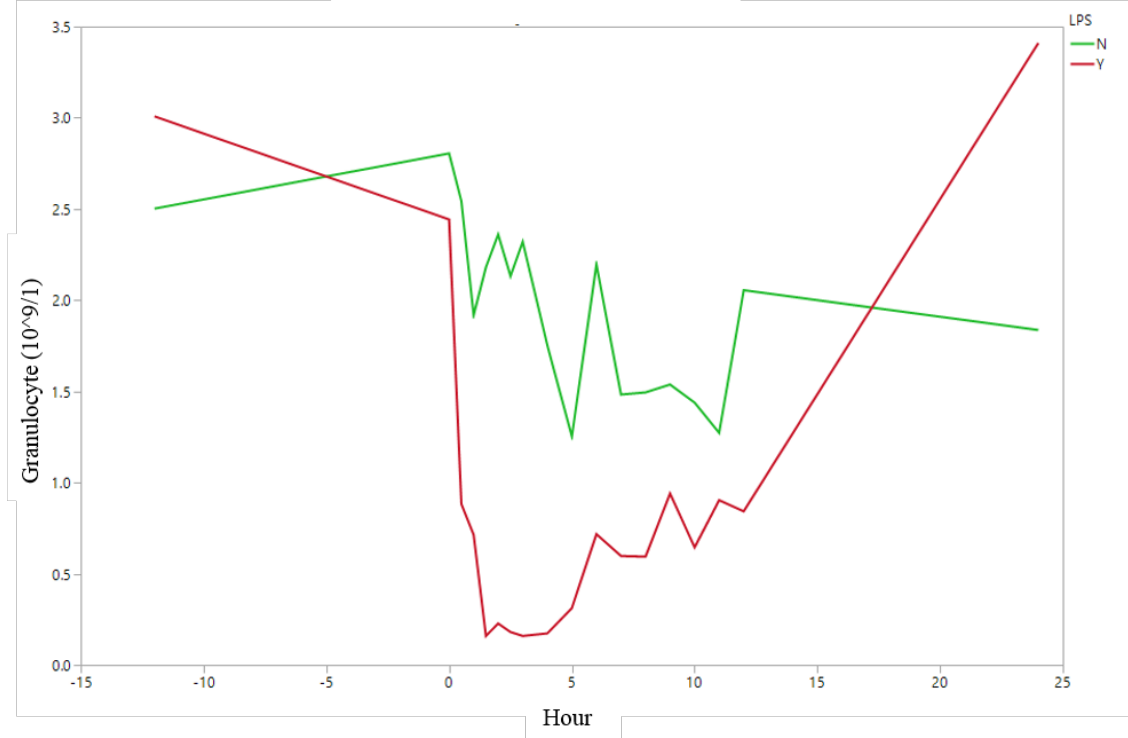

Figure 4-13 Concentrations of granulocytes in jugular blood after treatment with either saline or LPS.

Effect of LPS $(p<0.0001)$, hour $(p<0.0001)$, LPS $x$ hour $(p<0.0001)$.

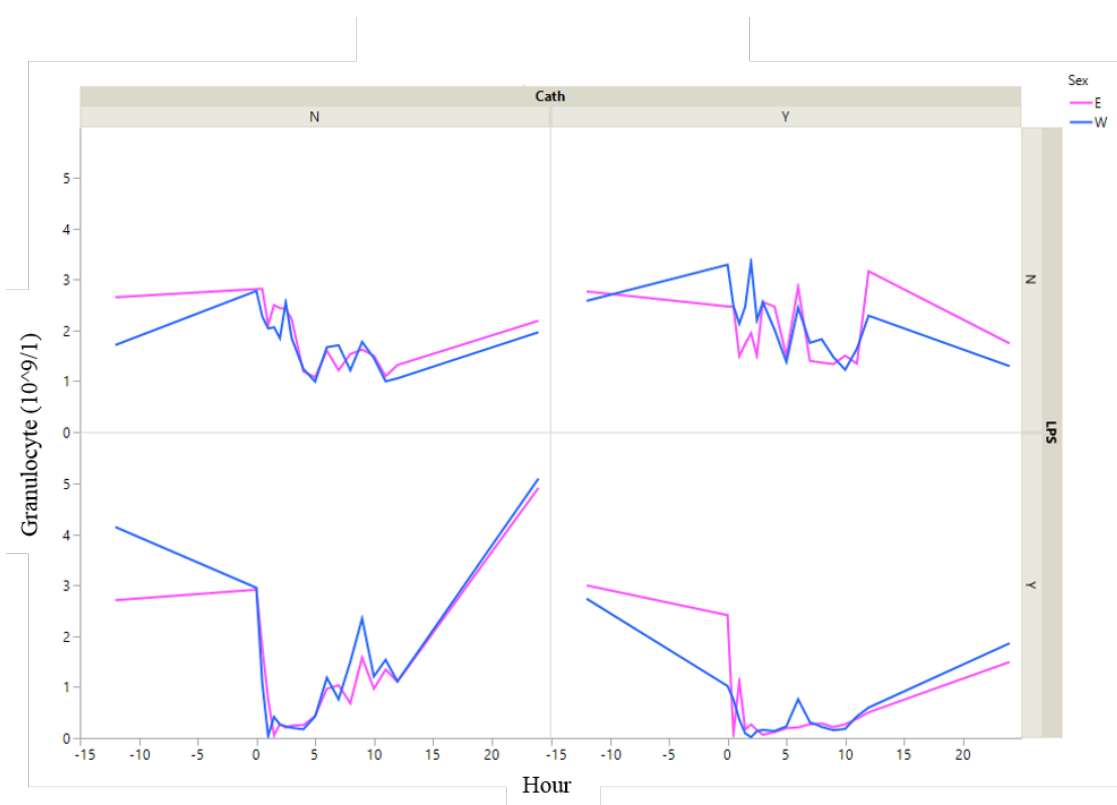

Figure 4-14 Concentrations of granulocytes in jugular blood in catheterized and non-catheterized ewes and wethers after treatment with either Saline or LPS.

Effect of LPS $(p<0.0001)$, hour $(p<0.0001)$, LPS $x$ hour $(p<0.0001)$, catheter $(p=0.0037)$, catheter $x$ hour $(p=0.0491)$, catheter $x$ LPS $(p=0.0005)$. 


\subsection{Rectal temperature}

Main effects of LPS $(p<0.0001)$, catheter $(p=0.0059$, Figure 4-15), sex $(p=0.0457)$, and LPS x sex $(p=0.006$, Figure 4-16) were found for rectal temperatures. Means of rectal temperatures for non-catheterized animals treated with saline was $38.43^{\circ} \mathrm{C}$ or with LPS was $38.98^{\circ} \mathrm{C}$, and for catheterized animals treated with saline was $38.26^{\circ} \mathrm{C}$ or with LPS was $38.68^{\circ} \mathrm{C}$, and was significantly different between ewes $\left(38.56^{\circ} \mathrm{C}\right)$ and wethers $\left(38.64^{\circ} \mathrm{C}\right)$. There was a difference in hour $(\mathrm{p}<0.0001)$, LPS $x$ hour $(\mathrm{p}<0.0001$, Figure $4-17)$, sex $x$ hour $(p=0.0114)$, and catheter $x$ hour $(p<0.0001$, Figure 4-18). Rectal temperatures increased in non-catheterized animals treated with saline or LPS at 1-hour post-treatment (means $38.57^{\circ} \mathrm{C}$ and $38.96^{\circ} \mathrm{C}$ respectively). It peaked at 4 hours in non-catheterized ewes and wethers (means $39.49^{\circ} \mathrm{C}$ and $40.72^{\circ} \mathrm{C}$ respectively) treated with LPS. Rectal temperatures for catheterized animals treated with LPS group first increased at hour 1 and then decreased for hours 2 and 3 but then peaked at hour 6 and remained high for 24 hours in wethers $\left(40.00^{\circ} \mathrm{C}\right)$ and peaked at hour 9 in ewes $\left(38.95^{\circ} \mathrm{C}\right)$ but declined after hour- 12 . 


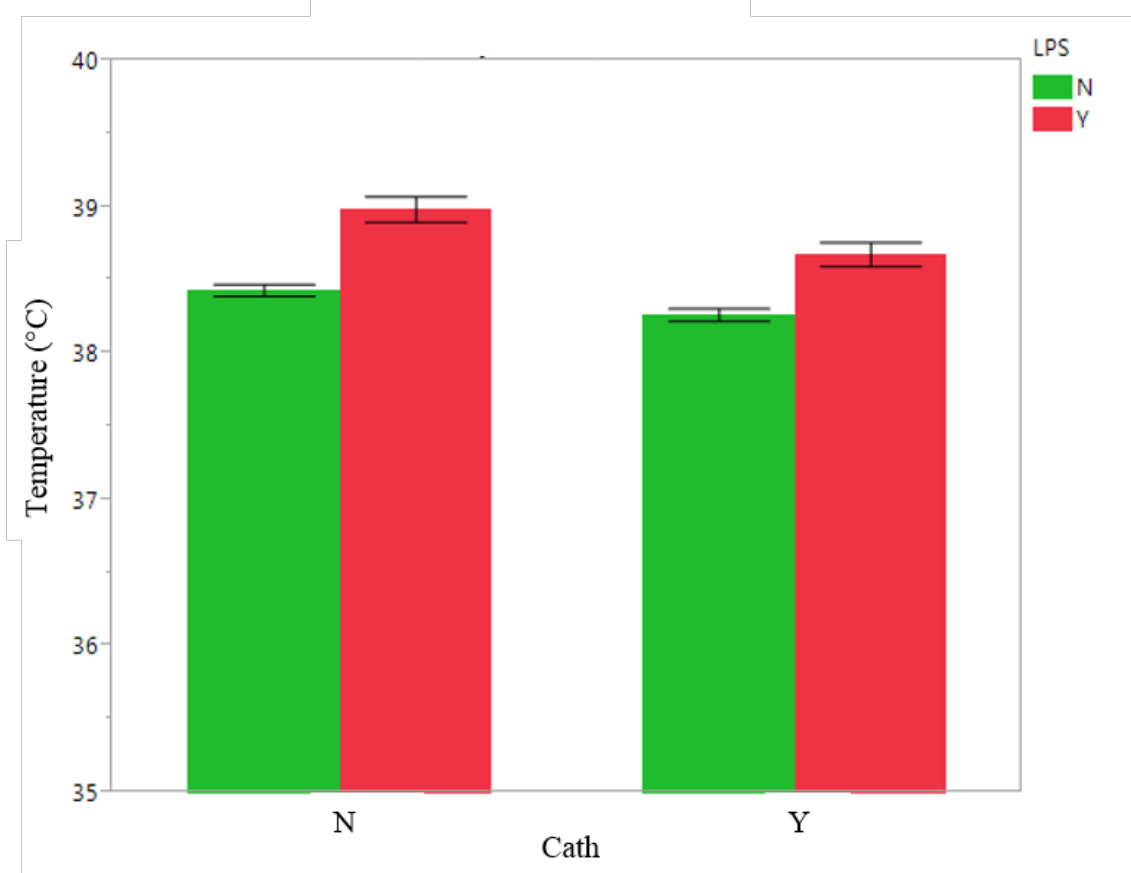

Figure 4-15 Rectal temperatures after treatment with either saline or LPS.

Effect of LPS $(\mathrm{p}<0.0001)$, catheter $(\mathrm{p}=0.0059)$.

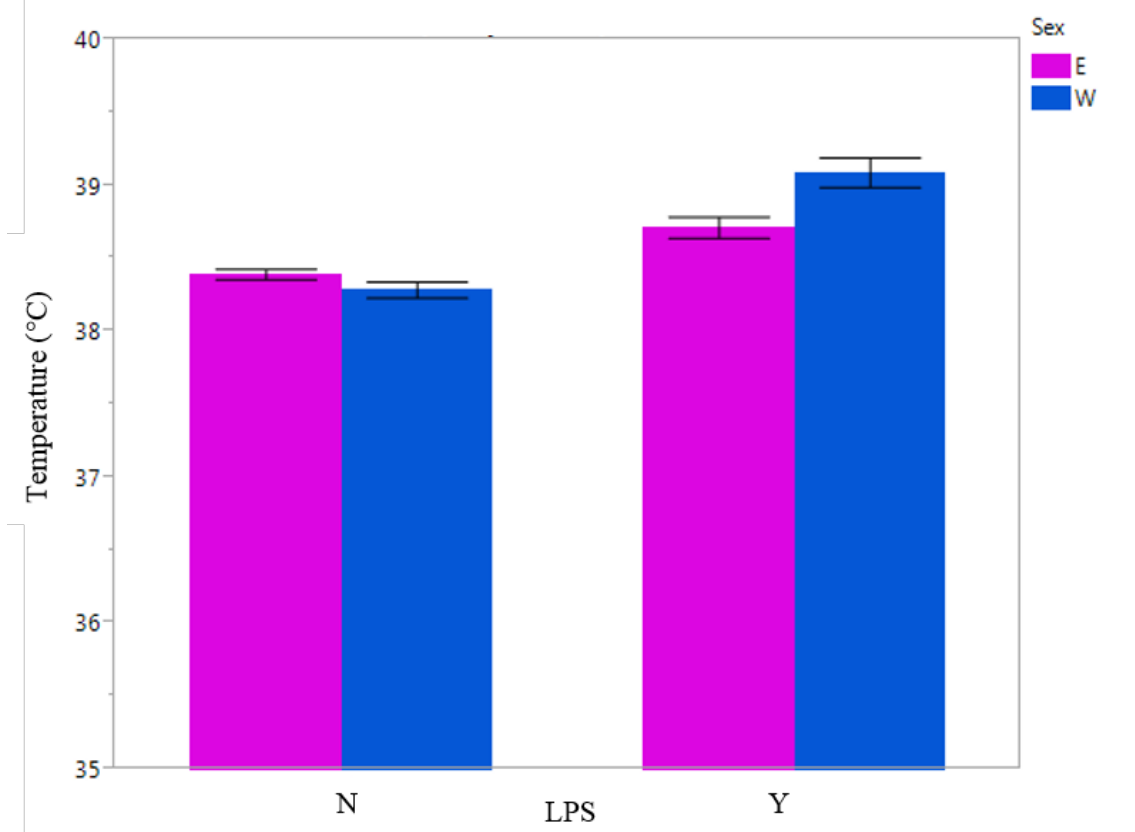

Figure 4-16 Rectal temperatures in ewes and wethers after treatment with either saline or LPS.

Effect of LPS $(p<0.0001)$, sex $(p=0.0457)$, LPS $x \operatorname{sex}(p=0.006)$. 


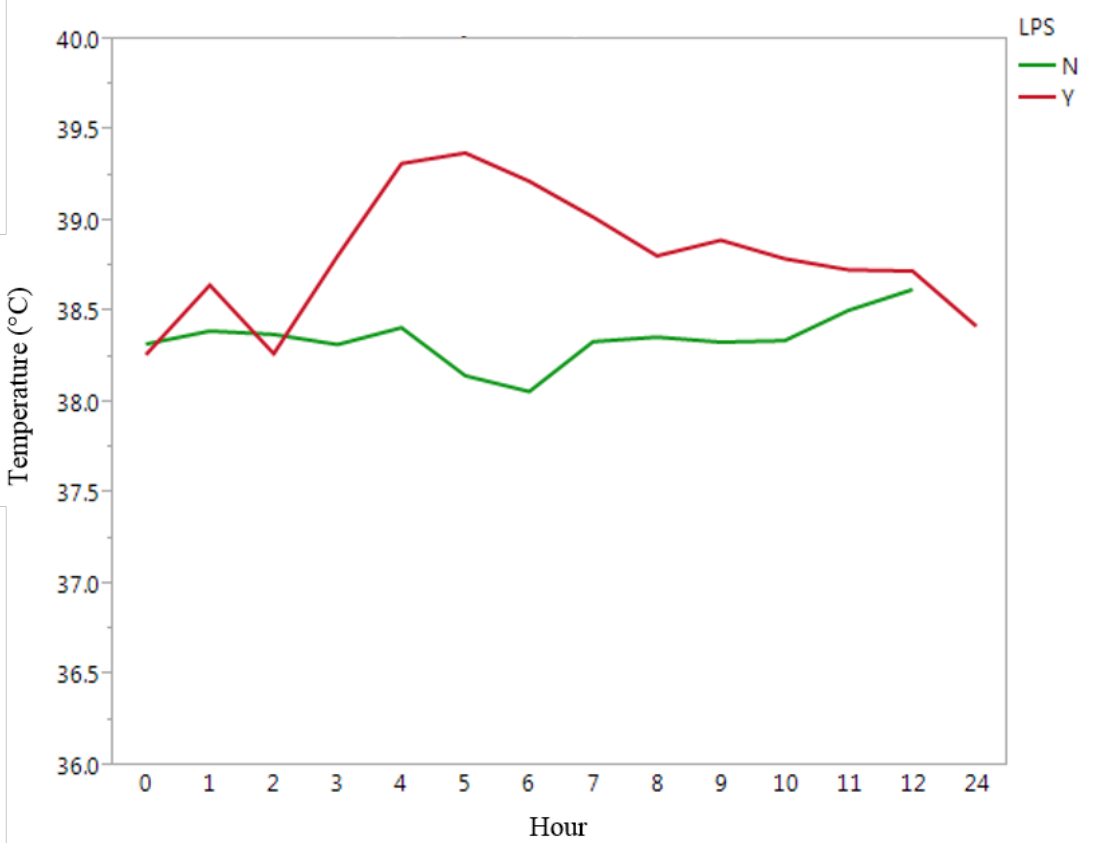

Figure 4-17 Rectal temperatures after treatment with either saline or LPS.

Effect of LPS ( $\mathrm{p}=0.0014)$, hour $(\mathrm{p}<0.0001)$, LPS $\mathrm{x}$ hour $(\mathrm{p}<0.0001)$. 


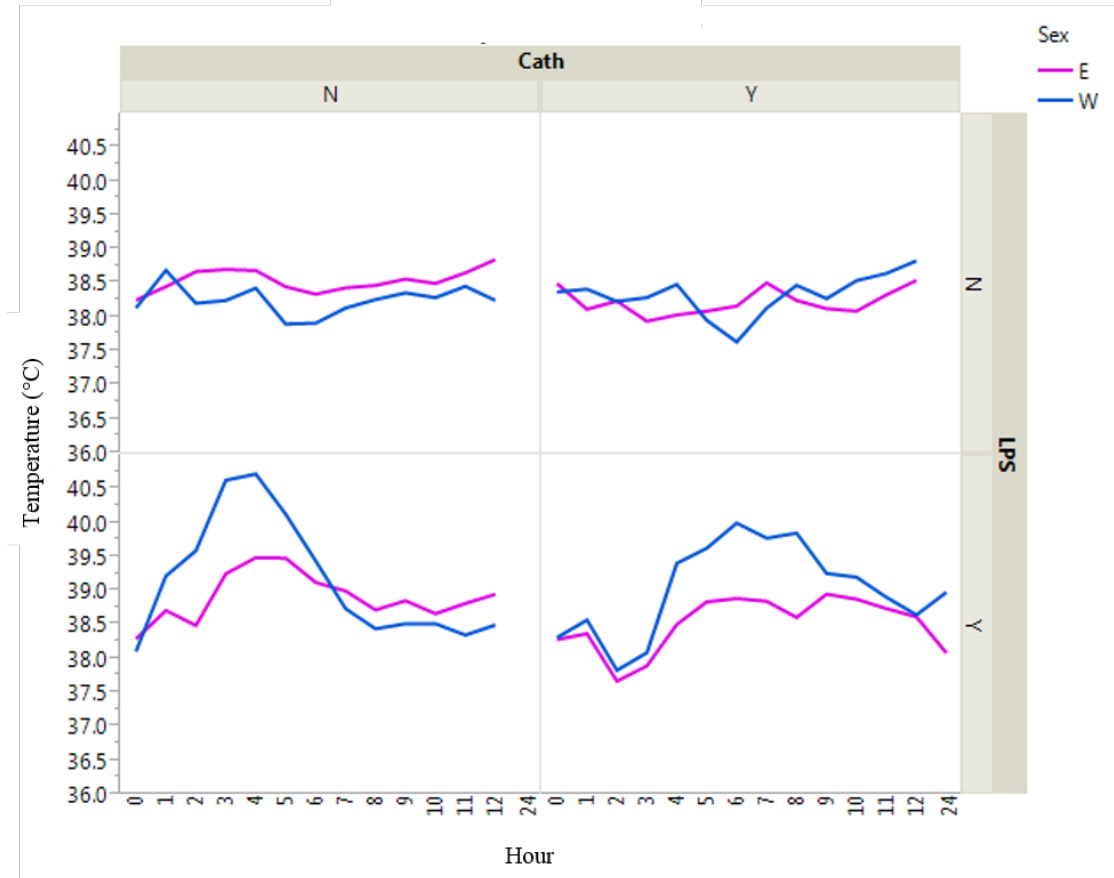

Figure 4-18 Rectal temperatures for $24 \mathrm{~h}$ in ewes and wethers with or without catheters and after treatment with either saline or LPS.

Effect of LPS ( $\mathrm{p}=0.0014)$, hour $(\mathrm{p}<0.0001)$, LPS $\mathrm{x}$ hour $(\mathrm{p}<0.0001)$, sex $\mathrm{x}$ hour $(\mathrm{p}=0.0114)$, catheter $\mathrm{x}$ hour $(\mathrm{p}<0.0001)$.

Table 4-1 Statistical significance (p-values) of treatment effects and interactions for all continuous variables.

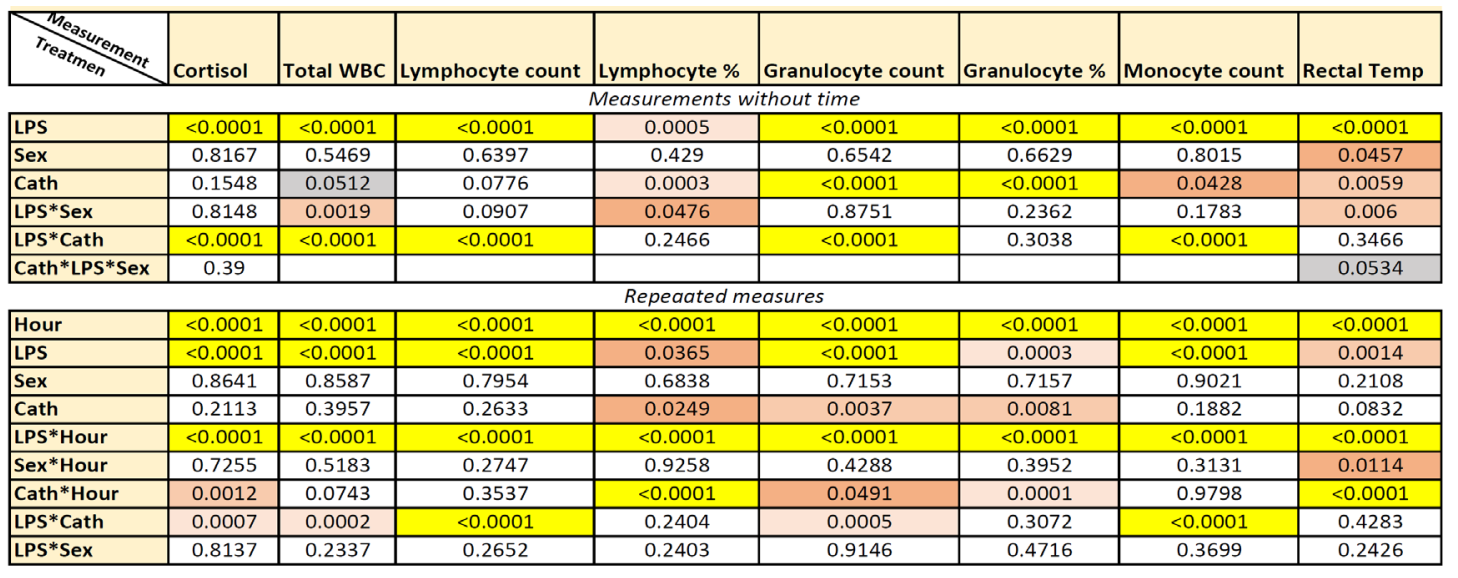




\subsection{Physical observation}

Ewes treated with LPS exhibited a vaginal discharge $(\mathrm{p}=0.0046)$ while controlling for effects of hour and catheter. In addition, $1.28 \%$ of the ewes in No-Catheter and No-LPS group and $12.82 \%$ in No-Catheter and LPS group showed vaginal discharge (Figure 4-19, Figure 4-24). Both wethers and ewes receiving LPS showed loss of appetite $(\mathrm{p}<0.0001)$, lethargy $(\mathrm{p}<0.0001)$, and mucosal responses including nasal discharges $(\mathrm{p}<0.0001)$ and coughing $(\mathrm{p}=0.0296)$. Lethargy occurred in $43.7 \%$ of ewes and $23.1 \%$ of wethers in LPS + Catheter group and $32.1 \%$ of ewes and $30.8 \%$ of wethers in LPS+No-Catheter, while just $2.56 \%$ of ewes and $1.92 \%$ of wethers in control group did so (Figure $4-21$ ). Ewes and wethers in LPS+Catheter group exhibited loss of appetite, $25.3 \%$ and $17.9 \%$, respectively (Figure 4-21). 2.30 of ewes and $2.56 \%$ of wethers in LPS+Catheter group showed coughing. Furthermore, $12.82 \%$ of ewes and $7.7 \%$ of wethers in LPS+No-Catheter and $7.7 \%$ of wethers in control group exhibited coughing (Figure 4-22). 5.8\% of wethers in control group had nasal discharge, while that number was zero for ewes of the same group. $11.5 \%$ of ewes and $20.5 \%$ of wethers in LPS+Catheter group showed nasal discharge and $15.4 \%$ of ewes and $20.5 \%$ of wethers in LPS+No-Catheter, while $5.8 \%$ of wethers in control group did so Figure 4-23. 


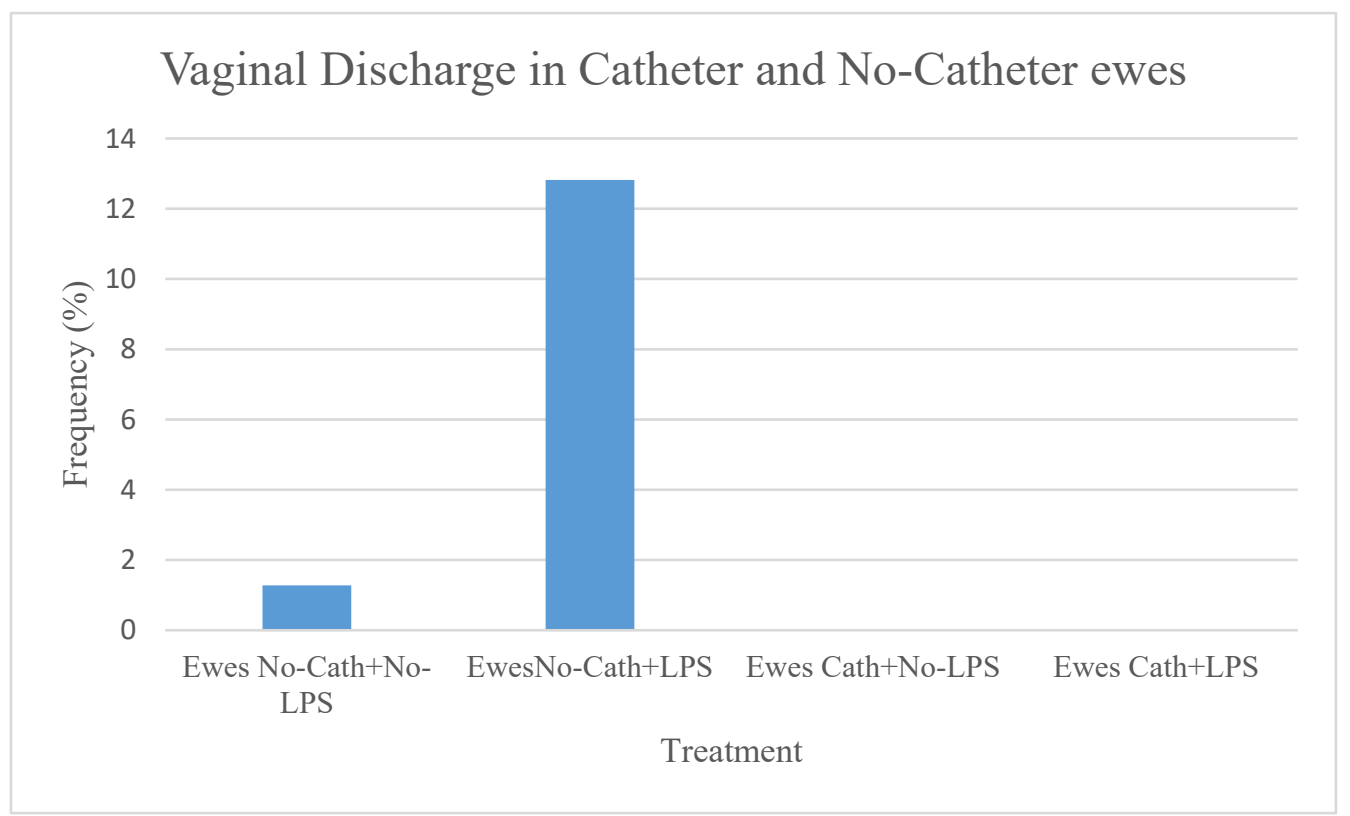

Figure 4-19 Vaginal discharge in Catheter and No-Catheter ewes after treatment with either saline or LPS (No-Catheter+No-LPS n $=6$, No-Catheter+LPS n=5, Catheter+No-LPS $n=6$, Catheter+LPS $n=6$ ). 


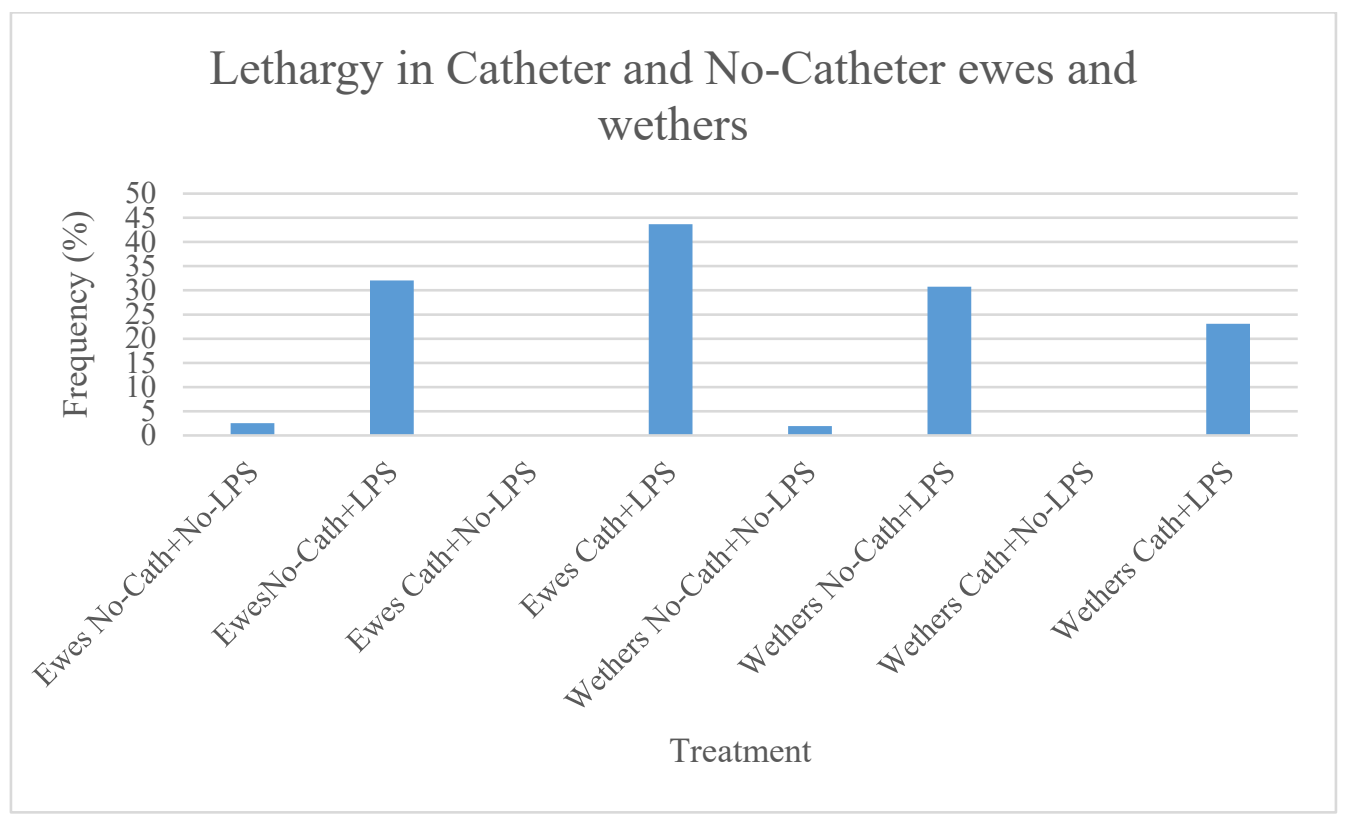

Figure 4-20 Lethargy in Catheter and No-Catheter ewes and wethers after treatment with either Saline or LPS.

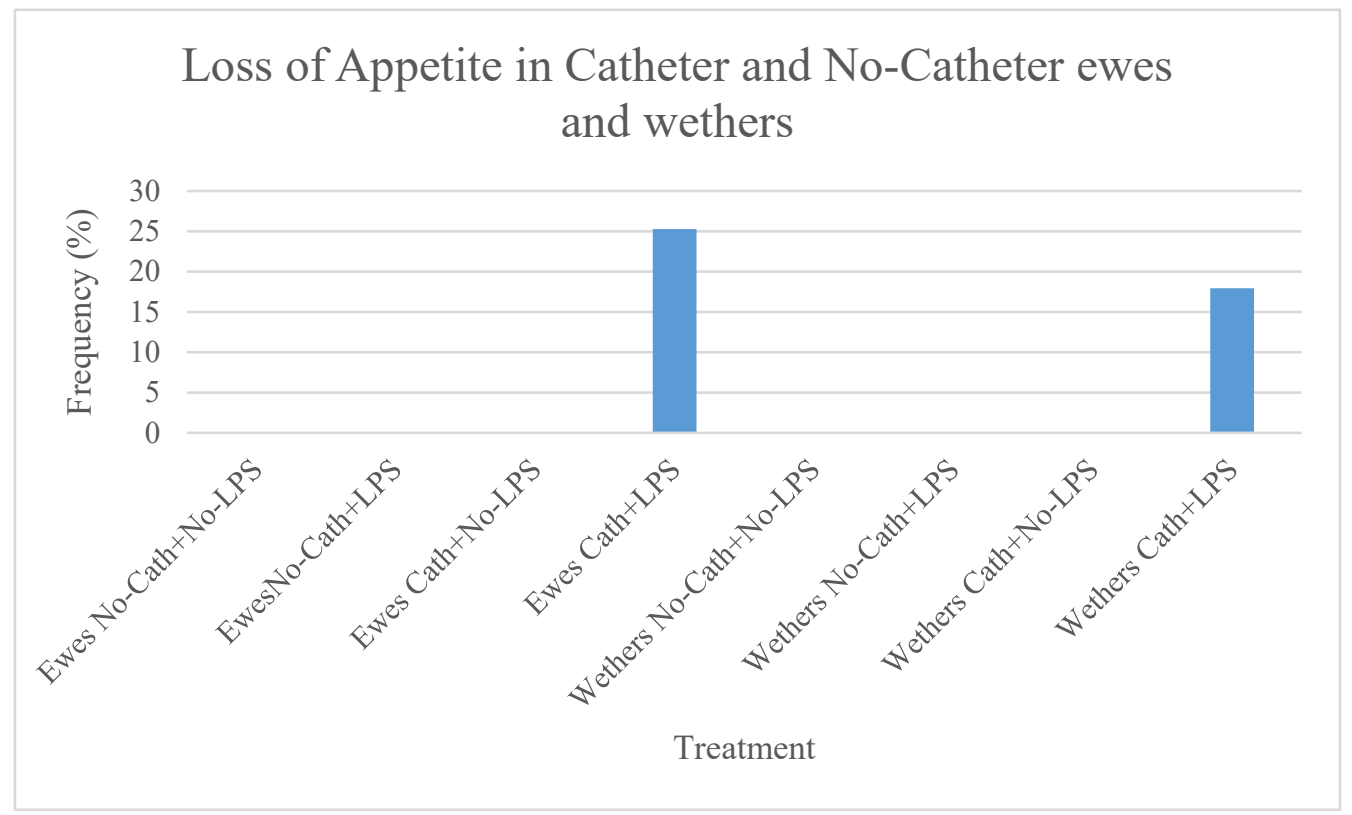

Figure 4-21 Loss of appettite in Catheter and No-Catheter ewes and wethers after treatment with either Saline or LPS. 


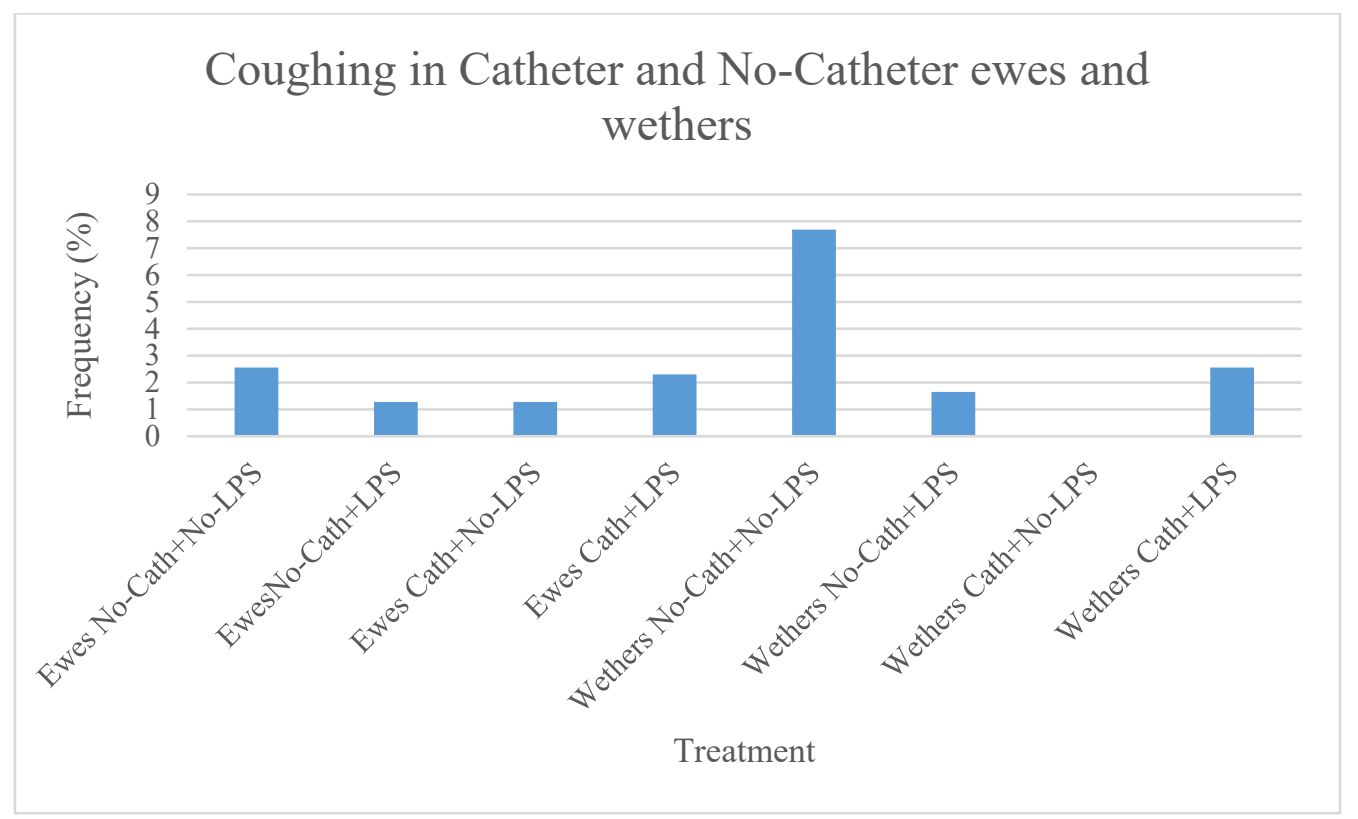

Figure 4-22 Coughing in Catheter and No-Catheter ewes and wethers after treatment with either Saline or LPS.

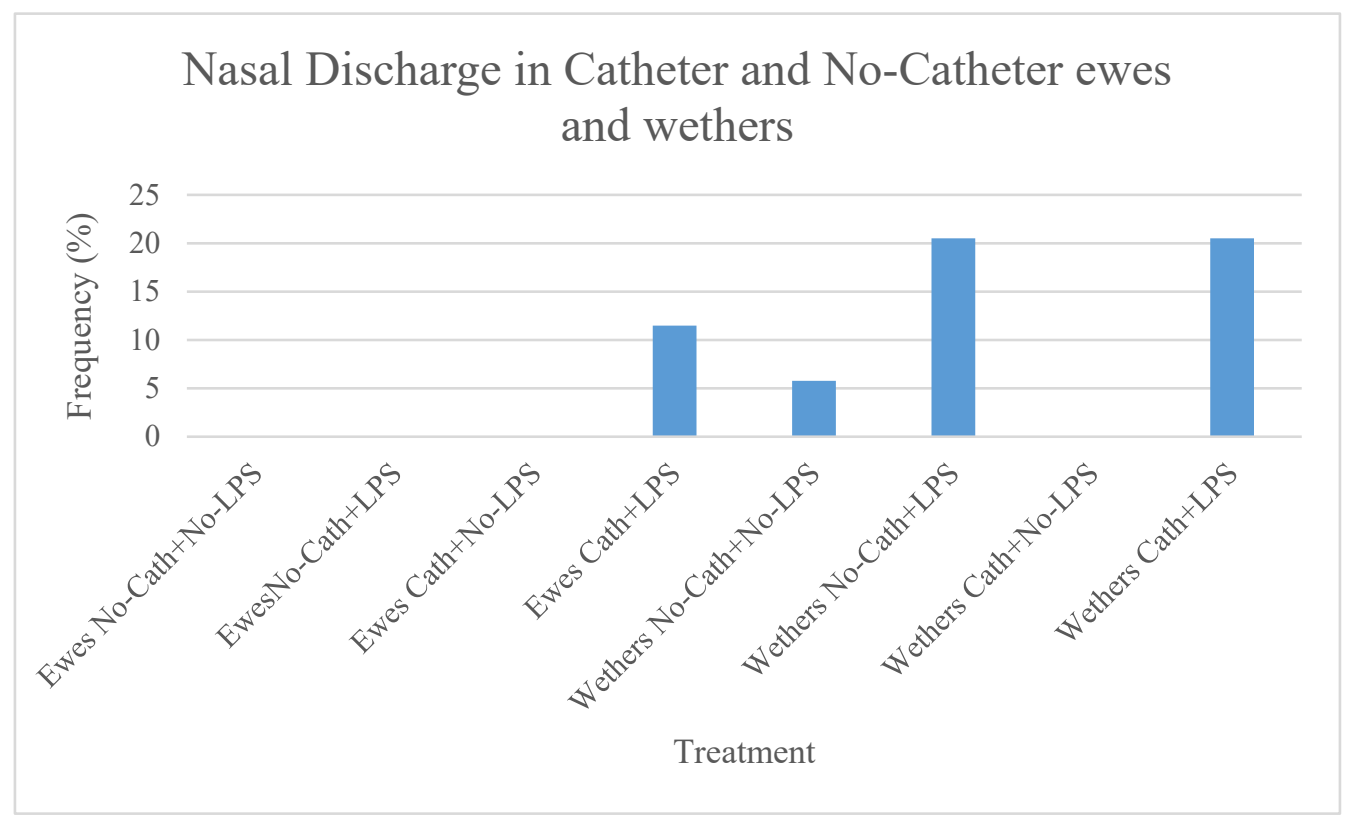

Figure 4-23 Nasal discharge in Catheter and No-Catheter ewes and wethers after treatment with either Saline or LPS. 


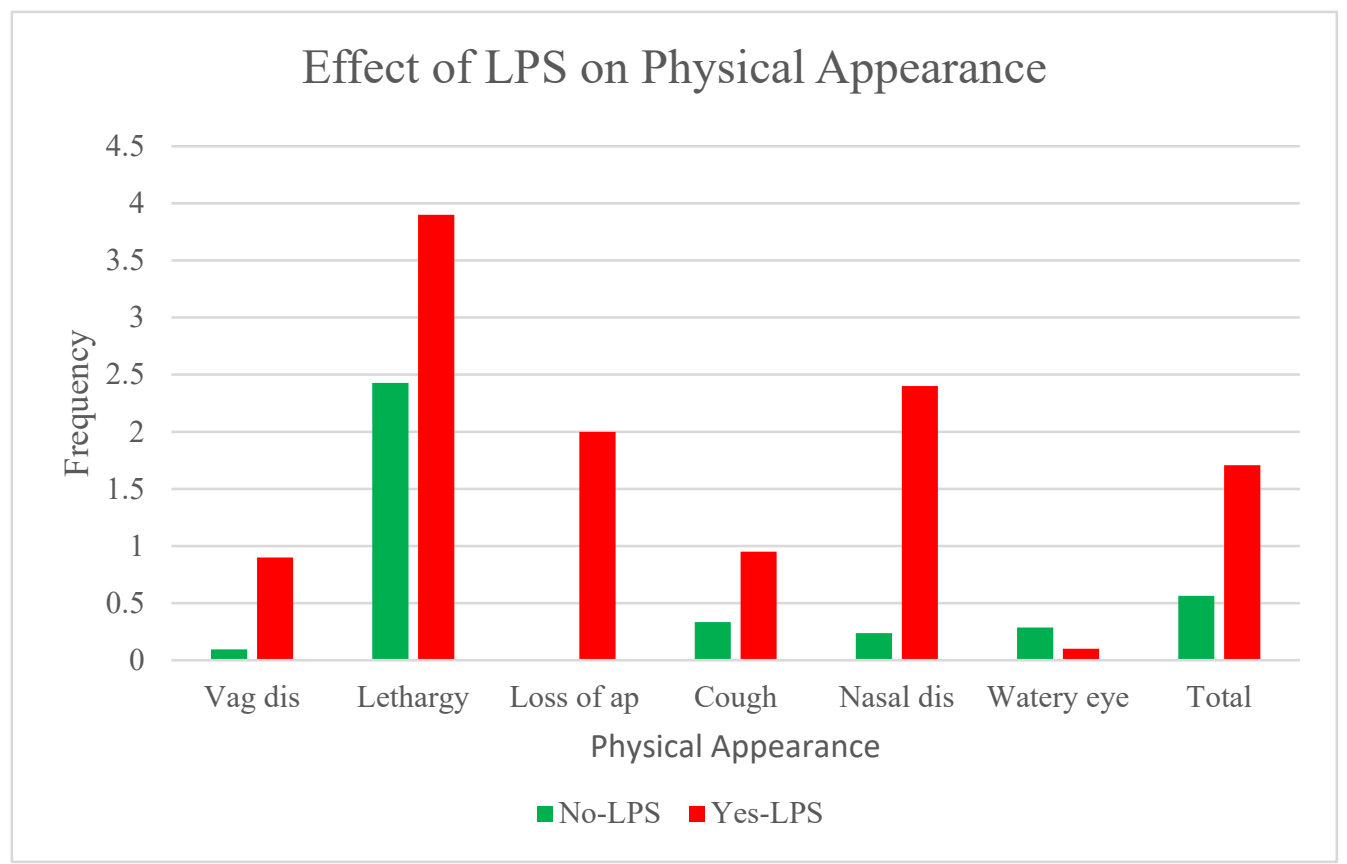

Figure 4-24 Physical appearance in LPS and No-LPS groups. 


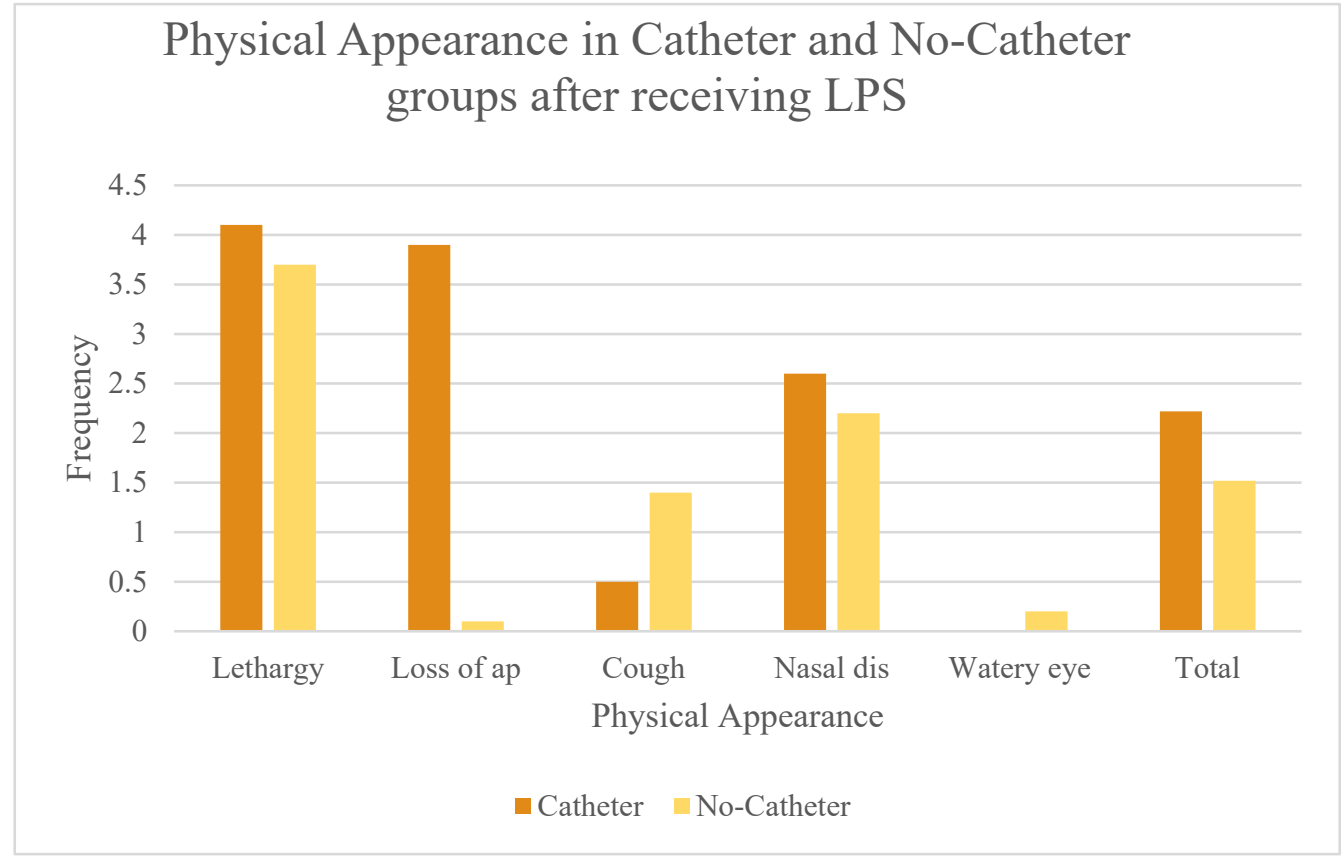

Figure 4-25 Physical appearance in Catheter and No-Catheter groups after treatment with LPS.

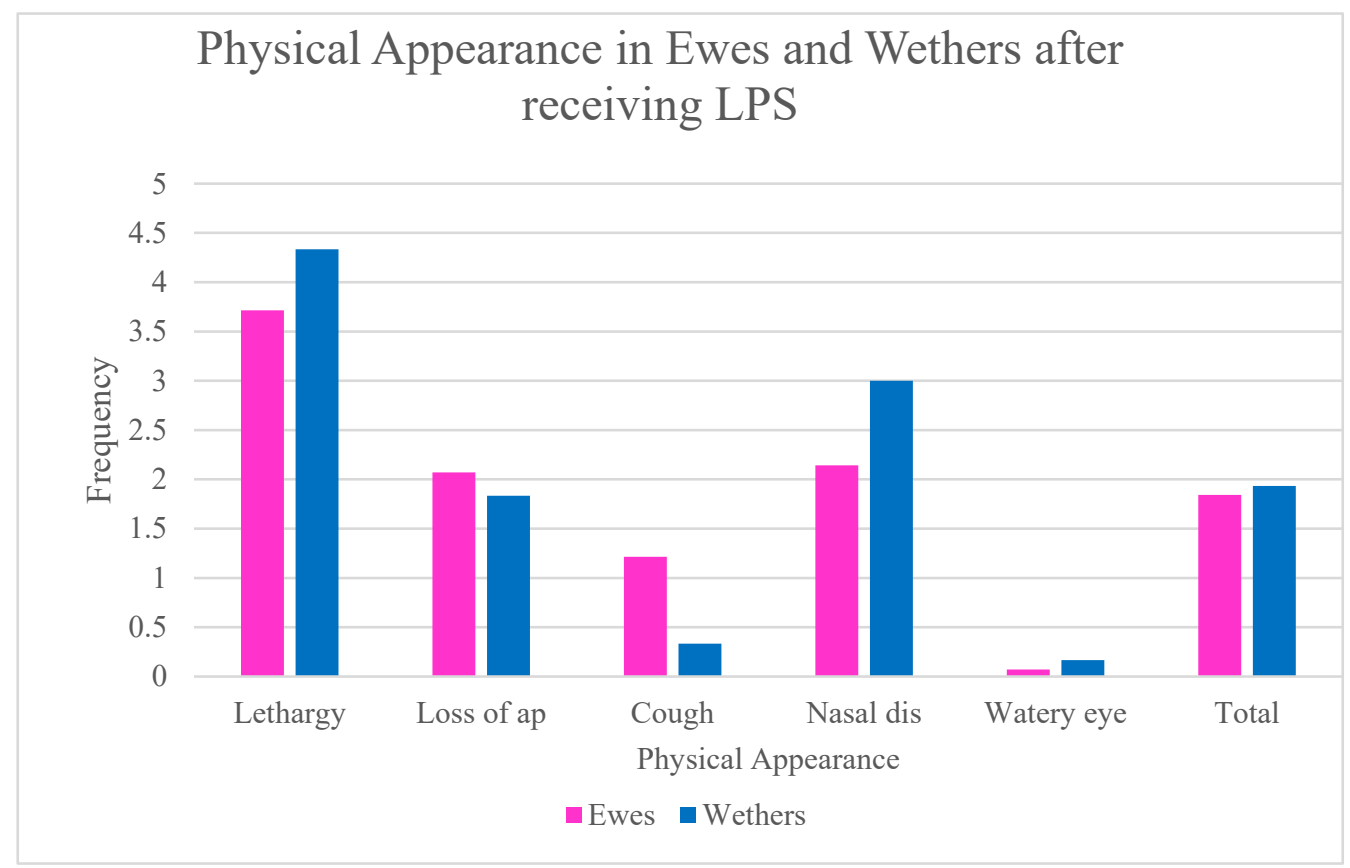

Figure 4-26 Physical appearance in ewes and wethers after treatment with LPS. 


\section{Chapter 5 Discussion}

Various methods are used for blood sampling. The procedures used most frequently in laboratory animals include venipuncture in rodents of the tail vein, jugular vein, or retroorbital sinus, and the saphenous vein in non-human primates. Other common methods in rodents are tail tip excision, cardiac puncture, and decapitation. Teilmann (2014) conducted a study in mice that showed that taking blood from the caudal and facial veins was stressful, inducing significant elevations in plasma corticosterone compared to automated blood sampling group through a catheter. Existing approaches for drawing blood manually by jugular venipuncture in sheep requires restraining the animal's neck, human presence, and repeated animal handling. This procedure, which can be stressful and even painful, mimics an attack by a predator, which can trigger a fight-or-flight response and result in HPA and ANS activation and secretion of GCs and catecholamines. Two alternative and less invasive methods used world-wide for taking samples for measuring cortisol in ruminants are salivary sampling and jugular catheterization. While being a good indicator for plasma cortisol, measuring salivary cortisol is invasive and has a time lag to reach its peak (Hernandez, 2014). In another study, pigs with indwelling catheters had lower cortisol and NE compared to jugular venipuncture (Marchant-Forde, 2012). In the present study, catheterized animals showed no clear elevation in cortisol concentrations, while animals that were manually sampled exhibited a sustained elevation $(41.79 \mu \mathrm{g} / \mathrm{d}$ vs $74.00 \mu \mathrm{g} / \mathrm{dL})$. No elevation in the GCs levels in the catheterized sheep emphasizes stress reduction in blood sampling via catheterization. The effectiveness of sampling via a catheter in reducing stress hormone responses may be affected by the animal's previous experience, genetic, and temperament.

Various stressors can influence different hematology measures among which the immune system, especially circulating leukocytes, are the most sensitive. Since there is an elaborate relationship between immune response and stressors, the immune system can be affected in different ways. For example, handling can impact some cells of the immune system while it might not have any effect on other ones in such a way that it can have both stimulatory and depressing effects. In general, increased leukocyte counts occur seconds to minutes subsequent to a short-term stressor based on the effect of NE. Then, after long- 
term effects due to the GCs, the stress leukogram (mature neutrophilia, lymphopenia, eosinopenia, and variable monocytosis) can be evoked. Not all of these changes might be seen with moderate stressors. Thus, duration and intensity of the stressor play a vital role in leukocyte response. In this study, total WBC, lymphocyte, monocyte, and granulocyte counts in blood samples were measured. There were significant effects of catheter and catheter*LPS interaction on total WBC count: decreased total WBC count in both NoCatheter and Catheter groups and it remained lower than the initial count for whole twelve hours.

Mature neutrophilia and eosinophilia are other components of the stress leukogram. Increases in circulating neutrophils might result from moving from margination to the circulation. Eosinophilia is the consequence of low utilization from the bone marrow, short survival, and retreatment in lymphoid tissue and marginal pool. Granulocyte (neutrophils, eosinophils and basophils) counts decreased in both Catheter and No-Catheter group compared to the initial level. In this study, lymphocyte count in Catheter group was lower than the initial count throughout the experiment while in No-Catheter group it decreased one hour after the experiment and back to normal after hour eleven. However, lymphopenia or low normal lymphocytes is one of the key elements of the stress leukogram, which was observed in both Catheter and No-Catheter groups. More evaluations such as physiological changes, clinical pathology, and histology are needed to discern the primary reason for these alterations. Furthermore, there was a catheter*LPS interaction on lymphocyte count showed that No-Catheter+No-LPS group had lower numbers of lymphocytes than the Catheter+No-LPS group while Catheter+LPS group had the lowest numbers of lymphocytes.

There is an inconsistent relationship between GCs production and monocytes level in different species. In rats, circulating monocytes follows the GCs circadian pattern but in human beings, after GCs injection it decreases transitionally for few hours before increasing above the basal level. Even though GCs have varying influence on monocyte counts, monocyte pattern matches pattern of lymphocytes after GCs infusion in human beings. In stress leukogram of dogs, monocytosis is one of the characteristics of the stress response, even though it is rarely seen in cattle and horses. The results for Catheter and No-Catheter groups showed declined in monocyte counts, which nearly paralleled the 
pattern for lymphocytes and remained lower than the basal level during the experiment, while no significant effect of the catheter was seen. In general, it is possible not to see all four elements of the stress response. However, two sensitive findings of stress leukogram are mature neutrophilia and lymphopenia. Therefore, it is fundamental to measure other signs of stress (clinical finding and chemical pathology), as well. Besides, the similarity of stress and inflammation leukograms makes it impossible to distinguish these changes based on the single hemogram. Interpreting data from sequential hemogram along with clinical findings and other laboratory exams can be helpful to discriminate each of these responses or concurrent presence.

There are controversial reports based on the animals' immune responses to various stressors. Male mice handled daily, and restrained for an injection established lower IgM and $\mathrm{IgG}$ to the antigen Keyhole Limpet Hemocyanin (KLH) compared to the unhandled controls, and female mice slightly handled without restraint for intraperitoneally injected KLH developed lower IgG. On the other hand, no difference has been shown between levels of IgM, CD4+ markers, and CD8+ markers of splenocytes of unhandled (control) mice and two-week-handled ones. Handled $\mathrm{C} 3 \mathrm{H} / \mathrm{HeJ}$ and $\mathrm{BALB} / \mathrm{c}$ mice exhibited lower IgM and IgG levels compared to unhandled control group. In contrast, isolated male rhesus macaques showed about $50 \%$ more CD8+ T-cells when bled after encountering a stressor (Balcombe, 2004). May (2010) has found interchangeable CBC result (total WBC count, segmented neutrophils, lymphocytes, eosinophils, basophils, and RBCs) in blood samples obtained directly from venipuncture versus jugular catheter in horses. Himberger (2001) established a study in human beings analyzing hematologic values including WBC and RBC drawn from peripheral IV catheters and direct venipuncture. Their results showed no significant difference between those two groups. Depending on blood sampling method, stress response can be the result of pain, repeated handling, and restraint. It is believed that repeated excision of the tail tip or "milking" the tail in rodents is a painful procedure, which results in inflammatory leukocytosis. However, Abatan (2008) did not show a classic stress leukogram between tail-clip method and saphenous vein catheterization. In this study, the effect of the catheter was significant on total WBC, lymphocyte, granulocyte, and monocyte. 
Administration of LPS triggers stimulatory effect of VP on ACTH secretion (Zelena, 2009), which increases GC secretion, which is one of the major inhibitory mechanisms that controls inflammatory and immunological responses. Following LPS administration, concentrations of the pro-inflammatory cytokines, TNF- $\alpha$, IL- $1 \beta$, and IL- 6 increase, as well as, secretion of the stress-related hormones such as GC, epinephrine, and norepinephrine. Production of acute-phase proteins also was enhanced following LPS injection. This study demonstrates that the sheep responded to LPS with an increase in the secretion of cortisol and becoming anorexic, lethargic and showing mucosal responses, which can be explained by the negative effect of GCs on the unnecessary behaviors such as digestion. Therefore, poor appetite was observed in the groups with high cortisol levels. These behavioral changes and altered neuroendocrine secretions are components of the acute-phase response (Ceciliani, 2002). In the present study, we also sought to measure ewes and wethers respond to the LPS injection. Manually sampled wethers, which did not receive LPS showed a peak at hour four post-treatment, while there was no noticeable elevation seen in ewes of the same group. Ewes treated with LPS and sampled via venipuncture showed slightly higher cortisol levels compared to the wethers at all time points, while both males and females sustained similar pattern. LPS administration has been known as a way to study HPA axis response to immune stimuli and a stimulator for TNF- $\alpha$ and cytokine secretion. High dose of LPS stimulates hypothalamic AVP synthesis and secretion as a fundamental correspondent in HPA axis activation by LPS (Zelena et al. 2009).

The current study challenges the hypothesis that there is no difference in cortisol response between ewes and wethers exposed to LPS administration and their stress response to be restrained for venipuncture. The results support the hypothesis and show statistically no difference in stress respond based on the sex. In the same way Turner et. al (2010) found same results in cortisol level of male and female sheep due to endotoxin stress and physical activity, while they saw a higher elevation in the females cortisol in response to other stressors such as restraint and wetting. It was suggesting that sexual dimorphism in stress response depends on the nature of the stressor means that some stressors might influence HPA axis separate from sex steroids. Therefore, it might not be accurate to generalize specific stress response. Restraint is known as an acute stressor, which has a stimulatory effect on the HPA axis and rapid elevation of ACTH and GCs. In response to the acute 
restraint CRH and AVP act synergically to increase ACTH release (Lightman, 2008). Sexual dimorphism can be diminished by gonadectomy, which causes gonadectomized animals to exhibit similar adrenal cortex activity because its secretory function is partially influenced by sex hormones. Studies on a gonadectomized female and male sheep showed the same cortisol level with no effect of sex differences. Furthermore, intact ewes showed higher cortisol level in comparison with gonadectomized ones in response to the ACTH injection. In contrast, there was no effect of gonadectomy found in rams and wethers, which suggested the regulatory effect of estrogen on cortisol level at the adrenal cortex but no effect of testosterone on it. The stimulatory effect of Estradiol benzoate (EB) was shown in gonadectomized ewes while administration of testosterone cypionate (TC) to wethers exhibited no effect on cortisol secretion in response to the ACTH. Possible mechanisms to explain the function of sex steroids at the adrenal cortex level include steroid precursor receptiveness, adrenocortical responsiveness, and enzyme initiation (Van Lier, 2003). In this study, there was no significantly different response between ewes and wethers to catheter and venipuncture, which means no significant effect of sex on cortisol levels due to restraint stressor. In another study done by Van Lier (2014) a direct regulatory aspect of sex steroids on adrenal cortex was shown by comparing cortisol level, androgen receptor (AR), melanocortin 2 receptor (MC2R), and estrogen receptor alpha (ERS1) in ovariectomised ewes and wethers treated with or without EB or TC. There was no difference in cortisol level in wethers receiving or not receiving TC while wethers with TC showed higher AR and MC2R than wethers without TC. Furthermore, AR, ERS1, and $\mathrm{MC} 2 \mathrm{R}$ expression were higher in wethers with TC in comparison with ovariectomized ewes received EB. Moreover, cortisol secretion was higher in EB-treated ewes than nontreated ewes even though non-treated ewes exhibited higher AR expression. Van Lier (2014) results confirmed the modulatory effect of sex hormones on cortisol secretion in adrenocortical level. Mabley (2005) reported the anti-inflammatory effect of estrogen in female mice by showing an attenuated inflammatory response in the female by producing less TNF- $\alpha$ and macrophage inflammatory protein- $1 \alpha$ (MIP-1 $1 \alpha)$ in the case of endotoxemia and showed less LPS-induced mortality. Male rats are often test subjects for stress studies. However, they have lower GCs levels with fewer secretory pulses than the female rats. Furthermore, females have quicker elevation in GCs levels following the stressors (Everds, 
2013). Generally, various factors such as sex, age, frequency and nature of the stressors can affect neural function in response to the stressors.

The present in vivo study reports that ewes and wethers subjected to the LPS injection exhibited the same response during systemic inflammation subsequent to the administration of $E$. coli endotoxin. Interestingly, total WBCs, monocytes, lymphocytes, and granulocytes of LPS-treated ewes and wethers and no-treated ones did not differ; however, there was a significant effect of sex on rectal temperature. Furthermore, there was an LPS*Sex interaction in total WBC count. Van Eijk (2007) demonstrated that higher inflammatory response in females compared with males after $E$. coli endotoxemia is due to the greater LPS-binding in the female, which is associated with ameliorated TLR-4 signaling. Moreover, females showed a rise in C-reactive proteins along with higher cytokines and TNF- $\alpha$, which suggested the pronounced pro-inflammatory response in females. They also reported no significant sexual dimorphism in leukocyte differential, although females showed more leukopenia. LPS-treated groups showed leukocyte sequestration and a higher level of cytokines, which showed no significant relation between circulating leukocytes and systemic cytokine release. TLR-4 is the main detector for LPS, which is found on the surface of MQ, DCs, and monocytes. There are some variations among of receptors expression and cytokines production between males and females. For example, females MQs express more MyD88 and p38 MAP kinase phosphorylation, therefore, their MQs activated more in response to the LPS administration. On the other hand, males MQs express a greater amount of TLR-4. There are also differences in level of inflammatory cytokines secretion, for instance, peripheral monocytes, and peritoneal MQs from male produce greater amounts of TNF- $\alpha$, IL-1b, and IL- 6 while producing lower levels of anti-inflammatory prostanoids after receiving LPS. Besides, males display less cytotoxic T-lymphocyte activity than females who have upregulated expression of proinflammatory genes. The activities of effector cells of the immune system such as T-cells, B-cells, DCs, MQs, and NK cells are modulated by sex hormones via their receptors on those cells. Unlike progesterone and testosterone which, have inhibitory effects on B-cells and antibody production, estradiol has a stimulatory effect on B-cells proliferation and differentiation into plasma cells facilitated by Th-2 (Klein, 2015). There is a sexual dimorphism in the thymic structure and its catecholamine composition such that males 
have higher levels of catecholamine in their thymus whereas females have a heavier thymus. Despite the greater number of T-cells in females, both sexes have similar total lymphocyte count (Pitychoutis, 2010). The present results not only mirror those for total lymphocytes but also for monocytes and granulocytes.

In the present study, as expected, LPS $(p<0.001)$ injection caused a surge in rectal temperature, whereas saline had no effect on rectal temperature. Furthermore, sexual dimorphism was observed in rectal temperature after LPS exposure. Similar dimorphic responses have been found by Queen (2015) in male and female mice. They also studied changes in six different cytokines/gene expression in the result of three separate strains of E. coli LPS exposure in male and female mice. The dimorphic responses in two cytokines/gene expression and body temperature were observed in their study. In the current study, subsequent to the LPS injection, all groups displayed the same predicted changes in physical behavior in both sexes. Likewise, Carroll (2015) found increased sickness behavior in bulls and heifers following LPS administration, females recovered quicker than males. However, heifers displayed prolonged and higher body temperature. They also observed leukopenia post LPS injection in both sexes, while heifers had less total leukocytes and lymphocytes pre-challenge, there were no significant differences in total leukocytes and lymphocytes between sexes after LPS administration. Similarly, no significant effect of sexes was oberved on circulating leukocytes obtained from ewes and wethers. However, there was a significant effect of sex*LPS interaction on total WBC and lymphocyte in such a way that ewes had higher baseline total WBC (11.37 in ewes, 10.50 in wethers) and displayed greater leukopenia following LPS challenge (4.23 in ewes, 5.45 in wethers). Lymphocyte concentration was comparable with total WBC pattern in ewes and wethers. In addition, the mean of rectal temperature was higher in heifers in comparison with bulls. Therefore, it was suggested that heifers displayed vigorous acute response following LPS administration even though bulls exhibited severe symptoms of sickness. Conversely, our results showed higher mean temperature in LPS-treated wethers $\left(39.09^{\circ} \mathrm{C}\right)$ compared to ewes $\left(38.7^{\circ} \mathrm{C}\right)$ of the same group while average for rectal temperature in no-LPS treated ewes $\left(38.39^{\circ} \mathrm{C}\right)$ was higher than no-LPS treated wethers $\left(38.28^{\circ} \mathrm{C}\right)$. Furthermore, LPS+No-Catheter group peaked in rectal temperature between hour 3-4 post-challenge while Catheter group delayed in increased temperature (6-7 hours 
post-challenge), which is a negative response for catheter. Moreover, females showed lag in their temperature responses while having sustained low grade fever. Generally, a febrile response post-LPS administration showed its assistance in determining endotoxic shock. There are various examples of sex susceptibility to different infections, which is complex and multifaceted. The principal basis for these variations is believed to be as a result of sex hormones and their influences on the immune system and gene expression in the same way. Likewise, it could be the consequence of diverse innate physiology among different sexes. Above all, type of microbe affects sex response to the particular infection, as well. Generally, testosterone is supposed to be anti-inflammatory while estrogen is proinflammatory. However, in some infections, there is different susceptibility between sexes microbe type (McClelland, 2011). 


\section{Chapter 6 Conclusion and Future Works}

The current study tested the hypothesis that catheterization minimizes handling and disturbance of plasma GCs levels compared to direct blood draw through venipuncture. However, catheter and LPS interaction seems to put an additional inflammatory response on top of the post-LPS inflammation, which affects total WBC as well as other leukocyte differentials. Data from this study and previous studies suggested that sex stress response and their vulnerability to the detrimental effect of stress on GCs level, leukocyte counts and differentials may be stressor specific. Along with those findings, examining a broad range of cytokines and stress gene expression and their correlation with temperature and sickness behavior may be beneficial for understanding the stress response and sexual dimorphism in response to various stressors and LPS administration. However, no differences between GCs level in both sexes and no significant effect of the catheter, it is not accurate to generalize these results to all types of stressors because it seems to be other factors involved, which need to be determined. In other words, genetic predilection, environmental conditions, and the situation in fetal life are feasibly significant for interpreting stress responses in adulthood. Therefore, one of the impportant factors to be considered is whether the anial is in his or her pre-pubertal, pubertal, or post-pubertal stage. In conclusion, blood collection via intravenous catheter is a practical possibility to lessen stress to the animal and has a positive effect on animal and staff interaction while making blood sampling simple with no need to restrainted the animal. Furthermore, waiting at least three days after catheterization to give the animal enough time to recover from the stress and inflammation, which were caused by the catheter might be the effective way to minimize the detrimental effect of catheter while using along with LPS. Last but not least, sex differences in response to the physical stressors and LPS model for immune response were multifactorial and are dependent on the LPS strain, animal's life stage, time, genetic, environmental condition, and individual characteristic and vulnerability. In summary, this study demonstrates the sheep responded to LPS with an increase in the secretion of cortisol and becoming anorexic, lethargic and showing mucosal responses. The effectiveness of 
sampling via a catheter in reducing stress hormone responses may be affected by animal's previous experience, temparment, and genetic. Sexual dimorphism in stress response depends on the nature of the stressor means that some stressors might influence HPA axis separate from sex steroids. Therefore, it might not be accurate to generalize specific response to the particular stressor to various stressors. 


\section{References}

Abatan, O. I., Welch, K. B., \& Nemzek, J. A. (2008). Evaluation of saphenous venipuncture and modified tail-clip blood collection in mice. Journal of the American Association for Laboratory Animal Science, 47(3), 8-15.

Aderem, A., \& Smith, K. D. (2004). A systems approach to dissecting immunity and inflammation. Seminars in Immunology, 16(1), 55-67. doi:S1044532303000952 [pii].

Alberts, B., Johnson, A., \& Lewis, J. (2002). Innate immunity. Molecular biology of the cell (4th ed., ). New York: Garland Science.

Alberts, B., Johnson, A., Lewis, J., Raff, M., Roberts, K., \& Walte, P. (2002). B cells and antibodies (4th ed.). New York: Garland Science.

Balcombe, J. P., Barnard, N. D., \& Sandusky, C. (2004). Laboratory routines cause animal stress. Journal of the American Association for Laboratory Animal Science, 43(6), 42-51.

Baumgartner, J. D., \& Glauser, M. P. (1993). Immunotherapy of endotoxemia and septicemia. Immunobiology, 187(3-5), 464-477. doi:S0171-2985(11)80357-8 [pii].

Barker, R. A., (1999). Factors associated with acute bacterial infection that limit fertility (Master thesis). Retrieved from WVU library database.

Beerda, B., Schilder, M. B. H., Janssen, N. S. C. R. M., \& Mol, J. A. (1996). The use of saliva cortisol, urinary cortisol, and catecholamine measurements for a noninvasive assessment of stress responses in dogs. Hormones and Behavior, 30 doi:10.1006/hbeh.1996.0033.

Bernheim, H. A., \& Kluger, M. J. (1976). Fever and antipyresis in the lizard dipsosaurus dorsalis. The American Journal of Physiology, 231(1), 198-203.

Beutler, B. A. (2009). Blood. TLRs and innate immunity (pp. 1399-1407).

Beutler, B., \& Rietschel, E. T. (2003). Innate immune sensing and its roots: The story of endotoxin. Nature Reviews Immunology, 3(2), 169-176.

Beutler, B. (2004). Innate immunity: An overview. Molecular Immunology, 40(12), 845-859. doi:S016158900300316X [pii].

Beutler, B. (2001). Sepsis begins at the interface of pathogen and host. Biochemical Society Transactions, 29(Pt 6), 853-859.

Bhattacharyya, S., Brown, D. E., Brewer, J. A., Vogt, S. K., \& Muglia, L. J. (2007). Macrophage glucocorticoid receptors regulate toll-like receptor 4-mediated inflammatory responses by 
selective inhibition of p38 MAP kinase. Blood, 109(10), 4313-4319. doi:blood-2006-10048215 [pii].

Blackshaw, J. K., \& Blackshaw, A. W. (1989). Limitations of salivary and blood cortisol determinations in pigs. Veterinary Research Communications, 13 doi:10.1007/BF00420834.

Boissy, A., \& Le Neindre, P. (1997). Behavioral, cardiac and cortisol responses to brief peer separation and reunion in cattle. Physiology \& Behavior, 61 doi:10.1016/S00319384(96)00521-5.

Box, G. E. P., \& Jenkins, G. M. (1976). Time series analysis: Forecasting and control. San Francisco: Holden-Day.

Brewer, J. A., Khor, B., Vogt, S. K., Muglia, L. M., Fujiwara, H., Haegele, K. E., Muglia, L. J. (2003). T-cell glucocorticoid receptor is required to suppress COX-2-mediated lethal immune activation. Nature Medicine, 9(10), 1318-1322. doi:10.1038/nm895 [doi].

Brien, T. G. (1980). Free cortisol in human plasma. Hormone and Metabolic Research. HormonUnd Stoffwechselforschung. Hormones Et Metabolisme, 12 doi:10.1055/s-2007-999224.

Bright, G. (1995). Corticosteroid-binding globulin influences kinetic parameters of plasma cortisol transport and clearance. The Journal of Clinical Endocrinology and Metabolism, 80.

Bright, G., \& Darmaun, D. (1995). Corticosteroid-binding globulin modulates cortisol concentration responses to a given production rate. The Journal of Clinical Endocrinology and Metabolism, 80 .

Bruckmaier, R. M., Schams, D., \& Blum, J. W. (1993). Milk removal in familiar and unfamiliar surroundings: Concentrations of oxytocin, prolactin, cortisol and beta-endorphin. The Journal of Dairy Research, 60 doi:10.1017/S0022029900027813.

Bushong, D. M., Friend, T. H., \& Knabe, D. A. (2000). Salivary and plasma cortisol response to adrenocorticotropin administration in pigs. Laboratory Animals, 34 doi:10.1258/002367700780457482.

Carroll, J. A., Sanchez, N. C. B., Hulbert, L. E., Ballou, M. A., Dailey, J. W., Caldwell, L. C., Randel, R. D. (2015). Sexually dimorphic innate immunological responses of pre-pubertal brahman cattle following an intravenous lipopolysaccharide challenge. Veterinary Immunology and Immunopathology, 166(3), 108-115.

Cartmell, T., Poole, S., Turnbull, A. V., Rothwell, N. J., \& Luheshi, G. N. (2000). Circulating interleukin-6 mediates the febrile response to localised inflammation in rats. The Journal of Physiology, 526 Pt 3, 653-661. doi:PHY_0602 [pii].

Ceciliani, F., Giordano, A., \& Spagnolo, V. (2002). The systemic reaction during inflammation: The acute-phase proteins. Protein and Peptide Letters, 9(3), 211-223. 
Cook, C. J. (2002). Rapid noninvasive measurement of hormones in transdermal exudate and saliva. Physiology \& Behavior, 75 doi:10.1016/S0031-9384(01)00658-8.

Dhawan, L., Liu, B., Blaxall, B. C., \& Taubman, M. B. (2007). A novel role for the glucocorticoid receptor in the regulation of monocyte chemoattractant protein-1 mRNA stability. The Journal of Biological Chemistry, 282(14), 10146-10152. doi:M605925200 [pii].

Dickerson, S. S., \& Kemeny, M. E. (2004). Acute stressors and cortisol responses: A theoretical integration and synthesis of laboratory research. Psychological Bulletin, 130(3), 355.

Dziarski, R., \& Gupta, D. (2000). Role of MD-2 in TLR2- and TLR4-mediated recognition of gram-negative and gram-positive bacteria and activation of chemokine genes. Journal of Endotoxin Research, 6(5), 401-405.

Edelson, B. T., Bradstreet, T. R., Hildner, K., Carrero, J. A., Frederick, K. E., KC, W., Murphy, K. M. (2011). CD8alpha(+) dendritic cells are an obligate cellular entry point for productive infection by listeria monocytogenes. Immunity, 35(2), 236-248. doi:10.1016/j.immuni.2011.06.012 [doi].

Elsbach, P., \& Weiss, J. (1998). Role of the bactericidal/permeability-increasing protein in host defence. Current Opinion in Immunology, 10(1), 45-49. doi:S0952-7915(98)80030-7 [pii].

Everds, N. E., Snyder, P. W., Bailey, K. L., Bolon, B., Creasy, D. M., Foley, G. L., Sellers, T. (2013). Interpreting stress responses during routine toxicity studies: A review of the biology, impact, and assessment. Toxicologic Pathology, 41(4), 560-614.

Fell, L. R., Shutt, D. A., \& Bentley, C. J. (1985). Development of a salivary cortisol method for detecting changes in plasma "free" cortisol arising from acute stress in sheep. Australian Veterinary Journal, 62doi:10.1111/j.1751-0813.1985.tb14120.

Frank, M. G., Watkins, L. R., \& Maier, S. F. (2013). Stress-induced glucocorticoids as a neuroendocrine alarm signal of danger. Brain, Behavior, and Immunity, 33, 1-6. doi:10.1016/j.bbi.2013.02.004 [doi].

Fritsch, F. N., \& Carlson, R. E. (1980). Monotone piecewise cubic interpolation. SIAM J Numer Anal, 17 doi:10.1137/0717021.

Gabay, C., \& Kushner, I. (1999). Acute-phase proteins and other systemic responses to inflammation. The New England Journal of Medicine, 340(6), 448-454. doi:10.1056/NEJM199902113400607 [doi].

Gayrard, V., Alvinerie, M., \& Toutain, P. L. (1996). Interspecies variations of corticosteroidbinding globulin parameters. Domestic Animal Endocrinology, 13 doi:10.1016/07397240(95)00042-9. 
Grandin, T. (1997). Assessment of stress during handling and transport. Journal of Animal Science, 75(1), 249-257.

Greenwood, P. L., \& Shutt, D. A. (1992). Salivary and plasma cortisol as an index of stress in goats. Australian Veterinary Journal, 69 doi:10.1111/j.1751-0813.1992.tb07501.

Gupta, D., Jin, Y. P., \& Dziarski, R. (1995). Peptidoglycan induces transcription and secretion of TNF-alpha and activation of lyn, extracellular signal-regulated kinase, and rsk signal transduction proteins in mouse macrophages. Journal of Immunology (Baltimore, Md.: 1950), 155(5), 2620-2630.

Gutierrez, O., Villalobos, P. T., Villasenor, M. M., Viveros, J. M., \& Puebla, A. M. (2015). Activation of the hypothalamic- pituitary-adrenal axis induces the differential release of proinflammatory cytokines in balb/c mice. European Scientific Journal, 11(27).

Handa, R. J., Weiser, M., \& Zuloaga, D. (2009). A role for the androgen metabolite, 5 $\alpha$ Androstane-3 $\beta$, 17 $\beta$-Diol, in modulating oestrogen receptor $\beta$-Mediated regulation of hormonal stress reactivity. Journal of Neuroendocrinology, 21(4), 351-358.

Handa, R. J., Sharma, D., \& Uht, R. M. (2011). A role for the androgen metabolite, 5alpha androstane 3 beta, 17 beta diol ( $3 \beta$-diol) in the regulation of the hypothalamo-pituitary-adrenal axis. Frontiers in Endocrinology, 2, 65.

Hernandez, C. E., Thierfelder, T., Svennersten-Sjaunja, K., Berg, C., Orihuela, A., \& Lidfors, L. (2014). Time lag between peak concentrations of plasma and salivary cortisol following a stressful procedure in dairy cattle. Acta Veterinaria Scandinavica, 56(1), 61. doi:10.1186/s13028-014-0061-3.

Hickey, M. C., Drennan, M., \& Earley, B. (2003). The effect of abrupt weaning of suckler calves on the plasma concentrations of cortisol, catecholamines, leukocytes, acute-phase proteins and in vitro interferon-gamma production. Journal of Animal Science, 81.

Himberger, J. R., \& Himberger, L. C. (2001). Accuracy of drawing blood through infusing intravenous lines. Heart \& Lung: The Journal of Acute and Critical Care, 30(1), 66-73. doi:http://dx.doi.org/10.1067/mhl.2001.110535.

Hinz, A., Jedamzick, J., Herbring, V., Fischbach, H., Hartmann, J., Parcej, D., Tampe, R. (2014). Assembly and function of the major histocompatibility complex (MHC) I peptide-loading complex are conserved across higher vertebrates. The Journal of Biological Chemistry, 289(48), 33109-33117. doi:10.1074/jbc.M114.609263 [doi].

Hopster, H., O'Connell, J. M., \& Blokhuis, H. J. (1995). Acute effects of cow-calf separation on heart rate, plasma cortisol and behaviour in multiparous dairy cows. Applied Animal Behaviour Science, 44doi:10.1016/0168-1591(95)00581-C. 
Hueston, C. M., \& Deak, T. (2014). The inflamed axis: The interaction between stress, hormones, and the expression of inflammatory-related genes within key structures comprising the hypothalamic-pituitary-adrenal axis. Physiology \& Behavior, 124, 77-91. doi:10.1016/j.physbeh.2013.10.035 [doi].

Iizasa, S., Iizasa, E., Matsuzaki, S., Tanaka, H., Kodama, Y., Watanabe, K., \& Nagano, Y. (2016). Arabidopsis LBP/BPI related-1 and -2 bind to LPS directly and regulate PR1 expression. Scientific Reports, 6, 27527. doi:10.1038/srep27527 [doi].

Iwasaki, A., \& Medzhitov, R. (2015). Control of adaptive immunity by the innate immune system. Nature Immunology, 16(4), 343-353. doi:10.1038/ni.3123 [doi].

Iwasaki, A., \& Medzhitov, R. (2010). Regulation of adaptive immunity by the innate immune system. Science (New York, N.Y.), 327(5963), 291-295. doi:10.1126/science.1183021 [doi].

Janeway, C. J., Traver, P., \& Walpor, . (2001). Principles of innate and adaptive immunity. Immunobiology: The immune system in health and disease (5th ed., ). .New York: Garland Science.

Janeway, C. A.,Jr, \& Medzhitov, R. (2002). Innate immune recognition. Annual Review of Immunology, 20, 197-216. doi:10.1146/annurev.immunol.20.083001.084359 [doi].

Jenkins, J. S., \& Connolly, J. (1968). Adrenocortical response to ethanol in man. British Medical Journal, 2(5608), 804-805.

Johnson, E. O., Kamilaris, T. C., Chrousos, G. P., \& Gold, P. W. (1992). Mechanisms of stress: A dynamic overview of hormonal and behavioral homeostasis. Neuroscience and Biobehavioral Reviews, 16(2), 115-130. doi:S0149-7634(05)80175-7 [pii].

Jones, P. P., Spraul, M., Matt, K. S., Seals, D. R., Skinner, J. S., \& Ravussin, E. (1996). Gender does not influence sympathetic neural reactivity to stress in healthy humans. The American Journal of Physiology, 270(1 Pt 2), H350-7.

Kirschbaum, C., \& Hellhammer, D. H. (1989). Salivary cortisol in psychobiological research: An overview. Neuropsychobiology, 22 doi:10.1159/000118611.

Klein, S. L., Marriott, I., \& Fish, E. N. (2015). Sex-based differences in immune function and responses to vaccination. Transactions of the Royal Society of Tropical Medicine and Hygiene, 109(1), 9-15. doi:10.1093/trstmh/tru167 [doi].

Kopecny, L. (2013). Veterinary immunology. 9th edn. edited by IR tizard . elsevier, st louis, 2013. 554 pages. price A\$92.99. ISBN 978145570362 3. Australian Veterinary Journal, 91(1-2), 51-51. doi:10.1111/avj.12004. 
Krasity, B. C., Troll, J. V., Weiss, J. P., \& McFall-Ngai, M. J. (2011). LBP/BPI proteins and their relatives: Conservation over evolution and roles in mutualism. Biochemical Society Transactions, 39(4), 1039-1044. doi:10.1042/BST0391039 [doi].

Kumsta, R., Entringer, S., Hellhammer, D. H., \& Wust, S. (2007). Cortisol and ACTH responses to psychosocial stress are modulated by corticosteroid binding globulin levels. Psychoneuroendocrinology, 32doi:10.1016/j.psyneuen.2007.08.007.

Kuwano, T., Nakao, S., Yamamoto, H., Tsuneyashi, M., Yamamoto, T., Kuwano, M., \& Ono, M. (2004). Cyclooxygenase 2 is a key enzyme for inflammatory cytokine-induced angiogenesis.18, 300-310.

Lac, G. (2001). Saliva assays in clinical and research biology. Pathologie Et Biologie, 49 doi:10.1016/S0369-8114(01)00228-0.

Lacy, P., \& Stow, J. L. (2011). Cytokine release from innate immune cells: Association with diverse membrane trafficking pathways. Blood, 118(1), 9-18. doi:10.1182/blood-2010-08265892 [doi].

Lay, D. C., Friend, T. H., Randel, R. D., Bowers, C. L., Grissom, K. K., \& Jenkins, O. C. (1992). Behavioral and physiological effects of freeze or hot-iron branding on crossbred cattle. Journal of Animal Science, 70.

Lefcourt, A. M., Bitman, J., Kahl, S., \& Wood, D. L. (1993). Circadian and ultradian rhythms of peripheral cortisol concentrations in lactating dairy cows. Journal of Dairy Science, 76 doi:10.3168/jds.S0022-0302(93)77595-5.

Lefcourt, A. M., \& Elsasser, T. H. (1995). Adrenal responses of angus x hereford cattle to the stress of weaning. Journal of Animal Science, 73.

Lidfors, L. M. (1996). Behavioural effects of separating the dairy calf immediately or 4 days postpartum. Applied Animal Behaviour Science, 49 doi:10.1016/0168-1591(96)01053-2.

Lightman, S. L., Wiles, C. C., Atkinson, H. C., Henley, D. E., Russell, G. M., Leendertz, J. A., Conway, C. B. L. (2008). The significance of glucocorticoid pulsatility. European Journal of Pharmacology, 583(2-3), 255-262. doi:10.1016/j.ejphar.2007.11.073 [doi].

Loberg, J. M., Hernandez, C. E., Thierfelder, T., Jensen, M. B., Berg, C., \& Lidfors, L. (2008). Weaning and separation in two steps - A way to decrease stress in dairy calves suckled by foster cows. Applied Animal Behaviour Science, 111 doi:10.1016/j.applanim.2007.06.011.

Loberg, J. M., Hernandez, C. E., Thierfelder, T., Jensen, M. B., Berg, C., \& Lidfors, L. (2007). Reaction of foster cows to prevention of suckling from and separation from four calves simultaneously or in two steps. Journal of Animal Science, 85 doi:10.2527/jas.2006-813. 
Mabley, J. G., Horvath, E. M., Murthy, K. G., Zsengeller, Z., Vaslin, A., Benko, R., Szabo, C. (2005). Gender differences in the endotoxin-induced inflammatory and vascular responses: Potential role of poly(ADP-ribose) polymerase activation. The Journal of Pharmacology and Experimental Therapeutics, 315(2), 812-820. doi:jpet.105.090480 [pii].

Marchant-Forde, J., Matthews, D., Poletto, R., McCain, R., Mann, D., DeGraw, R., Kissinger, C. (2012). Plasma cortisol and noradrenalin concentrations in pigs: Automated sampling of freely moving pigs housed in the PigTurn ${ }^{\circledR}$ versus manually sampled and restrained pigs. Animal Welfare-the UFAW Journal, 21(2), 197.

Mashayekhi, M., Sandau, M. M., Dunay, I. R., Frickel, E. M., Khan, A., Goldszmid, R. S., Murphy, K. M. (2011). CD8alpha(+) dendritic cells are the critical source of interleukin-12 that controls acute infection by toxoplasma gondii tachyzoites. Immunity, 35(2), 249-259. doi:10.1016/j.immuni.2011.08.008 [doi].

May, M. L., Nolen-Walston, R., Utter, M. E., \& Boston, R. C. (2010). Comparison of hematologic and biochemical results on blood obtained by jugular venipuncture as compared with intravenous catheter in adult horses. Journal of Veterinary Internal Medicine, 24(6), 14621466. doi:10.1111/j.1939-1676.2010.0582.

McClelland, E. E., \& Smith, J. M. (2011). Gender specific differences in the immune response to infection. Archivum Immunologiae Et Therapiae Experimentalis, 59(3), 203-213.

McEwen, B. S. (2007). Physiology and neurobiology of stress and adaptation: Central role of the brain. Physiological Reviews, 87(3), 873-904. doi:87/3/873 [pii].

McGettrick, A. F., \& O'Neill, L. A. (2007). Toll-like receptors: Key activators of leucocytes and regulator of haematopoiesis. British Journal of Haematology, 139(2), 185-193. doi:BJH6802 [pii].

Merle, N. S., Noe, R., Halbwachs-Mecarelli, L., Fremeaux-Bacchi, V., \& Roumenina, L. T. (2015). Complement System Part II: Role in Immunity. Frontiers in Immunology, 6, 257. http://doi.org/10.3389/fimmu.2015.00257

Mormede, P., Andanson, S., Auperin, B., Beerda, B., Guemene, D., Malmkvist, J., Veissier, I. (2007). Exploration of the hypothalamic-pituitary-adrenal function as a tool to evaluate animal welfare. Physiology \& Behavior, 92 doi:10.1016/j.physbeh.2006.12.003.

Munksgaard, L., \& Simonsen, H. B. (1996). Behavioral and pituitary adrenal-axis responses of dairy cows to social isolation and deprivation of lying down. Journal of Animal Science, 74.

Murphy, K. (2012). Janeway's immunobiology (8th ed.). New York, NY: Garland Science.

Negrao, J. A., Porcionato, M. A., de Passille, A. M., \& Rushen, J. (2004). Cortisol in saliva and plasma of cattle after ACTH administration and milking. Journal of Dairy Science, 87 doi:10.3168/jds.S0022-0302(04)73324. 
Obminski, Z., \& Stupnicki, R. (1996). Effect of temperature and $\mathrm{pH}$ on the magnitude of the free fraction of cortisol in serum. Experimental and Clinical Endocrinology \& Diabetes: Official Journal, German Society of Endocrinology [and] German Diabetes Association, 104 doi:10.1055/s-0029-1211466.

Ogilvie, K., Lee, S., \& Rivier, C. (1997). Role of vasopressin (AVP) and corticotropin-releasing factor in mediating alcohol-induced ACTH and AVP secretion in male rats bearing lesions of the paraventricular nuclei. Brain Res, 744, 83-95.

Ogilvie, K. M., \& Rivier, C. (1997). Gender difference in hypothalamic-pituitary-adrenal axis response to alcohol in the rat: Activational role of gonadal steroids. Brain Research, 766(1), $19-28$.

Ogilvie, K. M., \& Rivier, C. (1996). Gender difference in Alcohol-Evoked HypothalamicPituitary-Adrenal activity in the rat: Ontogeny and role of neonatal steroids. Alcoholism: Clinical and Experimental Research, 20(2), 255-261.

Ozinsky, A., Underhill, D. M., Fontenot, J. D., Hajjar, A. M., Smith, K. D., Wilson, C. B., Aderem, A. (2000). The repertoire for pattern recognition of pathogens by the innate immune system is defined by cooperation between toll-like receptors. Proceedings of the National Academy of Sciences of the United States of America,97(25), 13766-13771. doi:10.1073/pnas.250476497 [doi].

Pacak, K., Palkovits, M., Kopin, I. J., \& Goldstein, D. S. (April 1995). Stress-induced norepinephrine release in the hypothalamic paraventricular nucleus and pituitaryadrenocortical and sympathoadrenal activity: In vivo microdialysis studies.16(2), 89-150. doi:org/10.1006/frne.1995.1004.

Papanicolau, D., Wilder, R. L., Manlagas, S. C., \& Chrousos, P. (1998). The pathophysiologic roles of interleukin-6 in human disease. Ann Inter Med, 128, 127-137.

Parrott, R. F., Misson, B. H., \& Baldwin, B. A. (1989). Salivary cortisol in pigs following adrenocorticotrophic hormone stimulation: Comparison with plasma levels. Brit Vet J, 145 doi:10.1016/0007-1935(89)90034-1.

Pell, S. M., \& McGreevy, P. D. (1999). A study of cortisol and beta-endorphin levels in stereotypic and normal thoroughbreds. Applied Animal Behaviour Science, 64 doi:10.1016/S01681591(99)00029-5.

Penning, T. M. (1997). Molecular endocrinology of hydroxysteroid dehydrogenases. Endocrine Reviews, 18.

Pioli, P. A., Amiel, E., Schaefer, T. M., Connolly, J. E., Wira, C. R., \& Guyre, P. M. (2004). Differential expression of toll-like receptors 2 and 4 in tissues of the human female reproductive tract. Infection and Immunity, 72(10), 5799-5806. doi:10.1128/IAI.72.10.57995806.2004 [doi]. 
Pitychoutis, P. M., \& Papadopoulou-Daifoti, Z. (2010). Of depression and immunity: Does sex matter? The International Journal of Neuropsychopharmacology, 13(5), 675-689. doi:10.1017/S1461145710000465 [doi].

Poon, M., Megyesi, J., Green, R. S., Zhang, H., Rollins, B. J., Safirstein, R., \& Taubman, M. B. (1991). In vivo and in vitro inhibition of JE gene expression by glucocorticoids. The Journal of Biological Chemistry, 266(33), 22375-22379.

Porterfield, V. M., Zimomra, Z. R., Caldwell, E. A., Camp, R. M., Gabella, K. M., \& Johnson, J. D. (2011). Rat strain differences in restraint stress-induced brain cytokines. Neuroscience, 188, 48-54. doi:10.1016/j.neuroscience.2011.05.023 [doi].

Queen, A. E., Moerdyk-Schauwecker, M., McKee, L. M., Leamy, L. J., \& Huet, Y. M. (2016). Differential expression of inflammatory cytokines and stress genes in male and female mice in response to a lipopolysaccharide challenge. PloS One, 11(4), e0152289.

Raetz, C. R., \& Whitfield, C. (2002). Lipopolysaccharide endotoxins. Annual Review of Biochemistry, 71, 635-700. doi:10.1146/annurev.biochem.71.110601.135414 [doi].

Redbo, I. (1993). Stereotypies and cortisol secretion in heifers subjected to tethering. Applied Animal Behaviour Science, 38 doi:10.1016/0168-1591(93)90020-P.

Royet, J., \& Dziarski, R. (2007). Peptidoglycan recognition proteins: Pleiotropic sensors and effectors of antimicrobial defences. Nature Reviews.Microbiology, 5(4), 264-277. doi:nrmicro1620 [pii].

Rushen, J., Boissy, A., Terlouw, E. M., \& de Passille, A. M. (1999). Opioid peptides and behavioral and physiological responses of dairy cows to social isolation in unfamiliar surroundings. Journal of Animal Science, 77.

Schlotz, W., Kumsta, R., Layes, I., Entringer, S., Jones, A., \& Wust, S. (2008). Covariance between psychological and endocrine responses to pharmacological challenge and psychosocial stress: A question of timing. Psychosomatic Medicine, 70 doi:10.1097/PSY.0b013e3181810658.

Shumway, R. H., \& Stoffer, D. S. (2000). Time series analysis and its applications. New York: Springer-Verlag. doi:10.1007/978-1-4757-3261-0.

Silverman, M. H., \& Ostro, M. J. (1999). Bacterial endotoxin in human disease. Princeton, $N J$ : $K P M G, 35$.

Smith, S. M., \& Vale, W. W. (2006). The role of the hypothalamic-pituitary-adrenal axis in neuroendocrine responses to stress. Dialogues in Clinical Neuroscience, 8(4), 383-395. 
Solano, J., Galindo, F., Orihuela, A., \& Galina, C. S. (2004). The effect of social rank on the physiological response during repeated stressful handling in zebu cattle (bos indicus). Physiology \& Behavior, 82doi:10.1016/j.physbeh.2004.06.005.

Sorrells, S. F., \& Sapolsky, R. M. (2007). An inflammatory review of glucocorticoid actions in the CNS. Brain, Behavior, and Immunity, 21(3), 259-272. doi:S0889-1591(06)00359-X [pii].

StÄ`hulovÃ $i$, I., Lidfors, L., \& Å pinka, M. (2008). Response of dairy cows and calves to early separation: Effect of calf age and visual and auditory contact after separation. Applied Animal Behaviour Science, 110 doi:10.1016/j.applanim.2007.03.028.

Stackpole, C. A., Turner, A. I., Clarke, I. J., Lambert, G. W., \& Tilbrook, A. J. (2003). Seasonal differences in the effect of isolation and restraint stress on the luteinizing hormone response to gonadotropin-releasing hormone in hypothalamopituitary disconnected, gonadectomized rams and ewes. Biology of Reproduction, 69(4), 1158-1164. doi:10.1095/biolreprod.103.016428 [doi].

Stroud, L. R., Salovey, P., \& Epel, E. S. (2002). Sex differences in stress responses: Social rejection versus achievement stress. Biological Psychiatry, 52(4), 318-327.

Takeda, K., \& Akira, S. (2005). Toll-like receptors in innate immunity. International Immunology, 17(1), 1-14. doi:17/1/1 [pii].

Takeda, K., \& Akira, S. (2004). TLR signaling pathways. Seminars in Immunology, 16(1), 3-9. doi:S1044532303000964 [pii].

Takeuchi, O., \& Akira, S. (2010). Cell. Pattern recognition receptors and inflammation (pp. 805820 ).

Takeuchi, O., Kawai, T., Muhlradt, P. F., Morr, M., Radolf, J. D., Zychlinsky, A., . . Akira, S. (2001). Discrimination of bacterial lipoproteins by toll-like receptor 6. International Immunology, 13(7), 933-940.

Taylor, S. E., Klein, L. C., Lewis, B. P., Gruenewald, T. L., Gurung, R. A., \& Updegraff, J. A. (2000). Biobehavioral responses to stress in females: Tend-and-befriend, not fight-orflight. Psychological Review, 107(3), 411.

Teilmann, A. C., Kalliokoski, O., Sørensen, D.,B., Hau, J., \& Abelson, K. S. P. (2014). Manual versus automated blood sampling: Impact of repeated blood sampling on stress parameters and behavior in male NMRI mice. Laboratory Animals, 48(4), 278-291. doi: $10.1177 / 0023677214541438$.

Tersman, Z., Collins, A., \& Eneroth, P. (1991). Cardiovascular responses to psychological and physiological stressors during the menstrual cycle. Psychosomatic Medicine, 53(2), 185-197.

Tizard, I. R. (2004). Veterinary immunology: An introduction (7th ed.) Philadelphia Saunders. 
Turnbull, A. V., \& Rivier, C. L. (1999). Regulation of the hypothalamic-pituitary-adrenal axis by cytokines: Actions and mechanisms of action. Physiological Reviews, 79(1), 1-71.

Turner, A., Rivalland, E., Clarke, I., \& Tilbrook, A. (2010). Stressor specificity of sex differences in hypothalamo-pituitary-adrenal axis activity: Cortisol responses to exercise, endotoxin, wetting, and isolation/restraint stress in gonadectomized male and female sheep. Endocrinology, 151(9), 4324-4331.

Turner, A. I., Keating, C. L., \& Tilbrook, A. J. (2012). Sex differences and the role of sex steroids in sympatho-adrenal medullary system and hypothalamo-pituitary adrenal axis responses to stress InTech.

Turner, A. I., Canny, B. J., Hobbs, R. J., Bond, J. D., Clarke, I. J., \& Tilbrook, A. J. (2002). Influence of sex and gonadal status of sheep on cortisol secretion in response to ACTH and on cortisol and LH secretion in response to stress: Importance of different stressors. The Journal of Endocrinology, 173(1), 113-122. doi:JOE04507 [pii].

Turner, A. I., Hosking, B. J., Parr, R. A., \& Tilbrook, A. J. (2006). A sex difference in the cortisol response to tail docking and ACTH develops between 1 and 8 weeks of age in lambs. The Journal of Endocrinology, 188(3), 443-449. doi:188/3/443 [pii].

Uchoa, E. T., Aguilera Greti., Herman, J. P., Fiedle, J. L. r., Deak, T., \& de Sousa, M. B. C. (2014 September). Novel aspects of hypothalamic-pituitary-adrenal axis regulation and glucocorticoid actions.26(9), 557-572. doi:10.1111/jne.12157.

Van Deventer, S. J., Buller, H. R., ten Cate, J. W., Aarden, L. A., Hack, C. E., \& Sturk, A. (1990). Experimental endotoxemia in humans: Analysis of cytokine release and coagulation, fibrinolytic, and complement pathways. Blood, 76(12), 2520-2526.

Van Eijk, L. T., Dorresteijn, M. J., Smits, P., van der Hoeven, J. G., Netea, M. G., \& Pickkers, P. (2007). Gender differences in the innate immune response and vascular reactivity following the administration of endotoxin to human volunteers. Critical Care Medicine, 35(6), 14641469. doi:10.1097/01.CCM.0000266534.14262.E8 [doi].

Van Lier, E., Carriquiry, M., \& Meikle, A. (2014). Sex steroid modulation of cortisol secretion in sheep. Animal, 8(06), 960-967.

Van Lier, E., Pérez-Clariget, R., \& Forsberg, M. (2003). Sex differences in cortisol secretion after administration of an ACTH analogue in sheep during the breeding and non-breeding season. Animal Reproduction Science, 79(1), 81-92.

Vandaele, W. (1983). Applied time series and box-jenkins models. New York: Academic Press.

Veissier, I., \& Le Neindre, P. (1988). Cortisol responses to physical and pharmacological stimuli in heifers. Reproduction, Nutrition, Development, 28 doi:10.1051/rnd:19880402. 
Vincent, I. C., \& Michell, A. R. (1992). Comparison of cortisol concentrations in saliva and plasma of dogs. Research in Veterinary Science, 53 doi:10.1016/0034-5288(92)90137.

Vining, R. F., McGinley, R. A., Maksvytis, J. J., \& Ho, K. Y. (1983). Salivary cortisol: A better measure of adrenal cortical function than serum cortisol. Annals of Clinical Biochemistry, 20doi:10.1177/000456328302000601.

Walker, E. A., \& Stewart, P. M. (2003). 11beta]-hydroxysteroid dehydrogenase: Unexpected connections. Trends in Endocrinology and Metabolism: TEM, 14 doi:10.1016/S10432760(03)00134-6.

Waller, K. P. (2000). Mammary gland immunology around parturition. influence of stress, nutrition and genetics. Advances in Experimental Medicine and Biology, 480, 231-245. doi:10.1007/0-306-46832-8_29 [doi].

Wang, J., Korczykowski, M., Rao, H., Fan, Y., Pluta, J., Gur, R. C., Detre, J. A. (2007). Gender difference in neural response to psychological stress. Social Cognitive and Affective Neuroscience, 2(3), 227-239. doi:10.1093/scan/nsm018 [doi].

Weiss, J. (2003). Bactericidal/permeability-increasing protein (BPI) and lipopolysaccharidebinding protein (LBP): Structure, function and regulation in host defence against gramnegative bacteria. Biochemical Society Transactions, 31(4), 785-790. doi:10.1042/bst0310785.

Windle, R. J., Wood, S. A., Lightman, S. L., \& Ingram, C. D. (1998). The pulsatile characteristics of hypothalamo-pituitary-adrenal activity in female lewis and fischer 344 rats and its relationship to differential stress responses. Endocrinology, 139(10), 4044-4052. doi:10.1210/endo.139.10.6238 [doi].

Wira, C. R., Fahey, J. V., Sentman, C. L., Pioli, P. A., \& Shen, L. (2005). Innate and adaptive immunity in female genital tract: Cellular responses and interactions. Immunological Reviews, 206, 306-335. doi:IMR287 [pii].

Yanagihara, N., Liu, M., Toyohira, Y., Tsutsui, M., Ueno, S., Shinohara, Y., Tanaka, K. (2006). Stimulation of catecholamine synthesis through unique estrogen receptors in the bovine adrenomedullary plasma membrane by $17 \beta$-estradiol. Biochemical and Biophysical Research Communications, 339(2), 548-553.

Zelena, D., Domokos, Á., Jain, S. K., Jankord, R., \& Filaretova, L. (2009). The stimuli-specific role of vasopressin in the hypothalamus-pituitary-adrenal axis response to stress. Journal of Endocrinology, 202(2), 263-278. doi:10.1677/JOE-09-0096. 